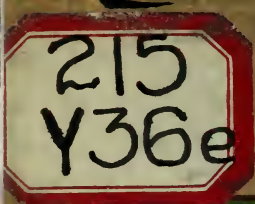

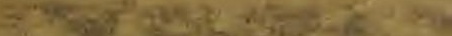

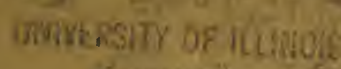

TURSAIVR.

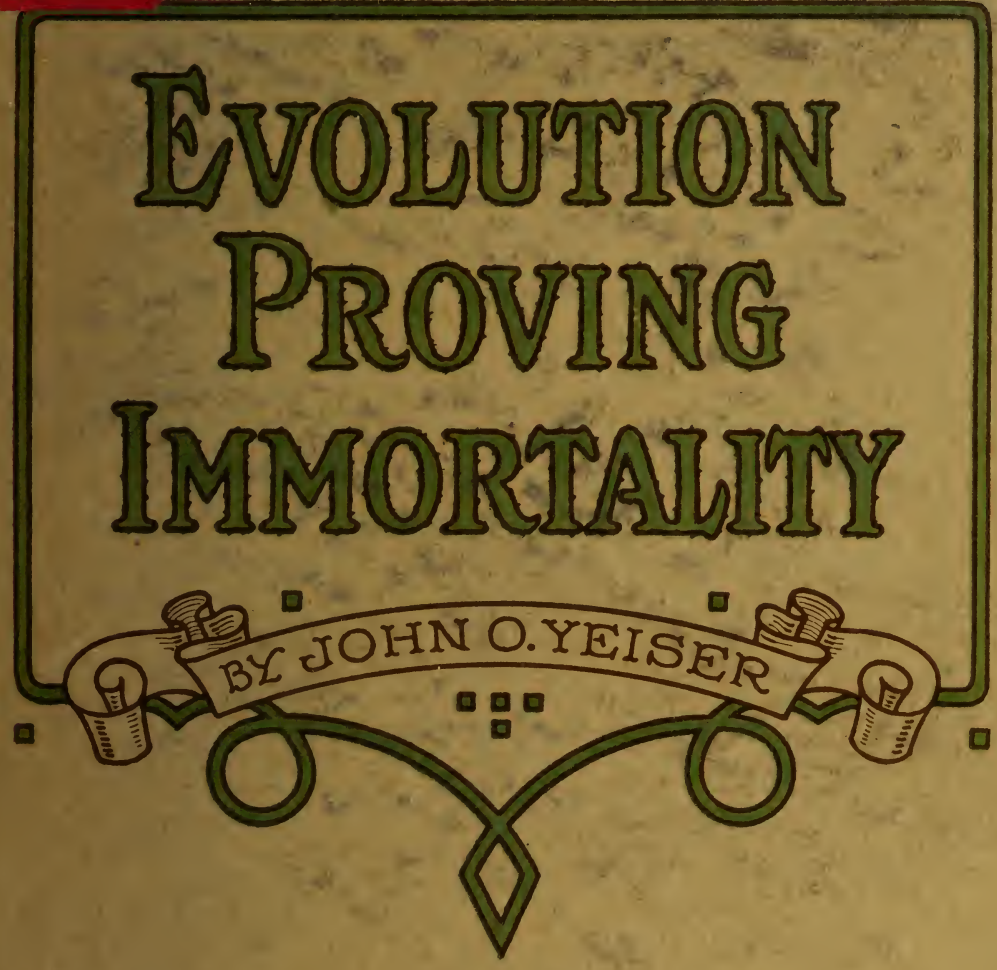



Return this book on or before the Latest Date stamped below. A charge is made on all overdue books.

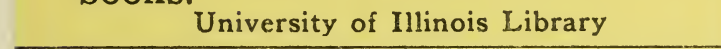

Jild I 6; $19: 8$ 



\title{
EVOLUTION PROVING IMMORTALITY
}

\author{
By John O. Yeiser
}

PRICE $\$ 1.50$ POSTPAID

Published by

National Magazine Association

Bee Building, Omaha, Neb. 
COPYRIGHT

1917

BY JOHN O. YEISER 


\section{FOREWORD}

While this volume is a revision of "Immortality Established Through Science," so much new matter has been added that this is really a new book and deserves a new title to distinguish it from all earlier editions.

This volume, like the one referred to, is not a veiled argument for or against any particular church or any religious doctrine, but is primarily a scientific search among things known to science for physical evidences of immortality utterly regardless of the dogmas of any church.

The editions mentioned under the other title were given such a cordial reception that it has caused the writer boundless gratification and made him feel that if so much satisfaction was afforded the readers, it justified all the other careful study and thought necessary to revise and enlarge the work.

Perhaps the practice of law cultivates a tendency to question and analyze and may account for the pleasure of this work. Besides the rest one derives from leaving routine work compensates for the time taken.

Why should we labor all the time, or study works of gloom and disappointment when we may absorb ourselves, deriving pleasure from that which is instructive and elevating and hope inspiring?

The "Sorrows of Wurther," an affecting tale of disappointment in love and of suicide, obtained many victims of self destruction for Goethe, its author. Strange is the fact that these suicides dressed themselves as Wurther, and died in the same manner. The brilliant Ingersoll wrote a book, "Is Suicide a Sin?" and martialed the sick and the sorrowful, the disgraced and degraded; arguing and convincing these men of disappointment that suicide was their right and privilege. They died by the advice 
of Ingersoll. They should have been taught that their lives from before birth, were but re-enactments of the millions of years of evolution it took to make a man, and that after this mortal pause life will continue. What disappointment in love, or domestic happiness; what disaster in business, or physical affliction; what calamity of nations or even loss to the broad field of astronomy, will overbalance a well-grounded belief in a future life?

This volume is intended to elevate mankind, to open their eyes, not only for the hereafter, but while here, living in this marvelous state of existence.

Christians are requested to read the letter in appendix before reading this work. All non-Christians are requested not to read the appendix until they have read all that goes before.

This suggestion is made out of fairness to the reader, because it should be understood that unusual statements, calculations, and deductions, of every man are under some suspicion until he has proven himself capable of agreeing with us in some of our unusual calculations and conclusions.

For the purpose of overcoming this obstacle, as far as possible, and starting out in harmonious agreement with every reader, and gradually laying down proposition after proposition in progressive order this division of readers is made with advice upon where to begin.

JOHN O. YEISER.

Omaha, Nebraska, January 12, 1917. 


\section{CONTENTS}

Chapter I. Introduction.

Chapter II. Birth of the World.

Chapter III. Life Development.

Chapter IV. Antiquity of Man.

Chapter V. Evolution of Man.

Chapter VI. Deductions from Evolution.

Chapter VII. Man Analyzed.

Chapter VIII. Deductions from Analysis.

Chapter IX. Have We a Soul Now?

Chapter X. Soul Independent of the Body.

Chapter XI. Origin of the Soul.

Chapter XII. Why a Soul Has no Pre-Birth

Memory.

Chapter XIII. Reincarnation Doubted.

Chapter XIV. Heaven and Hell.

Chapter XV. Conclusion.

Appendix. 
Digitized by the Internet Archive in 2016 


\section{INTRODUCTION}

CHAPTER I.

An attempt will be made to present an impartial and simple synthetic theory of the metaphysical existence of man after death, based upon scientific facts, for the gratification and satisfaction such evidence may be to both the theist and the atheist.

In order to lay the foundation for a few new ideas, which I believe are worthy of consideration, I desire to present some of the most generally known facts concerning evolution. This is necessary, because evolution is the basis for what I have to say, and because that subject is not understood generally for the reason that it has been shunned by a large class of people, owing to the fact that early apostles of evolution used their discoveries to combat religion.

Those familiar with the wide range of scientific knowledge upon this subject may, if they choose, omit the few selected fundamental steps, and catch one of the ideas inspiring this work by turning to chapter XI., or if time is not too precious, include the other by starting with Chapter VIII.

Although it is not essential to prove a first cause in order to maintain the position taken, at- 
tention is directed back several million years, upon the hypothesis that the earth has existed that long, in order to obtain something like an algebraic basis from which to reason, by process of induction, much as one learns the value of the unknown quantity in mathematics. 


\section{BIRTH OF THE WORLD}

CHAPTER II.

It most certainly is not satisfying to say this earth may have been thrown off by the sun and then disregard the origin of the sun. The principle of the origin of one world, or one sun, involves the origin of them all. Before going back to such a period, let us consider the world only from the time of an intense heat, so clearly visible over its entire surface, and beneath its contracting, crackling crust.

Experimenting with molten matter and slowly cooling disks of basalt, of varying sizes, to obtain the average increase of time for cooling, with the increase of size of such bodies, scientists have estimated that this earth, 25,000 miles in circumference, would not have been reduced from the sun's temperature of 3,600 degrees to 400 degrees in less than $350,000,000$ years. Sev eral million years were required before any conceivable form of vegetable or animal life could possibly have existed upon the earth.

After cooling sufficiently to form a crust of nearly 10,000 feet of sand, stone, lava, grit and shale, which many have estimated required an additional 500,000 years, the carboniferous strata, or coal, from fern growth, records an estimated age of nearly 1,000,000 years. The antiquity of the 
earth is shown by numerous facts unnecessary to catalogue in this work, but further on facts may make it convincing that several cyphers should be placed on the right of the highest estimate above.

It may be added that the conclusions reached would not be affected even though the earth may not have been thrown off from the sun and even though the sun may not be a seething mass of fire. 


\section{LIFE DEVELOPMENT}

CHAPTER III.

Volumes of clearly understood facts prove the age of the earth, reasonably close, from the crust period down, calculated by millions of years and conclusively showing that ample time has elapsed for the gradual development of all forms of life which exist upon the earth. Measured by the casual changes we are now permitted to witness, human life could have been developed, destroyed, and redeveloped over and over since the world began to support life. Moreover, what may have happened in the so-called beginning, or when the earth had cooled sufficiently to sustain life, is still happening for organized life permeates the air, not only to the highest altitudes from which it can be taken, but even exists in space beyond, from which we are constantly receiving these new visitors, and evidences thereof, sometimes in the meteors that fall to the ground. No attempt will be made, as previously stated, to go back to first causes and indicate the origin of all this, but attention is invited back far enough to show, that if we have made such wonderful advance as we behold today, may we not develop a little more according to the same law?

Time forbids a discussion of the operation of the principle of evolution which we may ac- 
tually observe in the heavens through modern astronomy. No more space will be consumed here than to mention that the brief history of the earth's age written by fire, and water, and growth, and decay, through the various and regular strata of the earth's surface, which, however, crushed and torn by internal pressure, and volcanic eruption, remain generally in the same relation to each other all over the world, and contain evidence in petrification, and volcanic lava, and in amber, and rock formations, that insects, plants, worms, snails, and other very low forms of life existed in the Archeozoic age, while no evidence whatever is found of higher life.

The strata of the Palaezoic period of earth formation, of several hundred thousand years later, contain remains of fishes, reptiles and birds as evidence of the highest form of life, while the higher strata, that beneath the soil of the present age, known as the deposits of the Cenozoic age, contain evidence of animal and vegetable life in form near that which exists today. 


\section{ANTIQUITY OF MAN}

CHAPTER IV.

Since the history of man is so incomplete and vague, and since even the fragmentary inscriptjons on tombs date back at most not exceeding 15,000 years before Christ, unless recent discoveries actually carry it back several hundred thousand years, still we are unable to know much about man's development and habits. Abundance of evidence of man's antiquity exists, in the fact that the skulls and vertebrae of extinct animals of the Quaternary period show embedded therein the flint arrows of men who lived contemporaneously with the cave bear, cave hyena, Irish deer, rhinoceros and hippopotamus of Europe when it was tropical. Human evidences have been discovered under various undisturbed strata of earth produced by glacial and interglacial periods, with bones of mastodons and other extinct animals. In one instance a human skeleton was found beneath four distinct buried forests in Florida and estimated as having been deposited 50,000 years ago. What once was considered the earliest evidence of man was found in Kent's Cavern of Torquay, where stalagmites are forming constantly from the minerals contained in the water dripping from the top of the cavern to the floor. In this cavern names of persons that were cut on the stalagmite formations 200 years ago are still visible, 


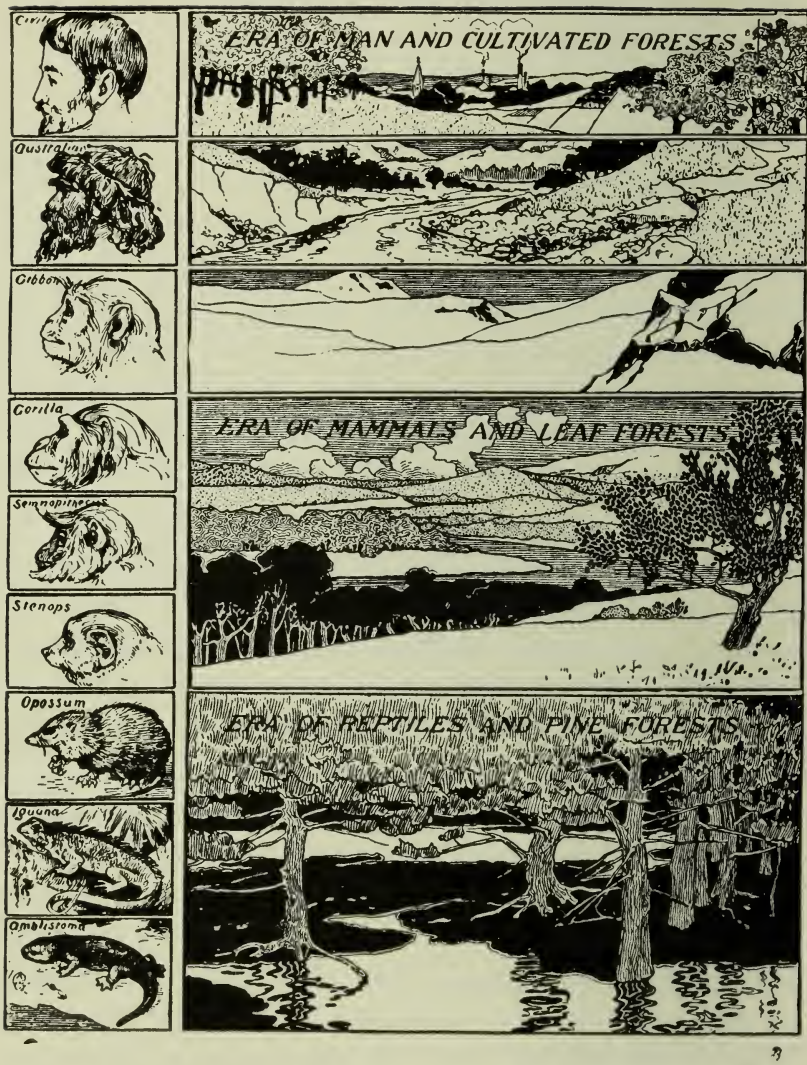




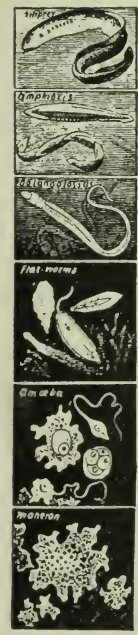

The Jesent of man.

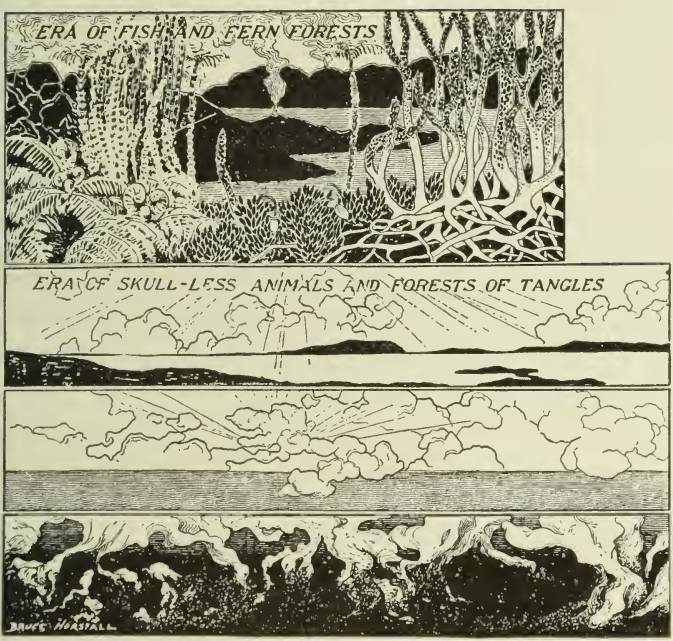

The aspet of the eurth in the different geological cras and periods.

\section{Portion of Diagram Illustrating Professor Hæckel's Theory}

of Evolution.

The animal forms, or "links" in the decent of man are not in all cases contemporaneous with the juxtaposed geological eras of this table. -Mcclure's. 
being covered by the formation only to a depth of a thin coat of varnish. From careful estimates as to how long it would take to form an inch of stalagmite the British association was led to determine that a foot could only be produced in 20,000 years. "Now," says the Science Record, "far below the stalagmite floor specimens of man's handicraft have been found. At the very lowest estimate the flint weapons in Kent's Cavern were made 500,000 years ago."

The museums and libraries of the world are filled with these evidences. The ruins of great cities in Mexico stand exposed without a record, or a word of tradition, as completely buried in forgetfulness as less ancient cities in the old world have been covered by ocean waves or desert sands.

Only a small part of the evidence of man's antiquity is herein presented, but the proof is overwhelming that the conception that the human race was created only 4,000 years before Christ is a result of some misunderstanding of the Bible.

These old illustrations are given in preference to newer evidences, because they are more generally known and because it is necessary to hurry on and not make an exhaustive study of anthropology. 


\section{EVOLUTION OF MAN}

CHAPTER V.

Man was created (his creation must be conceded because he is here) and it is no sin to inquire how he was created. The proof that the process of his creation is by a natural law is no less wonderful than if man, and all other species, had originally been created in the forms of today. The latter stated belief, of no change or improvement, is a lazy man's idea. It is considerably better than a worm could think, but along the same line.

It requires long patient study to trace the evolution of man, and in this discussion we cannot pause to analyze and compare the various forms of low animal life, rooted and growing in the ground, and plant life, existing without roots, some of which are actually possessed of motive power; we will pass over the comparison of the organisms of plants and animals that show marked resemblance to each other in habits, breathing, circulation, sexology, sight and digestion; we cannot stop to become interested in the similarity in embryo of the child, the dog, the fish, and other animals; we even have not time here to closely compare the skeleton of the ape and man, and other animals, and read of the intelligence of the ourang-outang to argue the prob- 

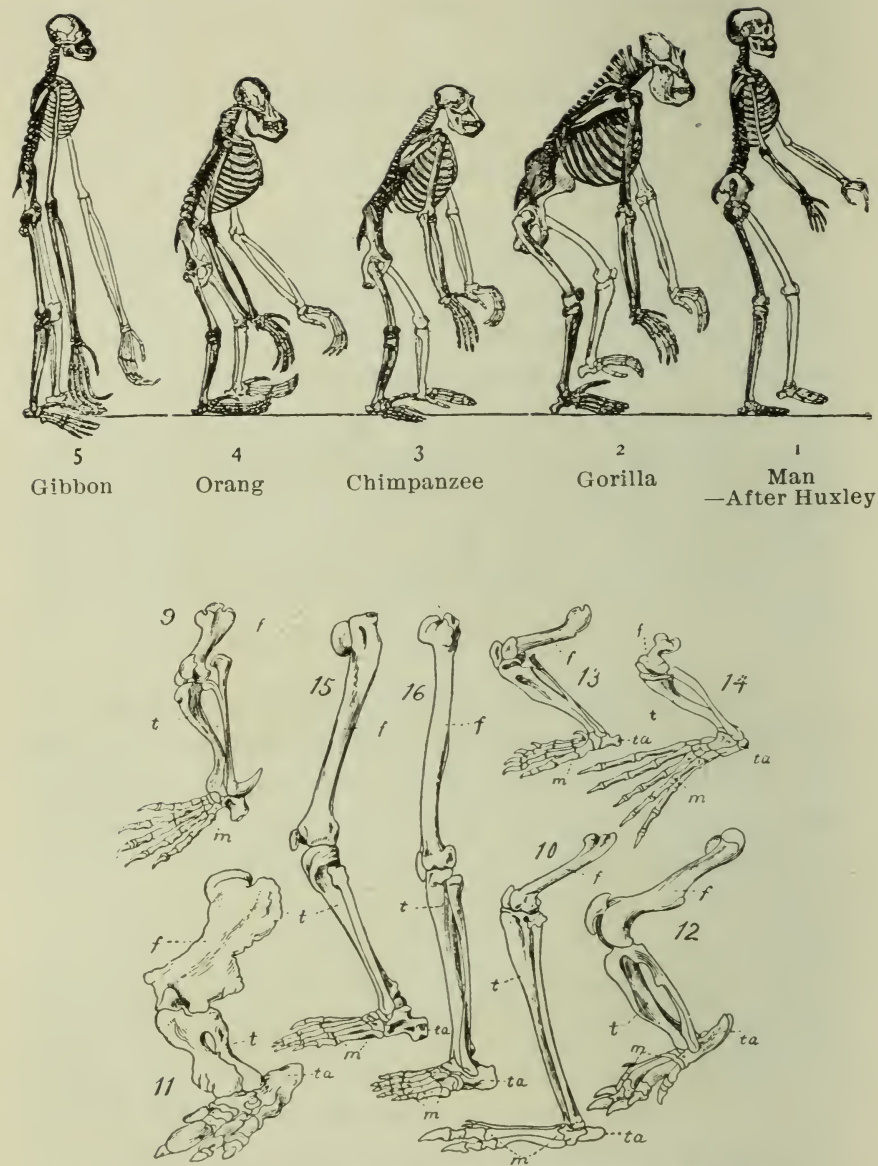

-Limb skeletons of various animals, showing homologous bones: 9. Ornıthorhynchus: 10, kangaroo; 11. Megatherium, 12, armadillo; 13, mole; 14, sea lion, 15, gorilla; 16, nuan.

From Evolution by Jordan \& Kellogg 

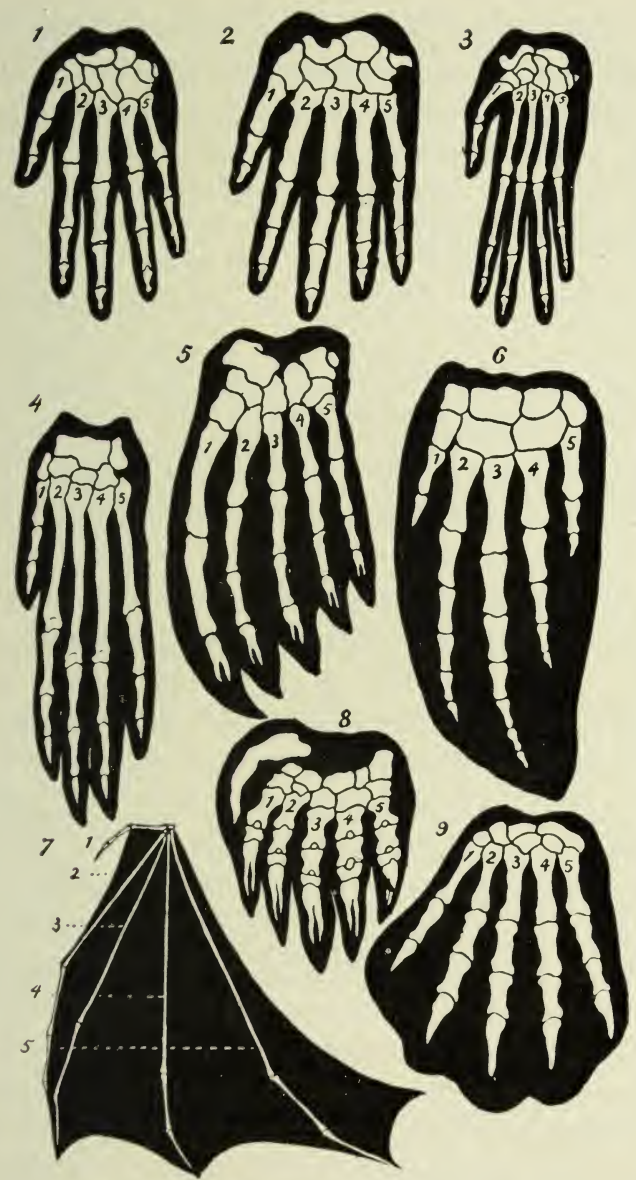

-Diagram showing arrangement of bones in the hand of fout of various animals 1 , man, 2 gorilla; 3 , orang; 4 , dog, 5, sea lion to dolphin: 7, bat; 8 , mole 9 Ornithorhynchus (After Haeckel.) 
ability that such animals and man sprang from a common ancestry. Immense numbers of books could be written on the subjects of animal, insect, and plant intelligence and relationship. Those already written are a marvelous study which strengthẹs the cause.

However, let us pause to observe that very recently Mr. M. I. Cassaigne, of Paris, has been experiemnting with anaesthetics upon plants. The species that writhe and contract, or curl up, with heat, which may or may not indicate pain, wnen subjected to anaesthetics endure much more heat, which almost proves a sensation of pain, or sensitiveness, in plant life resembling our pain and provokes an inquiry into plant intelligence.

Prof. Bose, from Calcutta, has advanced a step by using a mirror to reflect beams of light across a room upon a large screen from a carrot strapped to a vivisector's board. This enlarges or magnifies motions. He charges the carrot with electricity, or stabs it with pincers, when instantly he detects a shudder on this monster screen. By divers ingenious machines he discovers the pulsation of plants similar to the heart beating of animals, and assumes a nervous system from instantaneous response to various plant abuses. He records the changes of pulsations upon the administration of stimulants, and poisons, and detects a season of rest, or sleep, as contrasted with animation. If such surprises may be detected in plants, why not become prepared 
to expect something spiritually wonderful in the life of man? If this hidden force, or feeling, has been discovered in a carrot, what may we not more fully realize within ourselves?

Deviating again, we will look for life and intelligence in what has long been considered a field of dead matter.

Recent studies of crystalization of molten metals, and observations of disintegration in metals, show some outward signs of life after observing the familiar expansion and contraction fron heat and cold.

We observe many metals being disintegrated by rust and electric currents. We also see metals being rebuilt by electro-plating. Why may we not discover the environment where minerals increase under the same rule of division and multiplication of cells which perpetuate animal and vegetable life? Stalagmite crystals grow. Why not the same with diamonds, iron pyrites and every one of nature's metals? Miners have always insisted that metals increase in mines.

Even when metals are removed from their natural environment, become refined and are exposed to dangers of disintegration by moisture, air and constant uses strains and wearing always lessens their efficiency, whether the metal used is steel in a spring or copper as a conductor of electric current. Any kind of straining interferes with its internal molecular activity. Therefore ma- 
chines must be given frequent periods of rest or they will much sooner wear out and break. Even non-use of magnets, springs and all kinds of engines will make them sluggish in the same way that overwork will strain them. These peculiar indications of life, and vitality, of metals may not be marveled about when we realize that moisture carries something that eats into iron and steel, and that acids and poisons, are known to destroy nearly every kind of metal.

But at the root of it all is the fact, that in every atom of any mineral there are near a million electrons; in some, more, in others, less, constantly changing places, forming new combinations, and moving mostly in regular paths. As this is conceded by the whole scientific world, in the light of radium and various ray discoveries, is it not time to ascribe intelligence to these peculiar actions of minerals mentioned above?

Why should there not be a state conducive to its increase; why should it not tire; why should it not explode and snap; why should it not expand and contract with heat and cold; and why should it not quiver with electric energy, or even possess some peculiar nervous system of molecular intercommunication?

It is now contended by many people, with considerable reason, that we have a mineral king. dom, as a third division of life, to be coupled with the vegetable and animal kingdoms by a sort of protocosmos (if the word may be coined) to be 
discovered. The mineral kingdom, in its various forms of life, first appeared upon earth from a gaseous state, teeming with the kind of life existing before there was a world. Next came the vegetable life, with its many modified forms, and lastly animal life, yet each specimen of any newer form contains some trace of the earlier form, back through all three of said kingdoms of life.

We are to trace man back to the ancestor of all animals, and then still further back, to a life which is the progenitor, even of the whole vegetable kingdom, and on still further, to the primitive cells of the mineral kingdom, and then, without tiring, on to where there could have been no other origin, save and excepting such a power as we may by hypothesis, credit to God. But let us return for a while to the consideration of man as a basis from which to reason both backward and forward.

Considering man as he is today, and we see what effect climate, habit and diet have upon him; we observe how a family becomes divided and the children of one branch ascend in intelligence while the children of the other descend; we read of how nations have become extinct while others are dividing and forming into new types. These facts point to evolution and degeneration in a slight degree. What would five hundred thousand years do?

Those who first discovered the signs of evolution, apparently, became so intoxicated, by the excitement of their discoveries, that they conclud- 
ed all theories were upset. They, therefore, denied that consciousness of an individual continues after death, and contended that we have evolved in the course of millions of years from the protoplasm up to some oyster form of life and on through varying stages to human form. It was credited to accident, but should be credited mostly to the force of mind, or the action of the nervous system, responding to continuous desire and effort: some control superior to matter. But they always limited everything to tissue modifications and confined the work to matter. And there they stopped.

Volumes have been written to prove that evolution is the product of accident and not of design. I am convinced that we have evolved through a very low order of life and stand baffled at the complex organism of the lowest order of life, or even at the organization of any cell of any living thing. But I feel satisfied our progress was made more by the mental push, and physical exertion, directed by desire, than by the mere circumstance of accident. These directing accidents cause the lowest animals and insects to think and change their desires. It is said that a frog, by instinct, snaps at moving bugs and worms, but when six or seven have been doctored with bitterness, and so been taken in, it will afterward refuse them, or quit such snapping. It is also said when a spider's web is destroyed the spider will consider the extent of the injury to determine whether to repair, reconstruct, or to abandon tne 
location. Although this is disputed, it is conceded that a spider uses a different method to capture and poison stinging insects, a more wonderful exercise of intelligence than the use of discrimination in repairing or rebuilding its web.

With thousands of examples, more wonderful than these, showing continuing discrimination, we have evidence that mind has had in. finitely more influence than accident in the development of life. Accident, or calamity, does not cause the modification, but it merely influences the intelligence in all things, as the intelligence of the frog is influenced. I do not wish to deny the existence of a force in environment, if such it may be termed, but it is a negative force, or merely an obstacle. The positive, or true, force of evolution is in the mind, vitalism, or life-part, of the being which develops an intent upon overcoming the resistence. It is undoubtedly true that black animals and black birds may be more easily seen and caught, and be handicapped in catching food in the arctic regions, and in this way an advantage accrues to the white species. But, these living things know their advantages, or disadvantages, and mate with their own preferences, and look forward with affection to the appearance of their soft white off-spring with the same powerful prenatal influences that have been proven to exist in mankind.

While I will not deny the existence of some influence of a negative character in environment, 
I resent the denial of the positive influence of the mind. Who will analyze the wonders of animal, insect, and plant life, and deny the force of mind-the force of the composite mind of a long chain of ancestors-the mind with the force given it originally by the Infinite. We marvel at the possibility of a continuing Infinite design, but accept without question, crude and cumbersome notions of origin by chance.

If we in wonder examine the blind fish of cavern lakes, and speculate on how the eyes have dwindled into rudimentary organs, or reverted to what they were at some time in the past, because disuse obstructed their natural development, we cannot become convinced that accident destroyed all cave fish with perfect eyes and preserved the fish hatched blind to perpetuate that species. It is more reasonable to assume that the mind, or life part, of the fish, because of an environment of darkness, ceased its stimulation of these organs during germinating periods and eyes could not develop.

What accident "ulcerated" a gland in deepsea fishes to produce phosphorus bulbs to light their paths in the impenetrable darkness of the deep? Nothing else produced such a wonder but the living part of the fish. The everlasting necessity, and desire, produced these organs through the modification of cells. The accident of birth in this environment made it necessary to continue a desire for light until the "prayers" of even the 


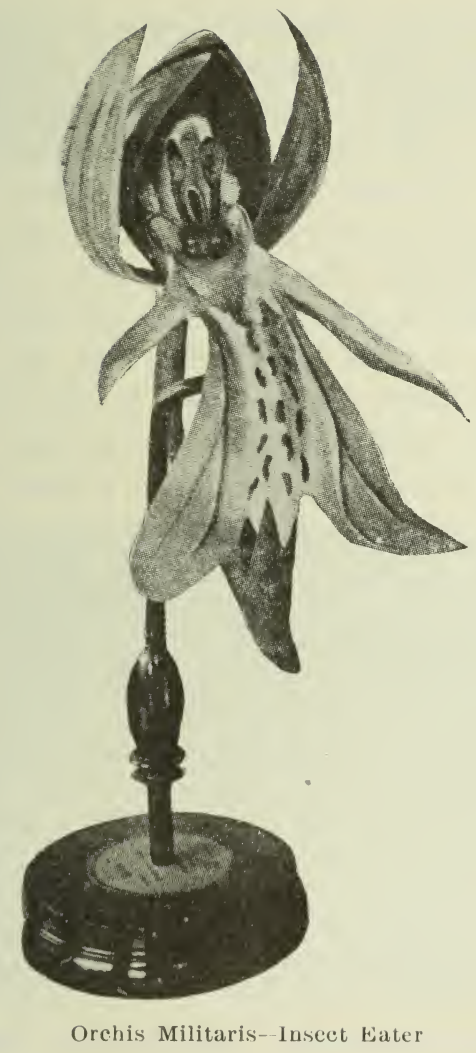


fishes were answered through God's law of evolution.

The whale's ancestors came up from the sea, as did ours, and they became monsters of the land. They had four legs and a coat of hair. They were later coaxed back to a sea life, where their legs became flippers and where they give birth to and suckle a calf. The same law that is now changing the side of a lazy flounder into a belly and which is moving the eye from the belly side to the back side was the law that transformed the whale from a land animal to a sea animal-that created eyes because there was light and created light because animals with eyes migrated to places of darkness - it is the law of persistent desire.

When we are told of the possibility that flowers produce gorgeous colors, delicious nectar. and fragrant odors, to attract as common carriers the little insects, that carry away the cells of perpetuation, simpletons will simply laugh. But if the deep sea fish produced its own lighting system in the ocean cavern because there was no light, why have not the stationary flowers produced a factor to induce and hire a form of life that does move to carry its fertilizing germs to places of perpetuation? If this is not plain enough to make men think, then turn to Venus's fly-trap, the pitcher plant, the bladder wort, and the sun dew and learn how they have developed their cells to entice, trap, devour and digest members of the socalled higher animal kingdom. 


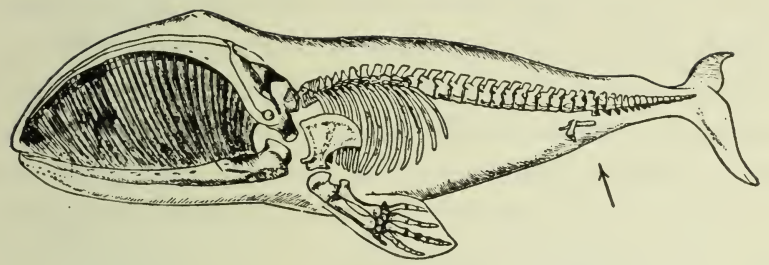

Five Fingers. Degenerate Legs.

-After Flower.

(Four or five of following cuts after those of Metcalf in

"Organic Evolution."

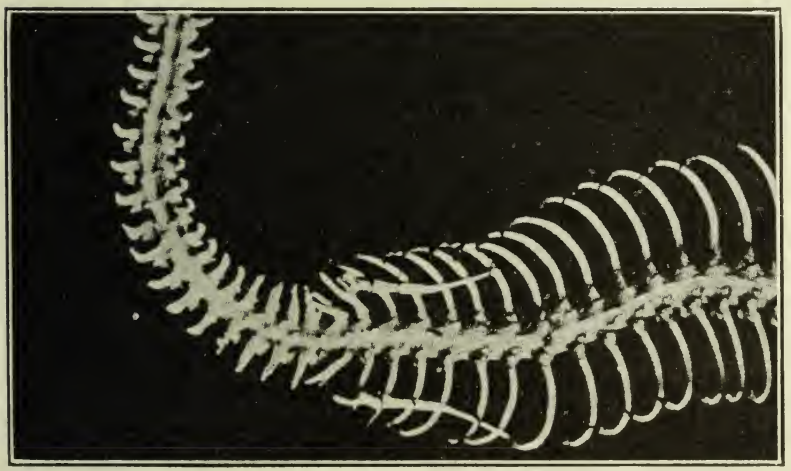

Boa Constrictor Skeleton Showing Degenerate Legs. 
The tree frog has assumed the color and shape of the oak leaf; the walking-stick insect cannot easily be distinguished from the stems to which it clings and we are told accident, and chance, kindly saved them, and that mind of neither the Infinite and its product-that of the animal-in its progress from generation to generation had nothing to do with it. True, there were accidents and to surmount them the intelligence of the different forms of life took different courses. While some animals desired the markings and attributes of those above for advantage we have fishes which for perpetuation lay millions of eggs, from which only two in a hundred millions reach maturity. Some intelligence stimulated this prolific energy in the fish while the whale is satisfied with one calf in two or more years.

The intelligence mentioned is not like that exhibited in colleges, but though ever so feeble, it is persistent and unvarying, from generation to generation, for some slight and at the same time limited change, that has wrought these miraculous types of life. It is not contended these low forms of life know the final consequences in desire and evolution. (The human race even does not know that.) But they do know enough to desire the slight step next to be taken.

However, some examples of quick changes may be noted:

Since biologists alter species of shrimps, water animals, and insects, while in the egg, or 
ovary, by changing temperature of the air or salts in the water in which they ordinarily live; and since butterflies produce young with greatly modified bodies by being subjected to different temperatures, or electric currents, can it be disputed that these changes affect the nervous system and excite, or frighten, this misunderstood intellect and the frightened, or disturbed, mind in time becomes the active agency in marking the young, so as to cause the change observed?

Many have accepted variation as the cause of evolution. It is sufficiently convincing to the physical materialist, or the causual thinker. They point to the fact that no two people are exactly alike. The same condition exists throughout the animal world. Yes, it is even true that no two leaves upon a tree are exactly the same and even. of all the grass that ever grew out of the ground, no two blades can be found exact in every detail. This is most truly wonderful and must be caused by some internal struggle in every direction for release. But leave this idea for the time being while the physical materialist cites you to teeth. hair, scales and feathers, and their wonderful lessons in the evolution of variation. A book could be written on a feather, or a fish scale, and not exhaust the material on the subject, and when it becomes cumbersome it is a record, still incomplete, of the gradual changes in a certain line. But it could not tell the cause of this universal variation; the inherent energy in feathers, or in any of the forms of life, that forces the variation. 


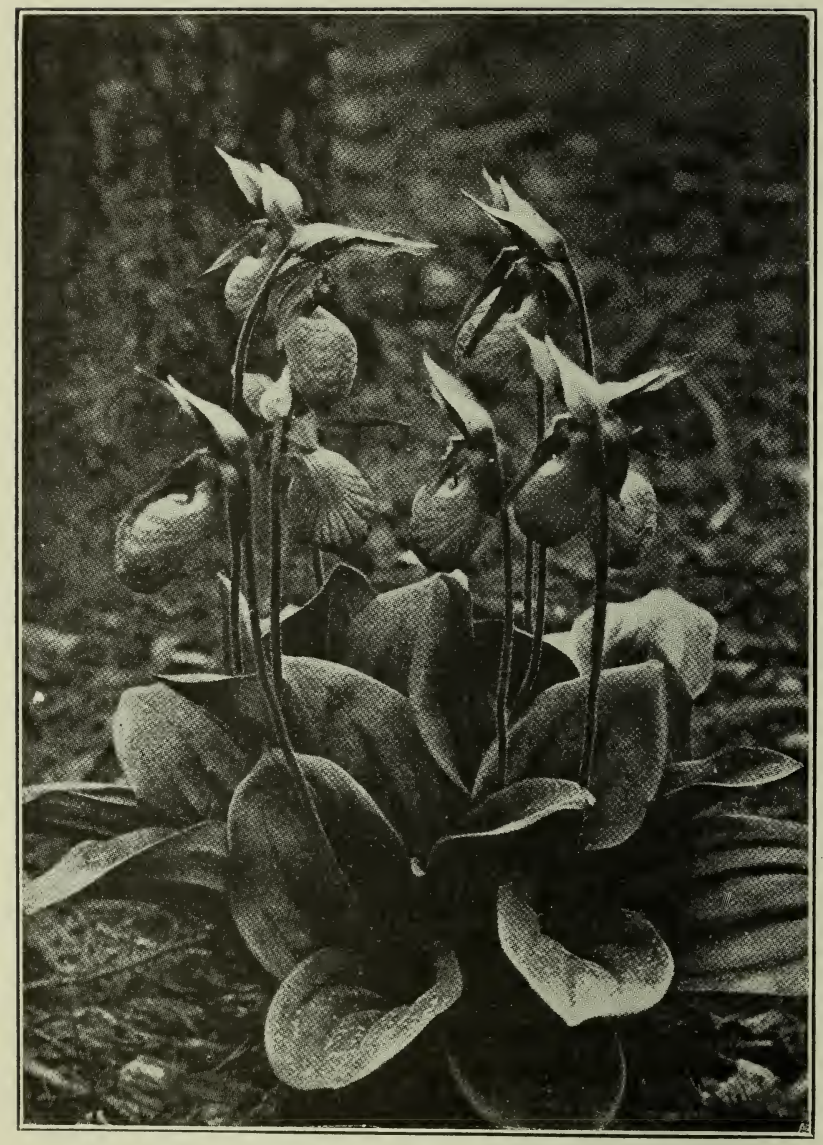

Moccasin Flower-Insect Catcher 
Consider a worm with the round pits of sensitive skin dotting a line on its sides and we may see the earliest signs of eyes. When the dots havis become sufficiently sensitive to strong lights and strong shadows, the variations in every direction leave some descendents with the dots more sensitive, and some less sensitive. Those more sensitive recognize the aimmer lights and shadows, and these in turn, because of this slight, but ever present variation, leave descendants with still more sensitive skin pits, until in a long course of time they become eyes such as we have. The blinder species lost out in the skirmish and the fittest went on evolving. They claim this to be true of strength as well as sight and in every direction of development. What is more, this assertion is true, as far as we see the physical results of variation, excepting that it is not equally persistent in every direction. But, however clearly we may observe the influence of climate, and other environments, on the existing tissue, it is only an obstacle which limits or mows down, checks, and destroys this mighty internal force of variation. What causes this universal internal force throughout all life? Bear in mind I am not asking for the environment that cuts it down with frost, ol withers it with heat, but I ask for the force that rnakes the variations so that they produce specimems which are capable of waging a battle with droughts and with lighter frosts. No one has ever told us what that force is. It is yet unknown. Since no one knows what this life principle is we 

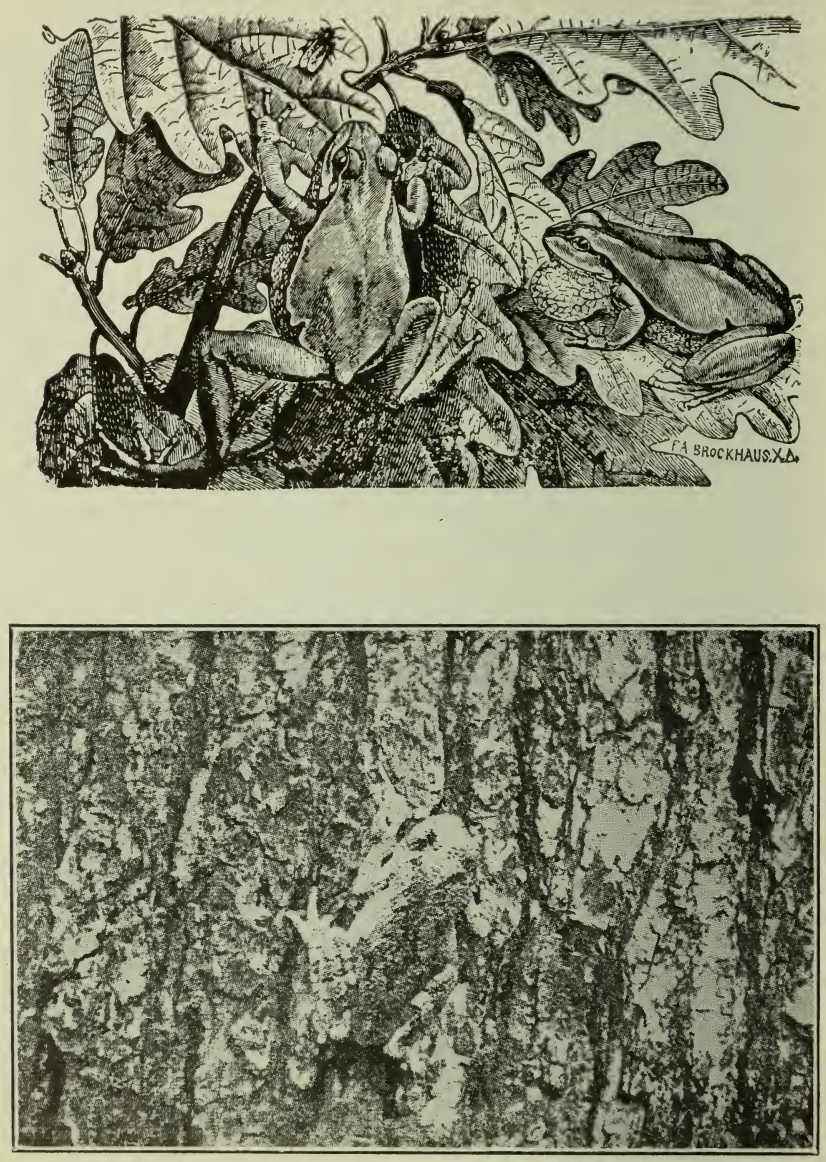

Tree Toud 
have a right to postulate for further scientific discovery. My postulation, subject to further explanation, is that this force of variation is the result of the force of life, struggling to be freed from its bondage of rest and sameness. All life

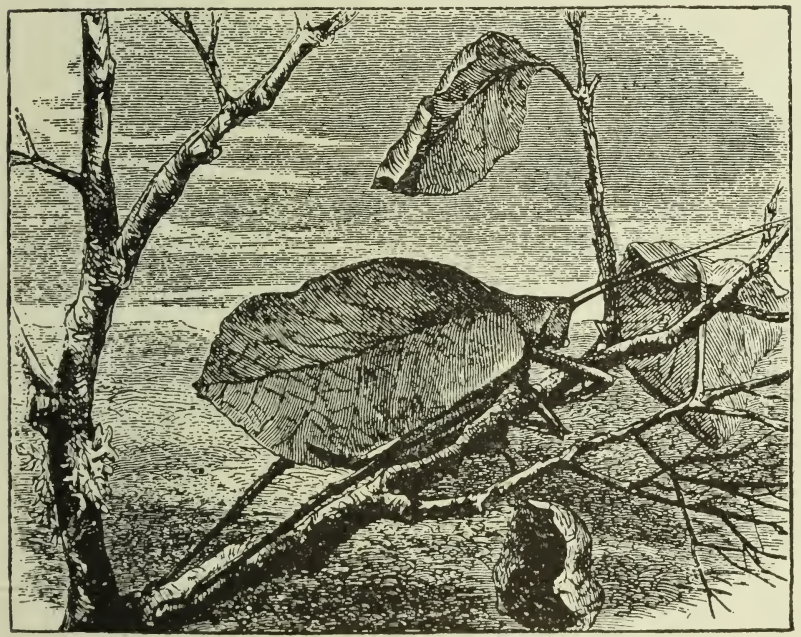

Leaf Locust

is activity, on the go, it craves a change. This condition indicates a will or desire. That desire in the direction of least resistance survives longer than the opposite desire or variation. In the same way we note this variation of plant development, we also note variation in the tendencies, and desires, of men which leads them into all kinds of actions and undertakings, no two of whom think or do everything exactly alike. The story 
of evolution will never be unraveled by materialists until they account for the push within the trees, and plants, and grass, and animals, and every living thing. They cannot answer this by telling us of impediments that stop progress in every direction excepting the right one-prevailing one-but what have they to say of the force which encounters these obstructions? Absolutely nothing.

Some criticism may be offered for the awful destruction due to the general push of life in so many directions. On this earth extreme cold, extreme heat, extreme moisture and extreme drought, destroy life development in countless millions of directions. But we must remember the principle of life exists not for our little planet alone: it exists for millions upon millions of others, each of which is developed differently from every other according to the same principle of nature. Hence we see the wonderful purpose.like work of nature, which annihilates nothing, building in such a way that every kind of habita. tion shall have inhabitants. 


\section{DEDUCTIONS FROM LAW OF EVOLUTION}

\section{CHAPTER VI.}

If man is a product of evolution, as contended and, as I believe, having traveled this long road through countless ages, developing the various new senses, emotions, tastes, and desires, now imbedded in the human body, and which were not possessed by his oyster-like ancestry, we may certainly continue our development by the same ceaseless process of evolution, and it will not be unreasonable to conclude, we may evolve other senses, or the power of existing under very different circumstances, and conditions.

Scientists contend in effect, as previously stated, that variation, or constant desire, environsnert, and natural selection, in life for generation after generation, and century upon century created a tendency in the offspring toward such desire and that this tendency developed into the present state of perfection. The abundance of evidence, which warrants such a conclusion, is not here presented, but, assuming this hypothesis to be true, are not the scientists compelled to go further in their theory of evolution and admit that man may yet progress into another state of existence? Again, assuming all this to be true, and taking into consideration the fact that nearly all members of the human race have for generations and 
centuries, been desiring, praying for, and believing, that they possessed a spiritual and eternal life, or fearing gods, idols and superstitions (which may have a similar effect), can the scientist deny the assertion that man has already evolved a purely mental, or spiritual, existence which will continue after the disintegration of the body? If this be true we have the possibility of eternal life conceded. Our next steps is to argue its probability.

Assuming that the Creator has made man by a process of evolution, how much more have we to hope for after having understood this process? This process has caused the original uncontented worms that lived and died as worms to leave as representatives other striving worms, that in a long course of time developed into larvae bursting into gorgeous butterflies. Considering this, have not the human family, now so highly developed, a marvelous hope of eternity under the demonstrable process of evolution which is more divine-like than any miracle theory which places a limit upon the hopes of man? The present ideal state of spiritual life is not too much to expect even now, but according to the process of evolution where will those who still desire to progress be halted?

In this discussion I care not to follow that question, and perhaps could not any more successfully than I could trace the origin of life back to that smallest speck, endowed with intelligent motion, which some scientists assert must be the 
origin of life, but fail to explain, or prove, how that originated. The original beginning of motion, space, matter, and intelligence, are simply beyond the present conception of the human mind, and it is no answer to say that life is merely matter, or chemical action, and that if matter was not created it always existed. This is not proving anything, but only guessing and the guess is no more unreasonable than to credit what is beyond our comprehension to the Creator and say that God must have ordained it.

Philosophy teaches that any object in motion would continue its course forever unless diverted by attraction or other impediment. Under such a principle, what could have stopped the will of God? Merely because no intelligent theory of how matter could have originated out of absolutely nothing has ever been presented for human understanding is no reason for saying "matter must have always existed." Furthermore, if we were guessing as stated, it is more reasonable to guess that intelligence first existed and always was, and that matter came into being from intelligence, because no counter will existed to stop the divine desire for this transformation.

If space and time, like matter, are incomprehensible, as Herbert Spencer contends in his First Principles, because we cannot trace or divide them to their ultimate limits, or because the division, and redivision, of particles of matter, and the pursuit of time, and space, on and on, why was 
not Kant right, though criticized by Spencer, where he says "Space and time are forms of the Intellect?'

What is time but motion? If we had no movements of the planets, no birth, no decay and everything stood still, we would have no time. 'Time would have disappeared. The past and the future join together so closely that there is no present. Time indicates movement and is as distinct from the present state, as motion and rest are distinct from each other. Therefore if time is motion or progress; if motion and progress is life; and if life is mind, or intellect, is not time then a purely mental creation?

Matter is divided into particles, step by step, down to what we once thought was its final solu. tion, the atom. But we may go on from the molecule to the atom and on to a point where one hundred thousand electrons are required merely to reach across an atom and yet have the same comparative space between them that there is between worlds. By using the imagination, or intelligence, you may carry it on to the etheron and on even beyond this, dividing and redividing, exactly as you can wearily trace time back, back into the past, until you find it was a product of the ever-present mind.

When matter is divided and redivided and reaches the limit of comprehension it will be made up of particles so small and so thin, so devoid of length, and breadth, and thickness, that you may 
indeed say that trillions of quintrillions of thoughts, or desires, for some concrete realization have been pressed together and built up or reduced into matter. Why may not this substance be concentrated thought, or the ash of ideas?

But before we reach that state we must remember that just one microscopic cell of an organ of the body-the liver-is said to contain $64,000,000,000$ molecules. A further division shows $300,000,000,000,000$ atoms in this cell and I should judge the number of electrons in this one miscroscopic cell would be over $1,000,000,000$,$000,000,000$. This calculation being from only one cell, it is probable that an attempt to multiply this number by the number of cells in the human body would make a person dizzy speculating from where all these were gathered. If there are about ten billion cells in the human body there are probably electrons in about the following staggering number: $20,000,000,000,000,000,000,000,000,000$.

As time and as matter are traceable to mind. so likewise is space, a real expanse without limit or bounds to its length, breath or thickness, filled with great suns and planets of mind-created matter, also traceable to the same source. It has no definite bounds, because it is likewise a creation of that eternal mind of which we are but electronfractions and which goes on creating more space without limit, as fast, as far, as thought can travel. The limits and confines of all matter, 
space and time seem to be traceable to mind. It all seems to resolve itself into mentality which has no limitations. If there is mentality moving or working it emanated from some source or it could not be going somewhere. That source is a supreme central intelligence from which all harmonious things were thought. That mind from which all has evolved, I choose to call Divine-I recognize as God's, and all things of God's or man's conception are but the evolution or the inharmonious disintegration of divine purposes.

In order not to be considered an adherent of a class who insist that there is no matter, I most earnestly urge that because all matter must have been the product of mind, does not signify that a rock falling upon the head is not a rock and is merely mind. Because the particles of the construction of a rock may have once been the product of mind, does not justify us in saying it is not now matter. Neither can we determine into what form, or state, it may later be converted.

After redivision, and reduction, of matter into the dizzy distance of calculations, and after passing one limit after another with modern inventions we will at some time reach the last limit, or dividing line, between mind and matter. This feeling expressed of late about mind and matter being so closely related may derive much of its force from consideration of color and sound.

Black is no color because the so-called black substance absorbs all rays of light. White is all 
colors because the substance reflects all rays of the light, absorbing none of them. The different colors of the spectroscope are reflections of light not absorbed, broken, or disturbed, so that they travel back in longer or shorter vibrations or waves, producing with these changes the effect of the different hues. These waves of light, so deflected, produce what the eye perceives to be colors. All longer waves below the human scope of vision or shorter waves above this scope have the possibility of conveying other color sensations, when eyes are discovered or created to see themif indeed insects and microscopic life do not have a vision of the ultra short waves.

Sound is the name of another recognition of vibrations or waves that the human ear catches, if not too slow or too rapid. These rapid vibrations which man could not sense are produced and interpreted by the lower orders of life. Those above the human range-perhaps the whirling of other worlds-would terrify us if we had ears to compare them with the greatest vibrations that now impress us.

If there are vibrations of some energy which produce matter, animal or vegetable, hard or soft, substantial or rotten, they are no less wonderful to me than the basis of our gorgeous colors and musical sounds. A color looks as real to the uneducated as a piece of wood, in my ignorance of that substance, looks real to me. There is no abiding color in any substance, as we discover in 
lowering and turning on the light. A bright light is required to bring out, or produce colors. In a similar way, it may be said life, a stronger and more rapidly vibrating element than light, brings out and produces matter for more or less enduring periods.

After resolving mind and matter to the farthest limit in its genesis, it does not seem strange to think, and pursue the thought for investigation, that matter is concentrated particles of thought embodied in realization or some changing form of its disintegration. It may be the infinitesimal mind of one man, or even the minds of many, have no such force. But a strong supreme mind, which all creation tends to prove does exist, may have cast off such particles of thought, which become concentrated in matter.

This pause is made, not to prove the absolute truth of such speculation, too far in the future, or too far in the past, but more for the purpose of illustrating the narrow compass of the human mind, and arriving at the thought that we at the present time, can no more conceive nor enjoy a state of existence above the angelic, than an oyster of the Palaeozoic age could have conceived of such a heaven as man hopes to inhabit, or exist therein. Such an attempted conception is like attempting to touch an odor, or see a sound, or hear a color or smell a thought.

Taking it for granted that man has evolved from the very simplest form of life which th? 
human mind can comprehend, admitting that we do not know from what that "single" celled form of life sprang, and we are obliged to conclude that such wonderful development has taken place by some force which, from the absence of any other name, we can better understand by the term "evolution." In reaching this consideration it is not concluded that all the types of life have deve?oped in a direct line like the steps of a ladder one above the other. But it is contended that it was done in countless directions more like the branches of a tree, excepting that some types have developed to a higher degree and then perhaps descended into degenerates. The main branch, in some instances becoming extinct, while other branches from these may have again ascended. But, at all times, each specimen is inhabited ard directed by an intelligence striving for something. 


\section{MAN ANALYZED}

CHAPTER VII.

Studying man today in his highest state of perfection, what do we find as a result? His mental self dominating his physical self; yet he is treated by physicians as a purely physical being. He contracts disease oftener by fear and mental suggestion than by contact, whether this suggestion originates, or merely creates a tendency, which invites the cause of the disease. On the other hand, a cheerful disposition, and optimism has cured where medicine failed. Mesmerism, or hypnotism, has been shown to be an influence which may be exerted by one individual over the mind of another. It naturally follows that this influence is also exerted over the body controlled by a mind subservient to the mind of the hypnotic operator. If by hypnotism, sug. gestions of fear, pain, and joy are excited, may not fear and pain be so forcibly suggested as to result in death, ultimately if not immediately? Such was the case of the felon at Rome who was slightly lacerated and made to listen to dripping water, after being told it was his blood and caused to hear feigned statements as to his sinking condition, and who died from this suggestion as quickly as if he had bled to death. It was the same with another experiment on a felon who was condemned to death and informed by the 
jailer that as he was soon to be executed they could as well place him in a cell where a prisoner had recently died of small-pox. Although this was a falsehood, as no one in the prison had died of small-pox, the prisoner so deceived actually contracted the disease after the lapse of the usual time from contact, and died. Whether these particular reports so generally mentioned may be verified and accounted for or not, abundance of others well founded may be substituted. Why should we not find them, for every healthy body carries in its system germs of nearly every disease? These germs are waiting to take advantage of any debility, whether from a cold, or a mere suggestion, that may weaken the system.

It is also true that persons may hypnotize themselves or produce an abnormal imagination, by crystal gazing, to dispel recent or strong impressions, rendering the brain sensitive, and receptive to suggestion on the same principle that the ordinary man adopts who naturally closes his eyes, and holds his head in his hands when trying to think. Of course it is a very delicate influence. But oh! what an awful impediment to this delicate influence of soul development, is the suggestion of funerals and graveyards!

We know of the remarkable influence called hypnotism, upon both the body and the mind. We know that the heart of the sensitive subject may be reduced by mere suggestion, to the lowest pulsations-a condition impossible in the normal state; we know that he may be made insensible 
to pain under conditions which the normal body could not endure in silence, or, conversely, by suggestion make his epidermis as sensitive to touch as the cornea of his eye. It is true that he may be caused to suffer pain from mere suggested injuries; the sight and taste may be augmented, suppressed, or deceived. Bear in mind that this state of intelligence is manifested when the normal condition of the brain appears to be at a very low ebb, or abnormally at rest, and even with but the faintest circulation of the blood-an unpropitious condition for the functioning of ideas, if they are in fact material and originate in the brain. Yet such a "subject," in this induced sleep, will, under extraneous mental stimulation,-(i. e., suggestion), tell the most wonderful things of the remote past when questioned; and it is claimed by Mr. C. C. Redwood, of Omaha, (whom I know to be a thorough student of hypnosis,) that such a "subject" may, while in this condition, be taught in a few hours prodigious lessons even in languages foreign to him, that he could not learn through his normal brain-functioning in years. Yet all this education, (in our present state of knowledge,) is useless to the subject when released from the hypnotic spell. It is said that even the insane may be hypnotized, and while in this condition will talk as rationally as they did before becoming insane; but when released, they are still insane. These things indicate that mind, or thought, is not secreted by the brain, as bile is secreted by the liver, but that it is something 
which may function while the brain is dormant, or diseased; and when this latent, potential intelligence does so function, it is more rapid than when manifested through conscious or voluntary action of the brain. 


\section{DEDUCTIONS FROM ANALYSIS.}

CHAPTER VIII.

Now then, if man is such a mental being, susceptible to such remote influences, which we have merely pointed to, and having evolved from such an humble and simple starting point, chiefly by reason of mental desire, should not considerable importance attach to the numerous Biblical injunctions that it is necessary to have faith to have eternal life? By constant faith, desire, or prayer, as you may choose to call it, man has evolved to what he is today.

It required persistent thought, faith, desire, and practice, of man's ancestors for thousands of generations, studying shadows on the more sensitive pigment cells to produce the eye. We may think ourselves up, or down. By thought, and persistent practice, we may evolve higher, or degenerate lower. By disuse, and mental and physical abandonment, we have shortened the appendage to the spinal column, and changed the shape of the foot, while other forms of life have closed their eyes in their sockets.

If some of us are satisfied to remain physical matter, and go through life suggesting to ourselves that when certain physical calamities occur we shall die, and mentally lose consciousness, and cease to exist, it is reasonable to be- 
lieve that we may obey the suggestion and either become absolutely exterminated by being separated, and reduced to primary elements, or in a state of coma, if permitted to continue as an entity. Some may stop to mark the progress of nature and remain men with mere rudimentary souls. Countless forms of life have representatives in the living natural history of today who stopped contented with what they were, to mark the pages of the progress of life.

Suppose, for illustration, the caterpillar, which crawls over the ground, now and then raising its head and the fore part of its body to reach out in space, as if endeavoring to float off, should reject the instincts of the future butterfly life, and cease to desire any change and neglect to prepare for its state of metamorphosis by resting for its cellular change, but continued to crawl and wriggle and revel in green foliage, would not all that its ancestors had done for it in evolving a higher life be lost?

With our present knowledge of the power of mind in evolution is it not better to have faith, and a desire and hope for a future life, whether as Methodist, Baptist, or any other protestant, or Catholic, Mohammedan, Jew, Spiritualist, Universalist, or of any other religion, and believe that regardless of what physical calamities may occur, the mental consciousness will not and cannot be destroyed? Any religion is better than the dangerous condition of none. By hoping for 
a. continuity of life, and believing we have the same, may we not enjoy such possibilities of the g'reat unlimited divine-like process of evolution?

That there may be a beneficial result from a strong and abiding faith in an eternal, and spiritual life, is an inference deducible from our present understanding of the process of evolution and recent studies of mental man. Therefore, I reiterate that, since we have physical proof in the wonderful progress we have made we must conclude that such a future life is possible according to the laws of nature and we cannot deny the assertion that a soul has already developed in man.

If by evolution an eye has been produced from a cell, or pigment of matter, may we not conclude that by the same process a soul may have been produced from a spark of intelligence?

The basis for such an assumption does not rest primarily upon a belief in the existence of Cod, but it rests simply upon even the ignorant obedience of these divine-like laws. We, in fact, have come up from a stage of life which was too low to recognize the existence of a God, but nevertheless we came in obedience to His laws, struggling and desiring, for something higher, until the final descendants of this energy stand, in the boasted perfection of the manhood of today. However, as man learned more, it was natural to progress faster and in time made to feel that he could not deny that there is a God. 
I do not dispute that this knowledge of such progress would be a support and a corroboration of the Bible. But the Bible question I am not discussing at this time. I am only discussing scientific facts, and am therefore contending that it has not been essential in early development to see, and become acquainted with God. It has not been essential to know of the first causes, or to decide whether matter always existed, or whether intelligence, or life, was the product of matter, or matter the product of life to prove the immortality of the soul. I do contend that, from the earliest beginning of which we can conceive, life has progressed far enough to prove that the present ideal state of a spiritual existence is not inconsistent with the immutable laws of nature termed evolution. 


\section{HAVE WE A SOUL NOW?}

CHAPTER IX.

I do not know exactly from what, or whence, man's soul, or life, comes. However, I think I can figure out the direction from which it comes, and can distinguish the conveyance, or the mode of coming, and will try and do so in a later chapter. I do not claim that the individual soul built up, as it is in a living man, has been evolving through ages, and without memory of the past, and not positively knowing, I do not pretend to deny any other theories upon the origin of the soul. I believe that theory which may be best fortified by reason is the nearest right. However, I do contend that it is as reasonable to believe that an individual intelligence may be created, or brought to self consciousness today as 10,000,000 years ago. The soul may be created, for worldly existence, coeval with the body in which it dwells, and be as independent of the source of its creation as the body of man becomes independent of the body of his mother.

You are invited to look forward to this proposition, in connection with what I am saying.

If everything comes from something else, as we trace them backwards, species become eliminated and those left are less complex. If we trace all life back far enough, I may say, it would appear 
less physical, or with fewer senses and sense variations to appreciate the vast physical effects. Going on back further and further we may realize a time when we may recognize an entry into the physical existence. If we recognize that everything comes from something, we must by analogy, recognize that if we approach the physical existence as a new abode (and then tarry as we do here) it must have been from somewhere else, because it could not have been from nowhere. There could be no such place, or state, as nowhere. There was, of necessity, a metaphysical before there was a physical, from which all physical things evolved. We all carry some proofs of our approach to the physical from the metaphysical, as later shown. The soul, an alien here, must have been born abroad. However, I realize that this proposition is advanced ahead of its real place in this discussion and recognize that I will not be understood in this until a second reading of the volume.

There is no doubt in my mind that every man's life existed previous to his present human existence, perhaps by being a subconscious part of a previous mentality. If there is not some reason in this why do small children so generally imagine that they have always existed? I shall later discuss this.

Not entirely dissimilar from this we have low orders of human life permiting their minds to be entirely directed by their bodies. Every thought, 
and every act, is directed towards obedience to some physical sense or appetite of the body. The mind becomes a slave to the body, as we observe throughout the animal kingdom. This obedience becomes known as a habit, which the mind experiences great difficulty in breaking. Such an effort indicates there is a hidden personality in every man. He wants his body to do and be different, but is often disappointed with himself. He sometimes kills his body-a suicide. But if he masters his body and his habits, if he shows to himself that he is honest and just, although there is no one else to know of it, he begins to feel that he is distinct from his body, which is a mere servant. Going a little further, even the mind is made the servant of something which may control both the mind and the body. What is it that finally arouses and asserts itself in a thoughtwandering boy, and directs the mind so that it will not work upon some subjects and will reason upon others? It is a consciousness and a power which is superior even to the mind. It is the man part of consciousness-his soul. But how can we show it aside from the great fact that we feel that we know it? It can not be shown in one statement, by one instrument or a single experiment, but a great collection of deductions, all pointing in that direction, may be stronger to many people than just one physical demonstration.

Every avenue of life is being searched for its secrets, every abiding place is being ransacked. Who has not tried to penetrate the mysteries of 
the fragrant rose, or of the gorgeous peony? We have cut into the buds and torn them apart to learn their secrets, with almost as much disappointment as a child, that cuts open the head of a drum to learn the mystery of its sound. But one thing is true. We find that although the fragrance, and color, have not then appeared, the leaves and form are there, diminishing in perfection as younger buds are examined. We may trace this design back to the stem, when it was a shoot, and on down in the root, and then reason it back still further, to a cell in another root, and further back to a point so small, so infinitisimal, as to pass the realms of matter, and on to some design, or purpose, of intelligence. If there is a push, or purpose, in a flower, is there not a greater force, or soul, in man?

One thing is certain, and that is, that we have a soul right now, for a soul is that self-consciousness of life we feel upon every occasion; that strong and independent feeling which separates every man from other men; that force which combats bodily death; that reserve which causes man to look at his hands as though they were mere tools; that essence which is moved by sweet strains of music and tender words from those we love. Why, the soul is the man, and what is left is the corpse.

We have occasionally looked into the cold, unnatural expressionless features of some deceased friend. That which is observed to be lost and causes the change is so shockingly absent that we 
instictively know the spirit has flown. We can no longer communicate with it, because our language has always been a physical sense language and the spirit we knew has deserted the body with which it spoke and looked upon us in conveying the sentiments of an innermost soul.

We have often secretly doubted the existence of a conscious soul of one deceased because we cannot see, or hear, or touch it. But why doubt merely on this account, because no human being ever saw, or touched, or heard, the soul of a living person. We know it only by what it directs the body to say or do.

The life, the love, the grace and character, mind and intelligence which you know and learn to love in a friend are finer than human sight and hidden from all human senses. We know our friends by the things they cause their tongues to say and the things they cause their hands to do. In life friendship's unusual statements occasionally seem strange and cause us to look with astonishment until a twinkle, or a wink of the eye, reveals the humor of the same old soul.

There is no more mystery about the soul of a departed being than there is about the soul of a living being. That which we knew and associated with and loved in life is not a part of the corpse it leaves. But the soul is all those grander qualities that direct a man, or an army of men; that make the world tremble, or soothe a troubled heart; it is everything the man ever was, excepting the cold, useless and rejected corpse. 


\section{SOUL INDEPENDENT OF THE BODY.}

CHAPTER X.

Perhaps it would also be interesting to consider whether or not the consciousness, intelligence, or soul, of a man can possibly exist without a body.

We are certainly able to prove that no particular part of a man's body is his soul, for every part of a man's brain and body has been removed and destroyed, part in one man, part in another and consciousness retained. The individuality and consciousness would remain when by brain injury most of the body would be paralyzed.

It would be as difficult to demonstrate to us mortal creatures that the consciousness, or soul, of a totally destroyed body, incapable of speaking, moving or feeling, continued independently of every part of its body, as it would be impossible for a rose (a form of life possessing a certain degree of intelligence, but being devoid of the usual senses with which man is blessed), to understand or teach a lily that such beings as men exist to care for, nurture, protect, or destroy them. It is also said that if man had neither feeling nor sight, and in walking came in contact with such obstacles as trees, he would be veered off, without knowing how, or why, his course was changed, or being able to explain it. Some sixth, or seventh, sense may in the future be developed to explain many of the very curious actions of men in their 
changeable opinions, in their daily walks and avocations of life, which we do not now understand.

These illustrations serve to show that if man possessed a soul independently of his body, it would be almost, if not entirely, impossible to explain its existence by mortal language, or mortal comparison, or in fact, to understand the same. All we are able to do is to make deductions by reasoning backward, and forward, from that which we do know and therefore all arguments upon this subject are bound to appear somewhat vague at first, because everything must be established in the abstract.

If the intelligence of man is dependent upon matter, which is entirely displaced every seven years, why is it that any two old people upon meeting after forty years' separation, revive a memory of little incidents never re-impressed upon their various new sets of brain cells by subsequent and intermediate thoughts since originally made? May it not be a fact that impressions are stamped upon something more durable than such tablets of decaying matter? If a memory will remain although the entire set of brain cells has been gradually displaced, time after time, may it not still remain in the same receptacle if the brain should be quickly removed?

We have so frequently seen newspaper accounts of serious brain injury with persistence of life, that I do not feel that it is out of place to insert the following, merely for its value in suggestion: 
"Can a man live with faculties unimpaired after a large portion of his brain has been removed, or with no brain at all? Several recent cases are leading scientists to answer the question in the affirmative, however much such an answer would have been scouted a little while ago.

There is now in the service of Dr. Daniel Moliere, surgeon in the Hotel Dieu Hospital Lyons, a capable little fellow of twelve years, who is apparently in perfect health. Some time ago, in sliding down the balusters, he fell and fractured his skull upon a chandelier below. As a bowl of brain matter oozed from the wound, no hope was entertained of his recovery. He lay in a coma for ten days, in fact, but upon awakening began to improve and is at present apparently sound in mind and body.

The famous surgeon, M. Destot, comes forward with an incident as striking. It is the case of a stone mason, who in mounting a large cornice was so seriously wounded that he lost the left frontal bone and the left frontal lobe of the brain. After twelve days of unconsciousness he began to recover and according to the surgeon, is not only well, but in the possession of all his senses.

When in Algiers some time ago, Dr. Bruch treated an Arab for an ugly wound about the left eye, which has been caused by the blow of a hammer. The patient remained in the hospital service fully two months and during that time did not show the slightest evidence of cerebral trouble. At the end of that period he became unconscious and died in a few days. The post mortem examination developed the astounding fact that he was totally destitute of brains.

The anatomist and the psychologist alike are studying these cases with tremendous interest but no explanation that harmonizes with our previous knowledge seems to be forthcoming."

Because a person may swoon, or in falling asleep, awaken with no memory of such periods does not prove a suspension of consciousness. No 
man ever dreamed he was anyone else than himself. Therefore, when he does dream, he doesn't lose his individuality and his consciousness, even though he may think himself transformed into an animal. It is true, however, that he doesn't recollect always what he dreams, because he may talk in his sleep and awake with no memory of any sleeping thought. Nevertheless, is such cases he would be conscious, but not being attentive, would not remember the fancies of a restless night any better than the listless thoughts of a day dream. However, there is no doubt about a person's ability to cultivate a memory of his dreams if he desires, and can afford to sacrifice the rest of sleep.

A man may have his leg, or his arm, cut off and buried, yet a spiritual corception of an arm will remain. He feels it, he attempts to use it and although years after its loss he may almost give it up, yet before his old age death a full consciousness of the presence of his amputated limb will return to him. The doctors may come forward with their reasonable sounding explanations of this, but if I can feel the consciousness of a right arm that is lost, why not feel both the right and left although lost; why not also be conscious of the legs, the head and the trunk if they are lost? A soul may be such a consciousness in process of development of which the mental shadow of the lost member is a part.

Attention is directed to sight, which perceives objects as continuous when less than one- 
tenth of a second intervenes between the succession of appearances to the human eye. Proceeding from this we measure nerve action, and thought response, when inquired about through the medium of senses. There is also here a capacity limit. But one or two ideas or thoughts, never more than ten, can be considered by a normal person in a second without running them together in confusion. But dreams indicate a mind activity that could never respond to physical sense direction. In a second or two we may live a day, or a week, and go through experiences it would require months to see, and hear, and do, if the brain and nerves were doing the work in the normal way within its capacity to receive and send out thoughts. These things are merely suggested here to be recalled later, but they may cause us to begin to doubt the talk of mind being tne product of matter and the brain the source of thoughts.

It is fairly reasonable to presume that a man's consciousness may be independent of his body and not suspended or exterminated in death any more than, nor as much as, in the short period of the restful sleep.

The brain seems to be an organ through which the will operates. It is a delicate engine of energy played upon by will or intelligence. The intelligence of man may desire to examine a plant, and by will cause the hand to pluck it. Again, the intelligence may conceive the plan of a canal, or a railroad across a continent, and by will induce other forces to co-operate and accomplish a collos- 
sal undertaking to satisfy this desire of an ego. This machine, the brain of man, may have a defective keyboard and not be able to perform in every instance the beautiful work performed by others. It may work so poorly as to be of no use to the intelligence operating it. It may, when commanded or willed, do the very reverse thing and in fact exasperate the operator or even totally deceive him. It may be that some insane patients are peculiar because of physical defects of brain or body as it is usual for such patients, who have what are termed hallucinations, and believe that a friend is an enemy, a fierce animal, or a fiend, to act as a sane person would act if the hallucination were a reality, and proceed to defend themselves. Possibly a premature breaking up of the mental cells, later herein referred to, may cause this mental marvel. The phenomena termed insanity are not very satisfactorily explained in medical works and consequently do not warrant more than the foregoing mere suggestions excepting, perhaps, to add that every crazy thought an insane man may have, is a perversion of some suggestion. In fact, every idea of any man, comes from something else. No thought is pure originality made from nothing, but every mental conception must be a transformation from some pre-existing suggestion, idea, or expression. If every misty imaginative thought of man must needs come from something, how can even a potential life, or soul, come from nothing? Right here is the place to call attention to that strong deduction of common usage, that if matter 
cannot be destroyed neither can intellect. If it cannot be destroyed, why would the soul not be independent of the body when the body is shucked from the soul and transposed into different matter?

Returning to the main question we are confronted with the instinctive desire of man for a future life. Every nation of the earth has a peculiar religion, or superstition, of its own. It is also noticed that aged persons, or those who are about confronting death, confess a belief in a future state, not so fervently felt in budding childhood. These things in themselves perhaps, would signify nothing were it not for the other slight evidences on this subject, merely pointed to in the foregoing. They are fortified by observation of the caterpillar, mothworm and other larva life impelled by what may be termed their old-age instinct, invar. iably preparing themselves by deliberate action for a transformation. Observe what nature has done for its creatures-how it crowns even the instinct of the moth worm with success-how it rewards every intuition of bird, animal, and insect. Will man, who has by evolution risen so high, and who possesses an inherited insatiable desire for a continued knowledge, and progress, and eternal life, be confronted with a reversal of the law of progress, and life, that has made him what he is and will he be disappointed, and tortured in this chief hope, and greatest desire, which is more persistent than any instinct of animal, bird, or insect? 


\section{ORIGIN OF THE SOUL.}

CHAPTER XI.

While I have argued, and still argue, that it is immaterial how, or where, the soul originated to establish that it may continue to exist, I shall add a few arguments on what occurs to me as a reasonable, probable, and natural origin of that form of life known as man's soul.

It may not be out of place to call attention to the condition of man's life at the period of conception. Two independent living germs of life unite to form the fertilized ovum later to be born as a child. This fact is cited by materialists as evidence against a pre-soul existence, and to prove that consequently a dissolution of the body is an extermination of the soul. They cynically ask from which of the two does the soul come? A careful reading of Hudson's theory of a dual personality in every human being or the subconscious mind and the reading of the many excellent magazine articles and reported cases of double personalities, shows a strong possibility that life comes from the life of the mother, or the father, and not from both. No one can, without further data, be certain of this.

It is claimed by good authority that there is not a tendency of blending, unless possibly in some cases of mere superficial color. The mixture of all 


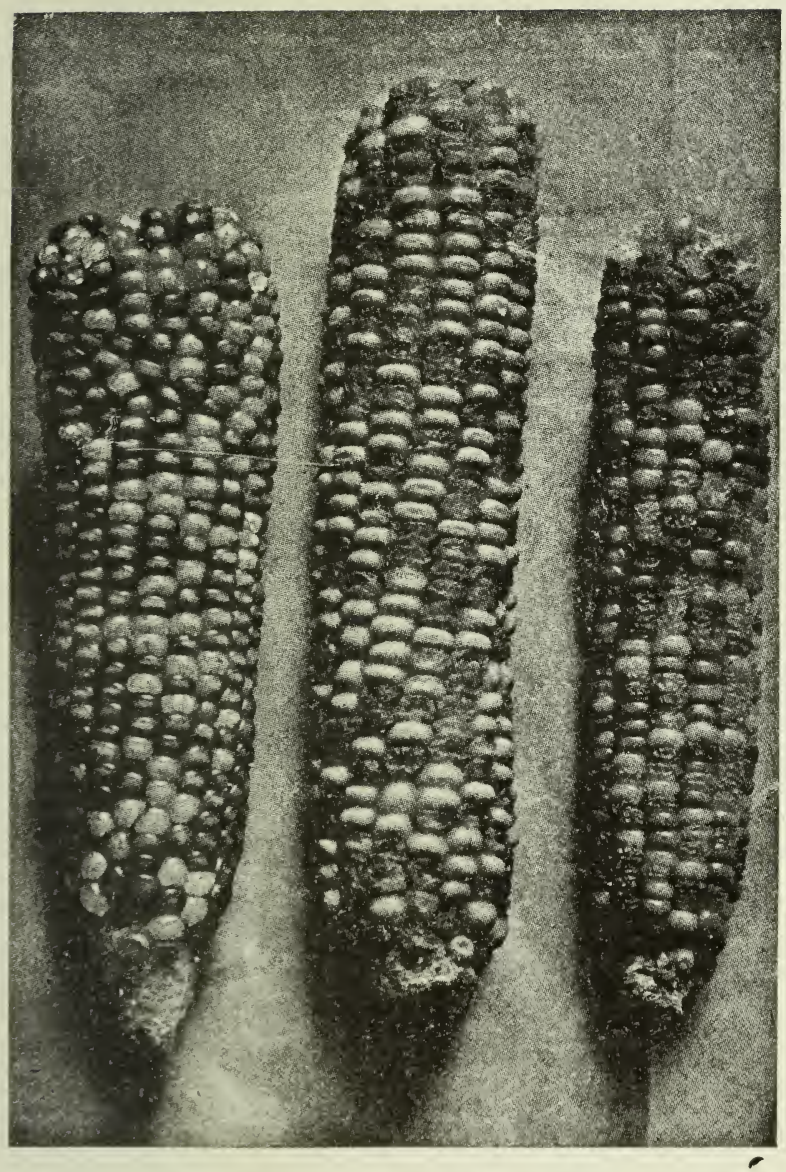

Menclelian proportions in maize. Cobs boin by heterozygote plants pollinated with the recessive, showing equality of smooth and wrinkled and of colored and white grains ( Lork) 
types or races does not give us a composite citizenship, but here and there distinct representatives recur, unmixed, and unchanged. The crossing of red and white corn accounts for the different kernels on the one cob, part of the kernels red and part white, but none pink. This mixing may result in sweet corn and flint corn being raised on the same cob and the same with yellow and white corn. In the same way the mating of different kinds of rats, mice and guinea pigs shows that the chances of the two parents are equally divided in marking the off-spring subject to a much smaller percentage of births that resemble the more remote ancestry.

It is likewise so with human beings in the marriage of idiots with persons of strong intellect. The children of an idiotic parent will be divided about half and half-part idiots and part normal. They are not merely average, but either iaiotic or intelligent.

There seems to be a dividing line or limit at this attempt to blend. In the far East, where the distinct races cross, they are known as half-breeds. Crossing again they are known as renegades. These renegades cease reproduction just as the mule-a cross between a donkey and a horse-will not breed. Nature protects the identity of many of its species by sterility when sex violations are persisted in after the third or fourth generation. It seems with this revulsion of the body against mingling that the soul, or life, takes its last step 
into mortality through either mother or father, but not half and half from each.

There may be a shuffling of well constructed bodily tissues of the two parents, but not a blending, breaking up and mixing, and most certainly not a confusion of soul life. The life germ of one parent may become dormant, or sub-conscious, while that of the other may become self assertive. The self assertive soul, or spark, of life may have come through either mother or father. This distinctive self assertive personality is the soul of which we are mostly concerned and the subconscious spark of life which we do not recognize, and which, perhaps, lost much of its identity, may have its future reward or continuity of life.

The independent life, spark, mind, or soul of either the spermatazoon or of the ovum, whichever is weakest, probably gives way to the leadership of the stronger. No proof has ever been advanced that a complete, inseparable union of the two particles of mind became one, or that neither had mind, or life, previously and consequently by a union gave origin to a new life that never lived before. Such a theory of mixing like liquids to the extent of breaking every complex cell, shown more fully hereinafter, is more strange and harder to establish than the one of co-operation I merely suggest for investigation, subject to the theory of reversion to a metaphysical origin later explained. Experiments in producing sea anemone and star fish without natural fertilization, indicates the union of life from the male is not necessary for 


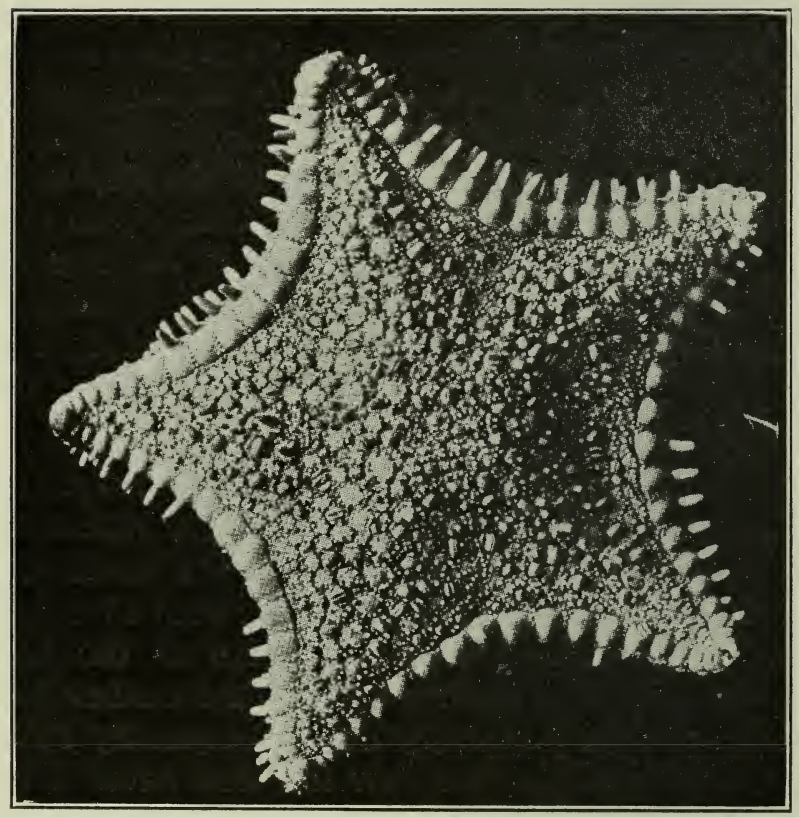

Star Fish 


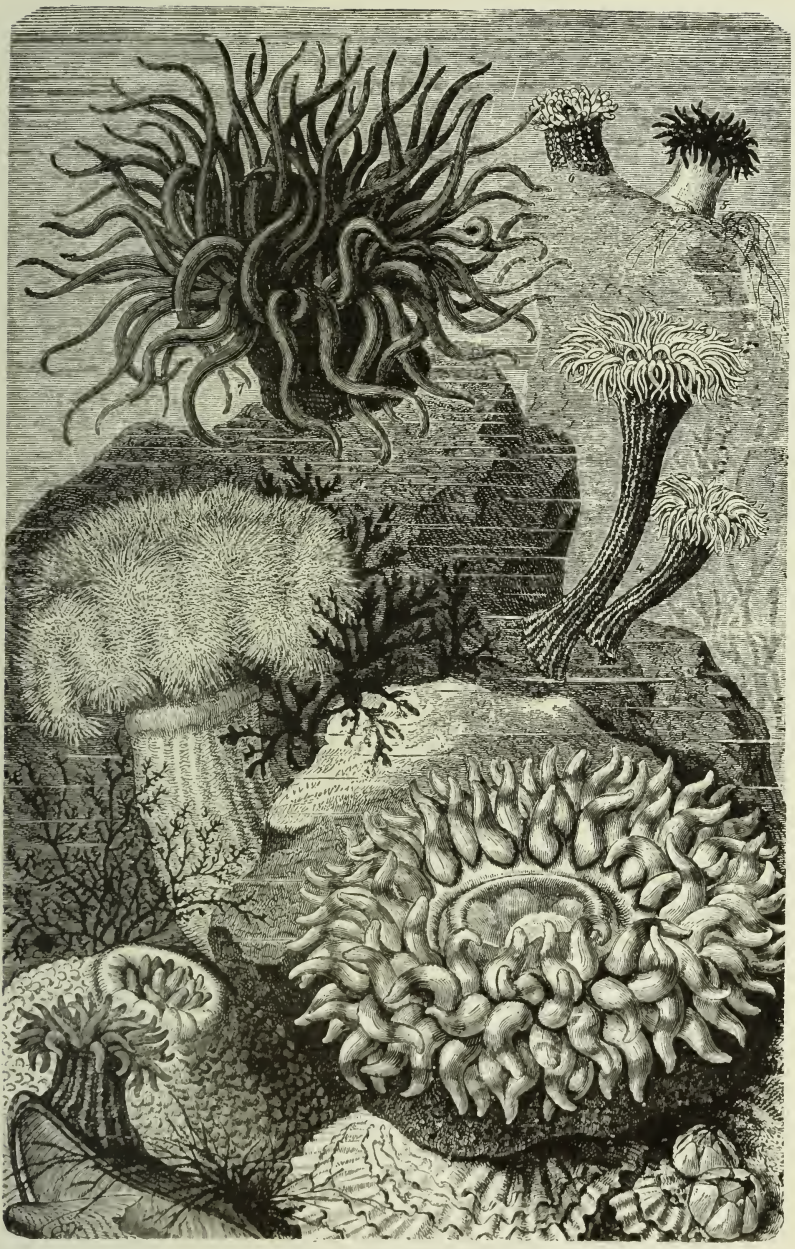

Sea Anemone 
purely female reproduction and may account for any distinct subconscious mind or life in all natural births. It also indicates that some beings may have a subconscious mind and some may not. The dual soul personality is acceptable and indeed demonstrable. They may, however, in fact leave the body at different periods and only where nearly balanced, remain throughout human existence.

More recent experiments than those concerning sea animals are shown from Associate Press dispatches. "Washington, D. C., Sept. 20, (1912.) A fatherless frog is a unique exhibit of artificial life of the International Hygiene Congress. An egg fertilized with acid (blood) developed a tadpole which today attained froghood."

Coming back to the primitive cell or ovum, it has life and also is made of material. How was the material made? Certainly like all tissue. All tissue growth is by cell development as in the original form of life. It is by division of cells and then normal expansion, redivision and re-expansion. Every man living is a part of the same original tissue of all his ancestors : a cell cast off and expanded by multiplication. It is an actual part of the parent body (the same with each ancestor) perfected and striving for greater attainments.

Let us next consider the life part of the ovum, or spermatozoon. As cells of matter, which we see, propagate themselves by this division in the 
material world, perhaps mental cells or soul cells, which we cannot sense, may in the same manner and even by co-operation with the material, likewise divide, or cast off circles, or buds, of soul life, to develop into independent mental identities. Some divine parent mind or soul may be the source of all souls, as one seedless orange tree, and its descendants, furnished sprouts for millions of independent trees in orange groves. After this material illustration of propagated, and decaying, tree trunks for a material comparison, I next give more of a mental or life illustration, in which it is said, "In the beginning was the word (the mind) and the word was with God and the word was God." Therefore, if in the beginning mind existed before matter, as we may easily reason, and this mentality said, or thought, let there be light, and there was light, because no matter, or counter force, existed to stay this supreme desire; and if it was also said, or thought, let there be man in the image of God, what force (if there was none) could stay the progress of evolution towards this eternal life?

If there is a Supreme Intelligence who always was, and always will be, (a phrase we use to describe the Infinite) and small gifts of life are imparted, or were imparted, even aeons ago, from this supreme mentality, like cells of matter are cast off to develop, why should they not strive in maturing to develop in likeness to the parent mentality, as do primary cells of matter and continue developing a life eternal? Why not consider our- 
selves truly sons of God made in His image? Why doubt and challenge the special Divinity of Jesus Christ when we ourselves have a spark of that divinity? Why scoff and hoot and secretly question the statement concerning the conception of Christ when we are compelled to accept the story of a fatherless frog and of fatherless fish? I trust I may be pardoned for diverging upon Biblical study at this time on the ground of its manifest interest to a large group of the world's population.

As previously stated, I do not know positively from whence the soul came originally, but believing it could not come from nothing, merely throw out the suggestion that life, distinguished from flesh, may have a growth analogous to matter, peculiar, however, in being metaphysical instead of physical, and without much self consciousnesss until fully developed. I speak of this merely as a possibility, or perhaps I am justified in saying, it is a probability and will bear further investigation. I will cheerfully change any conclusions not logically drawn from controlling facts as soon as my attention may be directed to the error, because I offer them as they may prove to be the truth. with the same confidence the proofs were presented that the world is round. If these evidences which indicate immortality cannot be destroyed, and are gradually added to, a recognition of such a principle of soul growth in nature is bound to be acknowledged. 


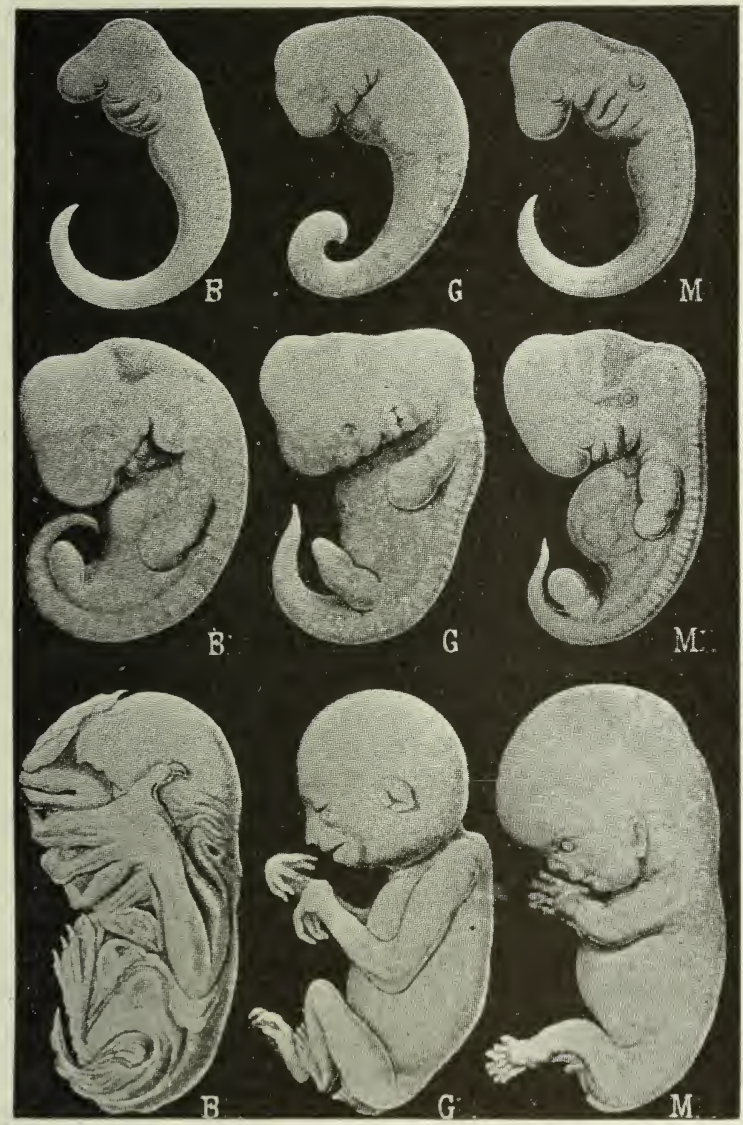

EMBRYOS OF THREE MAMMALS

B-Bat (Rhinoolphus) G-GibBoN (Hylobates) M-MaN (Hom) After Haeckel. 
Analyzing a man under the microscope we find him to be a corporation of cells; each cell much like the ancestor moner which propagated itself by uniting in the center and separating into two cells as previously stated. In higher development the human body allows a certain group of cells to do the digesting, and another set to do the seeing, and another set to do the casting off, or dividing of themselves for self propagation. Whereas, the moner, or its cousin, from which we developed, when walking was all legs, and when eating was all mouth and stomach, and when reproducing split itself in two.

In man, however, each group begins the performance of its distinct function in the original way, although ending with its highest development. Every foetal step records the true history of evolution from the so-called single celled protoplasm to the acquirement, and then the loss of gills like the fishes have, and on and on step at a time to what he is today. As man develops in future, much of the present day education will be developed in the womb, and still higher attainments cutlivated in colleges of the future. This is demonstrated now with musical and mathematical prodigies-not necessarily the son's of prodigies, but rather the sons of those who concentrate thoughts on mathematics, or music, at the susceptible period, perhaps stimulated by some necessary calculation, made laborious through ignorance, or by unusual appreciation of, or craving for music. 
The influence of the mind, with its constant desire, stimulates both soul and body development of each birth with more strength to achieve the ideal desired. That is why the physical, as well as mental, improvement of past ages is concentrated into such wonderful womb development in the short period of nine months. The net progress of the next 50,000 years together with all the wonderful past creations, will be concentrated in the womb development of the children of that age. It is easy to see every step of the past ages of physical development traced out in the rapid growth of a body during this short period of gestation. It is much more difficult to see the same rapid retracing of the evolution of a soul during the same period, however, it is there. As the body is cast off and developed in such wonderfully short time from another body, will you not now concede that life itself may be cast off from a parental life, or spirituality, and be developed into an independent soul This is no more wonderful than what you may see in the physical world.

That soul which separated as a mere sprout has for ages been evolving from an unconscious, potential, existence to a conscious immortality, not entirely unlike a very low order of immortality of matter I shall mention.

For the purpose of giving a living example of this theory of life development to prove by analogy that spiritual immortality is a possibility in nature, I shall first mention earth-worms which 
will develop a new head and extremity where severed, forming two independent worms. There is no doubt of the hydra growing new heads when the old ones are severed, as surely as asparagus roots shoot up new sprouts. We may add to this the information concerning the eggs of the sea urchin, which, when severed, will hatch out independent young for each fragment, much as the spores of mushrooms may be used to reproduce these plants. Many forms of animal life reproduce by budding and growing the offspring complete, as spiders and crabs regenerate legs, or the salamander regenerates legs, or tail, whenever destruction renders it necessary.

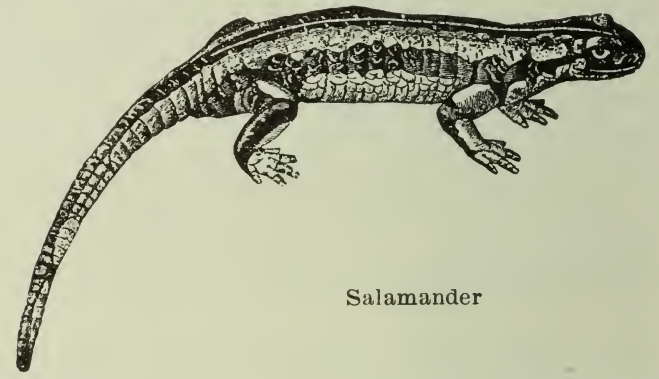

The amoeba and moner perpetually grow and divide. There is no infancy, distinguished from old age; no parent and child, nor natural birth, nor any birth, and no natural death. They simply divide, divide, divide. Unless unnatural conditions prevent they live and multiply forever. Those living today have lived millions of years and some of them will continue to live millions of 


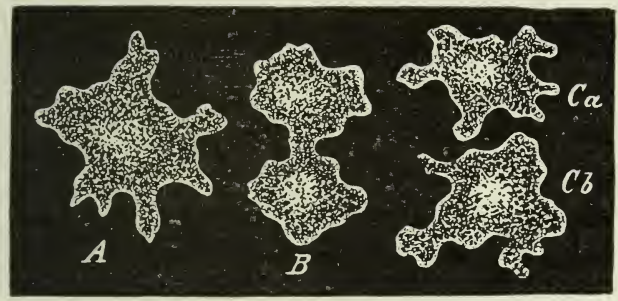

PROPAGATION OF A MONER.

The propagation of moners, the lowliest organized of beings, occurs by spontaneous division. $A$. The complete moner-a Protamœba. B. Splitting up of the same by a median contraction, into two halves. C. Each of the two halves has separated from its companion and makes up an independent in. dividual. (After Haeckel.)

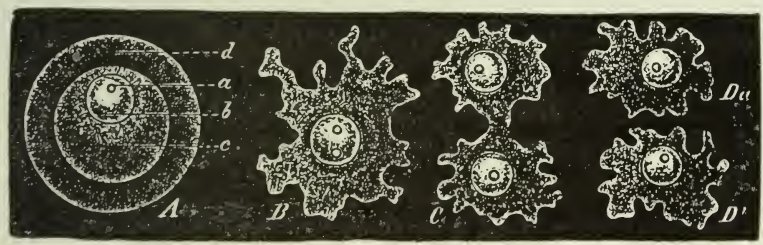

PROPAGATION OF AMEBA SPHAEROCOCCUS 
years to come. The specimens you examine under your microscope today were in some pond in the days of Pharaoh. They are all the same, but because of division there are more of them.

A study of the coral is a confirmation of the same story. The center of the top and bottom of the mouth unite and the division of the entire animal, which started at its mouth, is carried out until the animal is literally split and lo! we behold two animals, both of which have the same age, which was not the date of the first union of the mouth, nor the final separation, but reaches back for ages into the eternity of the past; for they were never born. Many other such examples could be given.

Any ultra microscopic cells even of microscopic animals, or the cells of any form of life reveal the same marvelous intelligent power of construction by the Omnipitent Architect of life.

It is possible for any one to see an independent life moving and acting in such harmonious rythm as an earth worm cut into two pieces and each part live and become separate and distinct. These worms reproduce internal organs as an eye is reproduced on the triton or a whole head is reproduced on many insects. Assuming a sort of worm intelligence, or memory, and a directing center of intelligence for a worm before severed, would not the tail half of the old worm remember something of the experience it had before it lost its head half and developed a new one? If, by di- 


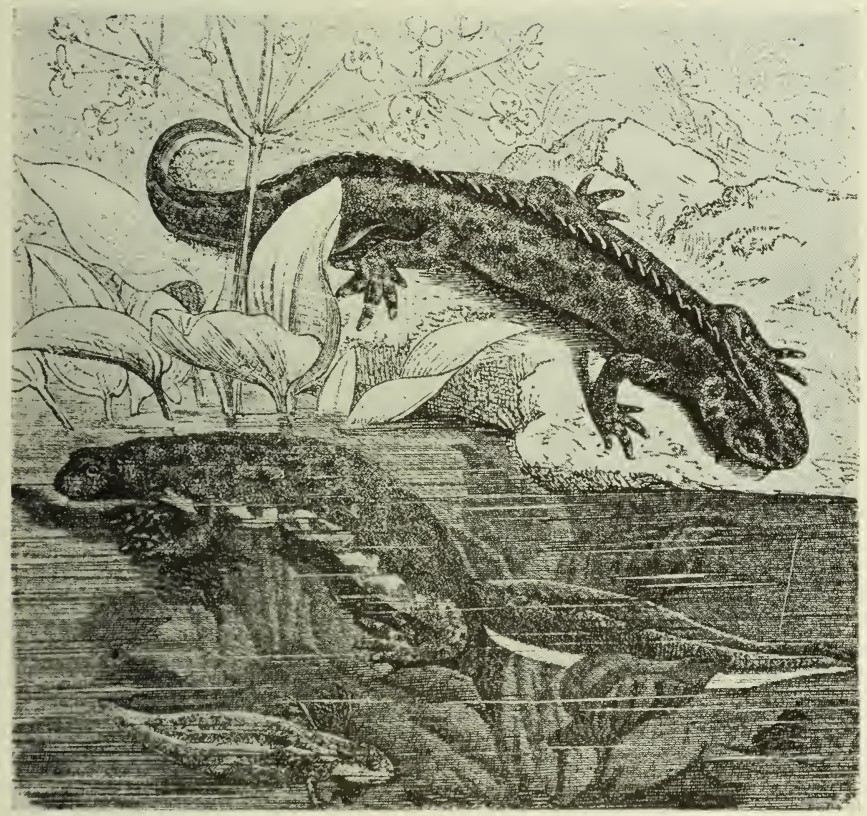

Triton cristatus, male, female, and larva. The upper figure is the male. -From Brehm's Thierleben. 
viding its body, it also divides its life and experience, as it surely must, why do not human parents (made up of the same cells that constitute the earth worm) impart some of their experience, instinct, or memory, with the cells of their bodies, and the sparks of their souls, that are surrendered to mature independent manhood and womanhood?

The answer must needs be they do, and per-haps, these memories remain dormant for generations and then become so responsive as to burst out in what he may think is his mere imagination, surprising himself and giving the credulous the impression that he is a re-incarnated soul of some great man of the past? All pre-birth memory is probably more like intuition, and instinct, than educational memory and knowledge. This manner of development is the basis for all arguments for pre-natal influence.

There is even more than this. In one sense death seems unnatural on account of the persistence of all these lower organisms. Where we have thought death occurred, it is only an interruption of the immortality of nature. Therefore it is no wonder that the interruption of so called death is not permanent, and that matter as well as life, will move on, and cannot be destroyed, but can only be diverted and temporarily changed from its course. As man's body has also existed for so many ages, and his likes and dislikes, are the net results of his experiences of ages before the birth from which he calculates everything, 
his soul has had the same immortality and may expect a longer, a stronger, and an individual, conscious, existence.

I presume no child ever lived without having dreams of fear-wanting to run and being unable to move, or more than creep; dreams of flyingjust floating off ; and dreams of running at a terrible speed. Perhaps, they were all caused, or developed, by some present suggestion. But the suggestion recalled long hidden, but tracable experiences of actual fright, ecstacies of ancestors, even in other forms. Our more immediate ancestors may have been fleet of foot, but long before the days of the vertebrae, and mammalia and marsupial families, which much later appeared, our ancestors must have had wings, as most of the insects, that surely descended from the slow crawling worms. It is no more remarkable that tendencies toward certain dreams, or even fantastic notions, should be inherited than family features, or indeed than intangible family traits should be handed down for generation after generation.

Why are not some of man's dreams either when wakeful, or asleep, put in motion by subconscious memories of occurrences when they were part of the ancestors mental corporation?

To illustrate this subject further consider some education as a process of recalling inherited memories. If it were not so you could teach a dog, or a cat, something like you teach a child. This inherited memory is called instinct when 
chickens, or birds, hatched in incubators, and not raised among nature's offspring, mate, build nests and go on rearing young. Such memories would come to mankind at the proper time by instinct, if not circumvented by education running wild.

The soul of man today originated, as far as his independence is concerned, when it separated from the soul of his parent. In another sense it is like the coral, never born, but always existed. Let us return to the materialist's origin of the soul-an alleged chemical union of the spermatazoon and ovum, referred to in the opening of this chapter. I think it probable such union was not originally necessary, but in later ages the practice was one adopted. I am of the opinion that all life at some early period of development increased by division without exterior co-operation. Later on they not only continued this process of reproduction but also became bisexual. Still later some types separated into groups of distinct sexes. Sex relationship seems to be an evolutionary step as clearly marked as the evolution of sight. It seems to have been adopted to aid and excite a natural condition of self-propagation, the power of which primitively existed independently with each individual.

Recurring to the illustration of immortality of certain animals and to the example of persistent life in both halves of an earth worm, when severed, I call attention to the recent experiments of Dr. Carrel, of the Rockefeller Institute. As previously referred to, when the worm is divided 
the tail half retains a share of its life and memories of the pain of light and the pleasures of proper moisture and darkness and lives on until a new head is developed and a fully grown wormmentality is brought into existence. Dr. Carrell has taken the tissues of animals from every part of a body and kept them alive and developing upon microscopic slides. He would give them the warmth of the body in an incubator and feed them by immersion in blood, or lymph, and occasionally wash them of excreted toxins. These cells would go on growing out of the body as they did within the body, developing to ten or twenty times the original bulk. In developing the tissues of the heart they would not only grow, but throb, or pulsate, in about the same normal manner for three or four months. In this way he has kept entire organs alive, and functioning, outside of the body. He has never created life, but he has only demonstrated that the brain is not the sole seat of life. Life and personality for some purposes extends over the entire body and when any part of the kody is surrendered in the natural manner for propagation, or by accident, and even violently, a part of this personality is surrendered. There was a memory and a motive of the heart tissues to go on repairing its waste from the wound of severing and to go on beating as if it was still pumping the blood. It was a limited memory-a mere heart memory. But the cells of perpetuation carrying life impressed with the broader duties of duplicating an entire animal will do more 
than merely pulsate. If a leaf of a tree could be kept green, although detached, it would never grow a tree because its life was a mere lung life. It would require a shoot with the potential elements of every part of a tree to go on growing and reproduce itself. Therefore, we may reason that while a piece of pulsating heart has life and may reproduce cells to repair wounds, and wear, it has not the whole potential soul-element to go on producing a whole heart, lungs, liver, eyes, bodr: brain and soul. It requires cells from a part of the body corresponding to the bud of a tree, that are impressed with a potential life, desirous of performing all the functions of a body. If you ask what becomes of that part of man separated with his amputated arm, which could not regenerate a man, I can with fair reason say that it is still loyal to the soul-life of the man from who it was taken and may return as inevitably as the waters of the ocean return, although torn and lashed and caught up in the clouds and storms. That part of his life was individual and dependent -it was not the part to develop into another individual.

As Maeterlink says: If all the wisest men of the world could be gathered around the flame in his lamp they could not tell what it was; where it came from; or where it went. Every question they would ask would reveal it a great marvel.

How much more wonderful is the spark or flame of life and consciousness of man? Life can be divided and prolonged-because nature divides 
it-but no one has ever produced a life otherwise than drawn it from an earlier life. Dr. Carrel has added evidence to the theory of immortality and sipirituality rather than given it a blow, as some writers have contended. There is a soul and a part of a soul-a soul nucleus-and soul cells, capable of division to form other souls. These experiments indicate such an existence of life. Elsewhere we show all matter is a product of life, rather than that life is produced from matter. Presently we will supplement this physical origin by taking the metaphysical origin. It will be traced back of any material origin in a mere parental source. Parents are but the channel of the soul.

There may be some proof of this in the dermoid tumor. This tumor may appear most anywhere in the body, regardless of the tendency upon one side, or one place, and upon either male or female. In some of these tumors a wisp of hair is found, or quantities of teeth and bones, or tissues from various parts of the body. It may be asked why I call this proof. It is known that from all species of life, occasionally some one shows a tendency to revert back several, or many generations-seeming to slip over or avoid any influence of parents or grandparents of either side-developing some trait, or physical peculiarity, of a remote ancestor. Because of this occasional tendency, for an entire human being to revert and in some instances to revert clear back to such a stage of degeneracy as to produce what we term an idiot 


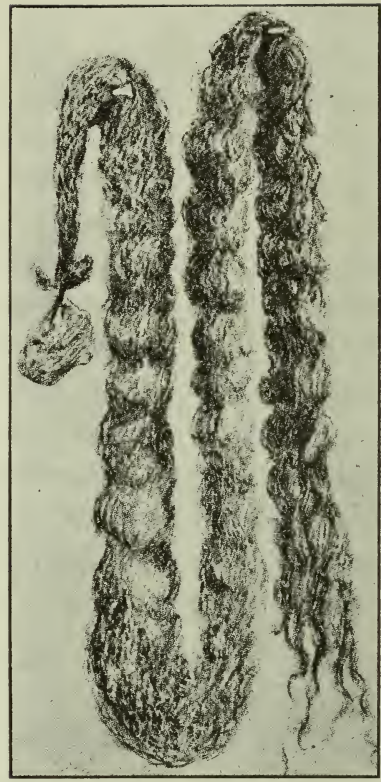

Hair from Dermoid Cyst Tumor, l'ive Feet Long.

-Thomas \& Mundle.

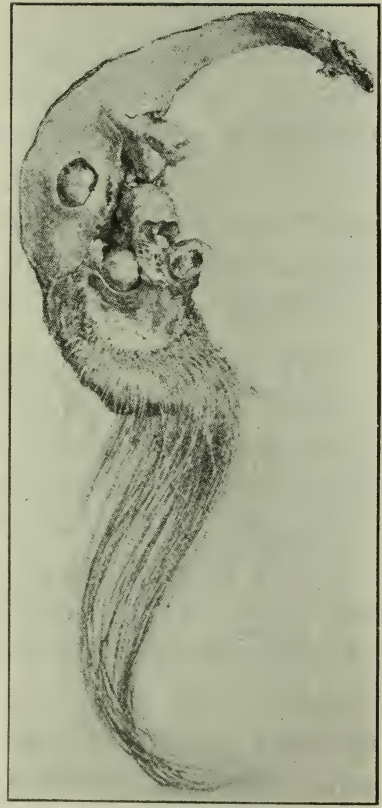

Bone, Teeth and Hair in Dermoid Tumor.-Kelly. 


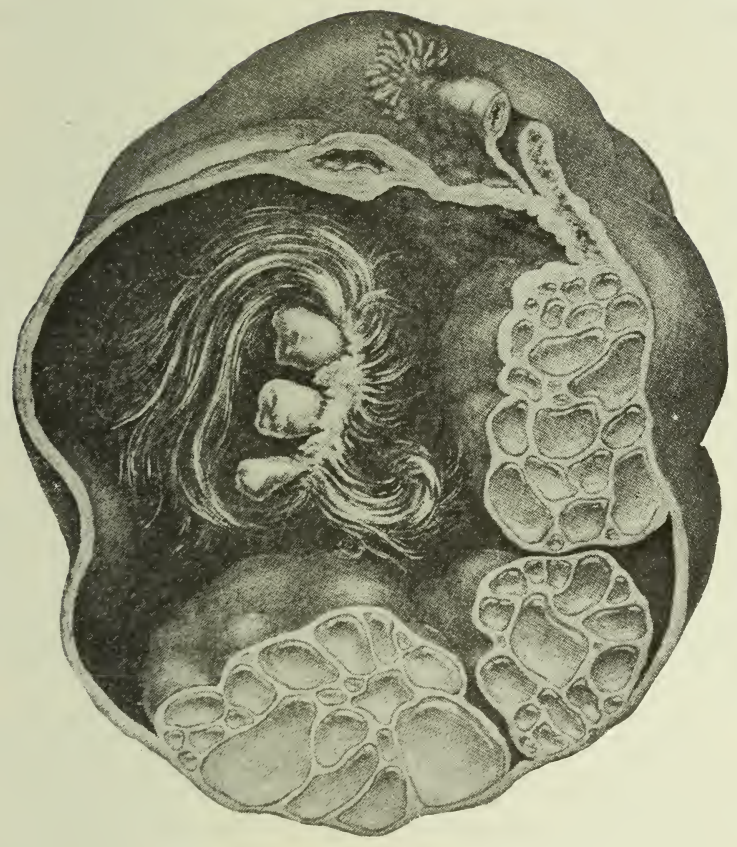

Dermoid Cyst Tumor.-Palmer Findley.

These tumors have been known to produce skin tissue, bone, nerves, muscle. sweat glands, hair of different color from that on the body, brain cells teeth - as many as $\mathbf{4 0 0}$ in one tumor-cartilage nail tissue, horn, nipple and various parts of the body. 
with brain cells below those of the cave maneven below those of many animals-I assume some single cell in man's body may come degenerated, while the rest are normal. I therefore assume that a dermoid tumor is the result of an effort of a degenerated or "idiotic" cell to reproduce the body by mere diversion of cells in the manner of ages ago when life was less complex, but because of inharmony with the rest of the cells, becomes abortive and much of the bulk breaks up and reverts into the contents of the cyst. You may doubt this theory, but when you ask a half dozen medical men the cause of dermoid tumors, or any kind of tumors, or cancers, and listen to different answers, or evasions, you may think there is something in the theory I suggest and admit that it is another evidence of evolution from a time so far back that man's ancestors were bisexual or rather non-sexual.

Fecundation among some insects occurs only once in a lifetime and is like a funeral rite as death surely follows the ceremony. Once the queen bee is fertilized the drone perishes while the bride, faithful to the union, may lay eggs and raise swarm after swarm for five or ten, years never again mating. Other insects including some spiders unite as a sort of experimental desire because such fertilization is not necessary to the laying of eggs that hatch.

All of this, with the cases of union of bisexual insects, indicates that higher families of life have developed distinct sex relationship, and rely 
upon such stimulation, as a substitute for inherent excitement until sex relationship became necessary in place of the primitive manner of reproduction.

But what of all this! It is a mere segment in the long chain of life extending down from ages without a broken link. A glimpse at the existence of life determined long previous to sex union was noted in pursuing an investigation in eugenics. The ovaries of the black guinea pig have been grafted, in an albino mother, in place of those removed and upon such albino mother being mated with an albino male she produced black offspring, twice successively, and after the third mating died, leaving the foetal young with coats of black hair. Does this not indicate the real parent of the three families of black guinea pigs was the black mother, from whom the living ovaries were taken to be grafted in the white foster mother, who nourished this germ life, in potential existence, on to actual existence? The impressed organs of reproduction, kept alive by the body upon which it was grafted, produced the new entire bodies of the offspring and the germs of life transmitted with the parts of the organ imparted.

If the body is thus projected and extended, as understood, through cell division of an organ consecrated to the service of real and complete reproduction, that cell which develops an independent entire body, is also accompanied by a spark of life that likewise becomes a fully developed soul. 


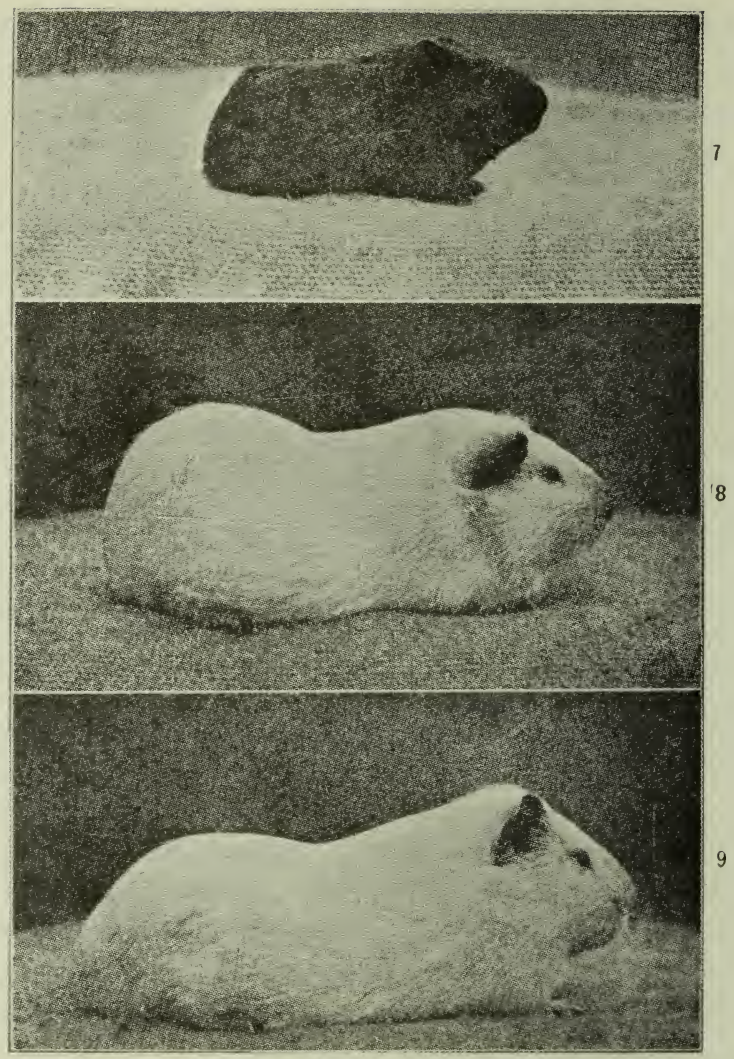

FIG. 7.- - y young, black guinea-pig, about three weeks old. Ovaries taken from an animal like this were transplanted into the albino shown immediately below it.

FIC 8.-An albino female guinea-pig Its ovaries were removed and in their place were introduced ovaries from a black guinea-pig, like the one shown in Fig. 7

FIG. 9.-An albino male guinea-pig, with which was mated the altino, shown in Fig. 8. 

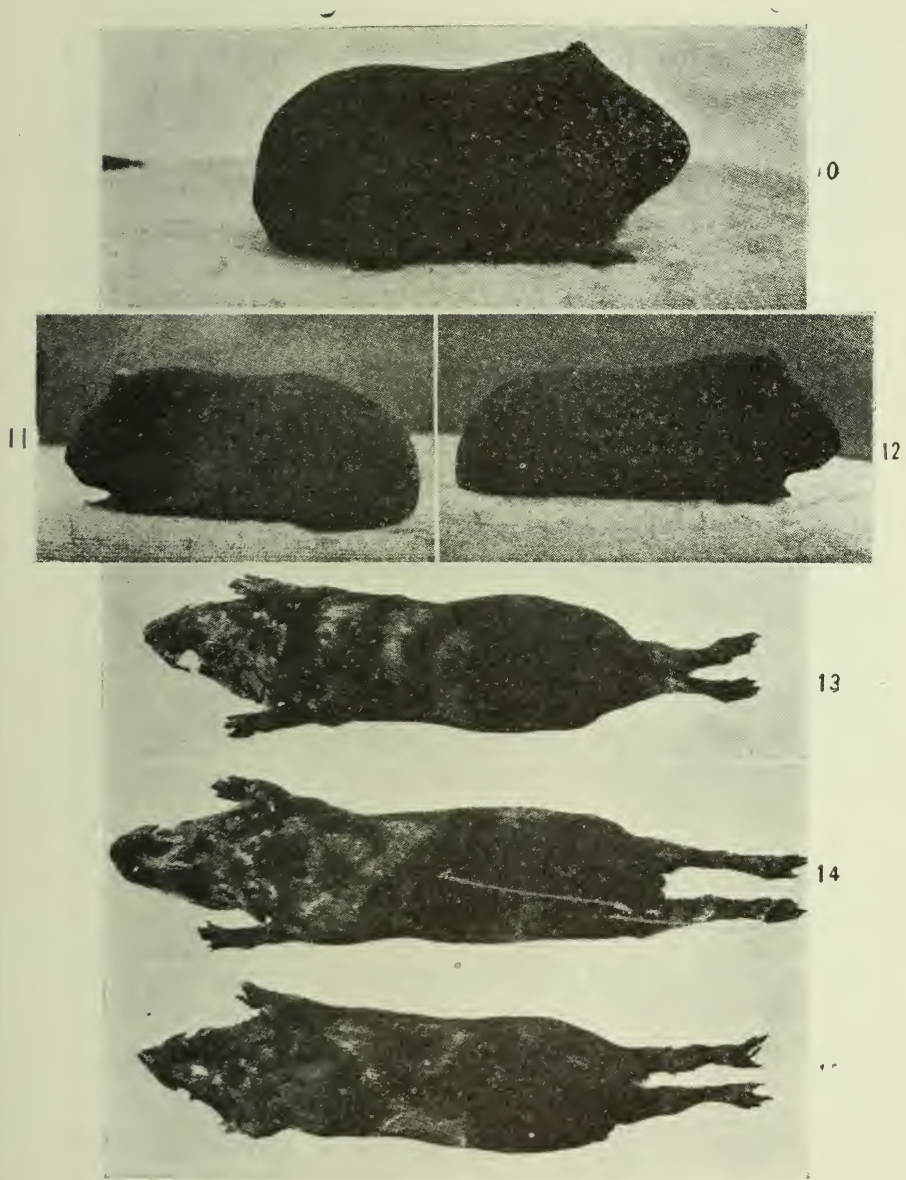

Figs. 10-15.-Pictures of three living guinca-pigs $(10-12)$ and of the preserved skins of three others $(13-15)$, all of which were produced by the pair of albinos shown in Figs. 8 and 9 .

From the excellent work of William Ernest Castle-Heredity \& Eugenics. 
That soul, in fact, never originated at the time of the union of the parental sex cells, because it existed long before and was merely excited and stimulated into a separation from the parent, with whom it had previously been temporarily entrusted, and from which it was taken, to assume an independent career. 


\section{WHY A SOUL HAS NO DEFINITE PRE-BIRTH MEMORY.}

CHAPTER XII.

It has been shown, beyond question, that our bodies have had immortality of the past in the unsatisfying way described. It has been shown this example of casting off, dividing, and expanding material tissues of the parent body is also followed by life, or spirituality, and therefore, in all probability, man's soul has had the same unsatisfying immortality, in being a bud or sprout from the soul, or life, of his ancestors. However, such past immortality has been a subservient dependent and an almost unconscious existence, until in the emancipation of birth we become a separate, distinct mortality and soul.

The eyelids of man bat without a conscious soul direction; his heart moves in the same way to keep up the circulation, and his intestines press on the digesting foods to nourish the seat of a soul. Thousands, yes millions, of similar intelligent motions of the body prolong its existence. These reflex, unconscious acts of intelligence impressed in the vitality of every cell of the body are bound to be felt, in a vague way, as they grow, although fading in the multiplication of cells for a new human being. Therefore, why should a young child not have a natural, inherent feeling 
that it always existed until mistaught that it did not? Even its body has always existed in the same way the bodies of corals and moners have for ages existed by continually stretching out and dividing, time after time. Why should not the sunlight, and warmth, feel familiar and soothing to its tissue? Why should not some cells, of our ancestor be more strongly impressed than others of this tissue memory of sensations that create a taste or pleasure or tendency which makes the descendant a genius? Why is it that this subconscious, obedient part of life, which never previous to independent birth, sent out ideas, but only received instructions, like the tail half of an angle worm, should not graduate to more independence and consequently be very delicately influenced by its unrecognized memory of past existence?

In the same manner that a man jerks his hands from the fire he touches, without stopping to think, he becomes expert in games or in the operating of machinery. In this same way we will say, his hands are taught to think, and perform marvelous duties, while his mind is busy in independent thought. Likewise, I have tried to show that the tissues of the old body, developing to form the new one, with its accompanying life, may have inherited something akin to this hand intelligence of which I have spoken.

It is an interesting pursuit, or inquiry, to try and ascertain whether all instinctive desires are the product of an inherited, but indistinct, mem- 
ory. When development sufficiently displaces infancy these vague memories are generally, though possibly not always, crowded out by present day happenings, and man is inspired and tempted to the sole consideration of a field of comprehensible possibilities of the preesnt. Yet these suppressed inherent traits are there. Something said or done may stimulate them, and possibly not recall much more than a primitive like or dislike. The life, or soul, may be added to, stimulated, or charged analogous to the charging of an electric battery.

For the purpose of giving some basis of speculative reason, to follow on this subject, attention is temporarily diverted to the almost unrecognizable latent force in matter, and the terrific explosion of this force when released.

When we realize something of the power and force stored within a small quantity of radium, which expels its electrons at a speed of 100,000 miles a second, we wonder at the source of the energy that concentrated it. The stored energy even in a piece of wood, in a bucket of water, or in a copper coin is more marvelous than any of the wonders of human construction. Whenever the secret is completely unlocked, whenever the particles of the package are wholly released, they return with terrific speed to a previous state of existence in the wide expanse of the universe from which they were gathered.

In considering the development of a soul, I have often wondered whether intelligence like 
matter, incapable of being reduced to nothing, was not made up of infinitesimal mind particles capable of division, and subdivision, to the extreme limits which confound us in separating the particles of matter to its ultimate limit. If so, then as truly as only about two dozen letters of our alphabets are used, in different combinations, to make the world's literature; and as truly as $\mathbf{1 0}$ figures, from one to cypher, are used to make the millions of billions of numbers in the world's calculations; and likewise, as truly as only 12 notes are used, in different combinations, to make all the music of this world; and also as truly as a lesser number of primary cells of matter are only placed in different combinations to make the different multitudinous forms of matter; so also may we expect similar primitive spiritual cells of intellect, or particles of mind, to be put together in different numbers, and in different ways, to constitute the many various forms of life.

If man persists in his faith demanding a future life, demanding that the corporation of mental cells be held together, he should have a greater mind, or soul, which would continue to grow and better prepare itself for a continuity of life. If a man reverses his natural power of attraction, to separate his unity of corporate intelligence, it may create a state of mental coma or it may be so disastrous as to explode and separate all these particles. Again, I say faith is necessary to continue this wonderfully strong mentality that man has developed and feels with- 
in himself. Possibly it would be difficult to think one man could disintegrate a soul, countless generations had evolved. However, faith is bound to make one stronger. It should require faith to counteract the powerful current developed against immortality. A child, not subject to this, may have a greater inherited faith than a mature man on the negative side.

In the same manner that food is necessary for the stimulation of the cell development of the body, so is the accumulation of mental nutrition contained in truth, and knowledge, and good deeds, necessary to cultivate a greater life, or soul. The things we think-the thoughts we receive and throw off or remember and forget-are to the soul what food is to the body. They carry, as a conveyance, a soul element, which, when retained, becomes a part of the soul life-part of man's mental nature and character. As you build up the body and protect it by food, drink and raiment, so would it appear to be natural that you would widen and strengthen the soul or mentality by what is concentrated in faith, hope, and charity. It is certain one cannot carry into the great beyond any part of his vast wealth accumulations, but there is a marvelous hope and a grand possibility that the accumulated knowledge of good things, or everlasting principles, in harmony with that which lives, may be taken as a part of the intellect, because it must become a part of the enduring soul. 
In this manner it would appear you may so develop, or concrete, a strong consciousness and individuality, which may become as much more invulnerable to disintegration, than a hopeless mentality, as the product of intelligence of a quartz crystal appears to be more invulnerable to disintegration than the intelligence of a toadstool. If this strong and abiding faith is not persisted in and we permit the soul to become weak, and emaciated, is there not some danger of disintegration of mind cells into primary elements of mentality-into that low ocean of the commonest intellect for a fresh struggle, which I should imagine the equal of any literal hell that has ever been described.

The world has heard so much of a hell that we may well expect to find some low sink holes of utterly useless and rotten human intellect. Some intellects do not desire to progress beyond the corruption of this world, and may not. Since they will not progress, and since they cannot remain (nothing stands still), they may be obliged to explode just as an egg dashed against a wall. I therefore wonder if death to some people, who do not desire a future life is a breaking up of the intellect and a dispelling of the mental cells, or particles, of spirituality constituting a soul, and whether or not they are broken so fine, that they must be made over by being absorbed and reconverted in other mental cell development, as low as the intelligence of insects, or even in vegetable life? I do not mean that the whole soul would be 
kept intact, and become an insect, or a flower, but only that the tiniest particles of his exploded mental cells, as distinguished from material cells, may be absorbed and reshaped to merely stimulate some other form of life, started and existing under the known laws of nature.

Worlds may have been destroyed and this earth received much of its accretion from their fragments in the showers of meteors which come within its attraction. Human bodies developing through our millions of annual births are growing, as explained, by cell expansion of the original tissues, but nourished, and fed, so as to enable a re-conversion of animal and vegetable cells to the same form as the tissues of our bodies in order to permit this division and expansion previously recalled.

Does it not follow that mind, and matter, which have so long and closely associated, would, like all associates in nature, develop similar traits in many particlulars? Therefore, the strong and vigorous mind may attract these meteors of intellect, in various combinations, thrown off from the minds of living, or departed intellects, like the earth attracts its brilliant constellation of earth cells from disintegrated worlds. The mind of a mighty man, who intends to live on, may strengthen itself by absorbing the particles of intellect, or whole ideas, from the oceans of intellect that come within the range of his attraction, and which he makes his own by a mental process similar to 
that by which cells of matter from plants and animals are reconverted, or metamorphosed, and made his own in bodily growth.

There are certainly both high and low orders of life. A man's soul is the highest conception of life. If organized, it is capable of growth. If it grows, it is complex and additions, or cells, of mentality are added probably like they are added to material growth. It would follow that these mental cells may be separated. This separation is personality annihilation-good-bye to yourself -it is hell.

This leads us squarely to the question of whether the soul is simple or compound. It would appear by analogy that it is both. It was simple, as it started in the nucleus of the first spiritual cell, that parted in company with the first material cell. By expansion and division, if it operates like matter, with which it simultaneously appears, it becomes the pattern spiritual cell, which never had an additional number of compound cells, excepting as this one created them by division, with which to think, act and co-operate. They are, while in development, made up of many cells under the influences of the original soul cell. While the additions appear to make it complex, none of these spiritual cells could be annexed as they were constituted, but all are spiritually absorbed, reworked, or changed, and thus adopted as a part and as associates, of the one original ego. Each cell, while once independent, later becomes a part of the central soul. In a peculiar way each 
soul is independent and still associated with its soul subjects, and yet in another way it is a part of the great Infinite to which it returns for some unknown reason as later herein mentioned, illustrated with the Medusa colony, referred to next herein.

Two comparisons of complex organizations may aid us in understanding a third-the wonderful organizations of mind particles constituting the soul.

First: Attention is directed to what has been said of man's bodily organization of material cells to perform the various offices of the body by each set of cells-the distributed intelligence and the central intelligence.

Second: Nature reveals a clearer illustration of this in the Medusa, known as the sea nettle or jelly fish. They are raised in colonies, each member an identity, but held together by segments and connected by something similar to a nervous and circulation system. The microscopic yeast cells, we may observe any day, are produced by cell divisions which are slow to separate and remain in chains or groups perhaps to co-operate. But the Medusa, holding together in much the same way, being large enough to observe, goes far beyond this, demonstrating its wonderful co-operative work. In this colony a part devote almost their sole energy to dividing or casting off for reproduction as a foundation for new colonies, and another part assumes the special duty of defense and conquest. Still others 


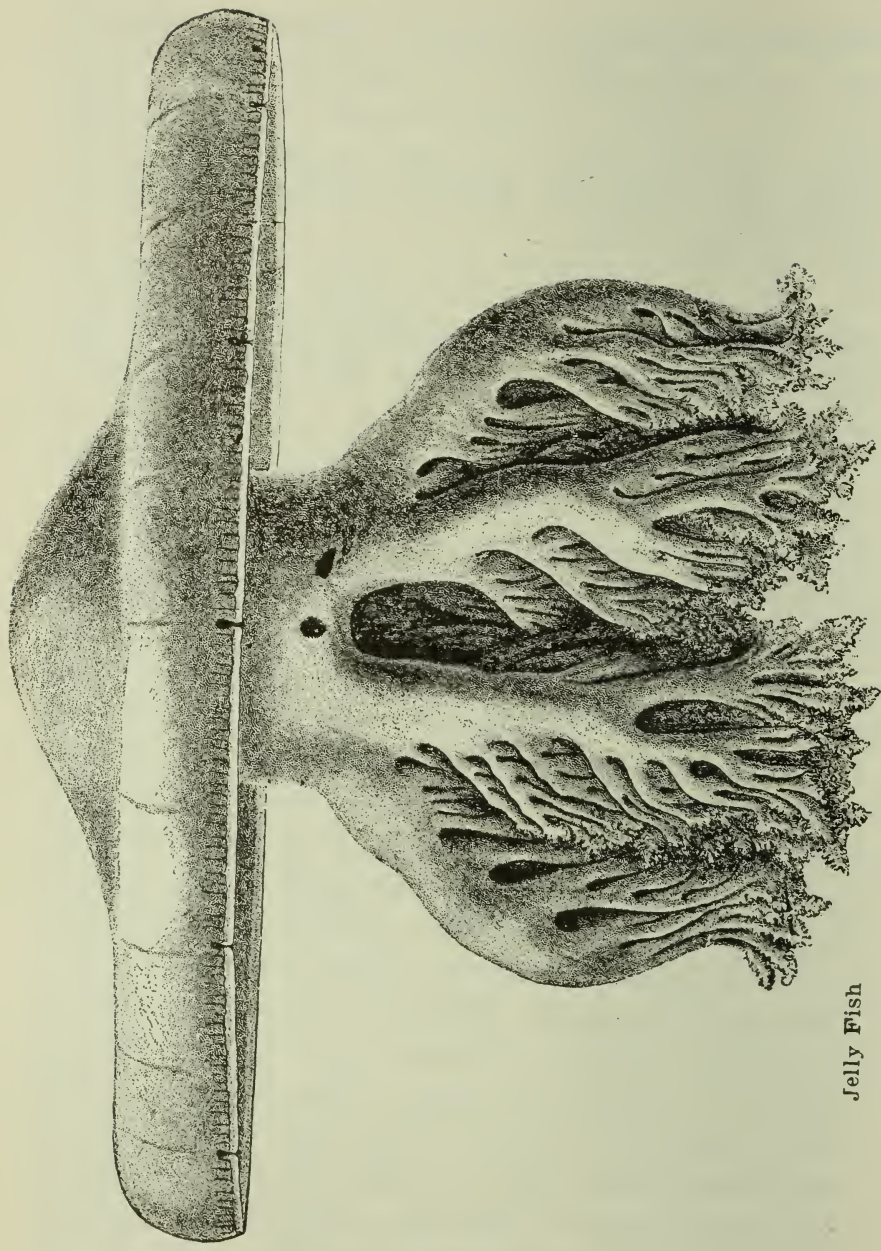


perform the function of digesting-one continuous round of banqueting for the benefit of all others who share in nutrition without the labor of eating. In the same manner of division of duties other marvelous work is accomplished.

Haeckel says of this species of life, described also as a glorious spectacle, compared to a floating flower bush with leaves, blossoms and fruit, which appear like polished crystal of most graceful forms and delicate colors-an unforgetable wonder to behold:

"As in a community of ants, so in the Siphonophore republic a number of differently formed animals have combined into a kind of higher social organization. But, while in the republic of ants, which is of a much higher order, the ideal bond of social interests and that of a political sense of duty unites all the individuals as free and independent citizens, in the Siphonophore republic the members of the community are by bodily connection riveted like slaves directly to the yoke of their communal unity. Still even in this close coherence each person is endowed with an individual soul of its own. If severed from the common stem, it cannot move about and live and have an independent being. The entire sea-nettle, as a whole, also possesses a will of its own, a central will, on which the single individual depends. It possesses a common sensation which at once communicates the perceptions of the single individuals to all the others.

"Woe to any Medusa that, in the infatuation of egotism, would break away from the communal stock in order to lead an independent life. Unable to perform all the particular functions that are indispensable to its self preservation, most of which were performed by its several fellow-citizens, it needs soon perish if it be detached from its old companions. For one Medusa of the Siphonophore 


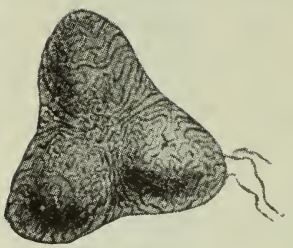

RHODODENDRON.

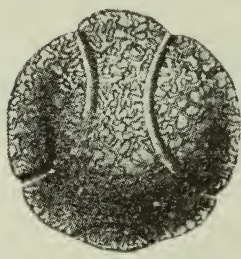

PASSION-FLOWER.
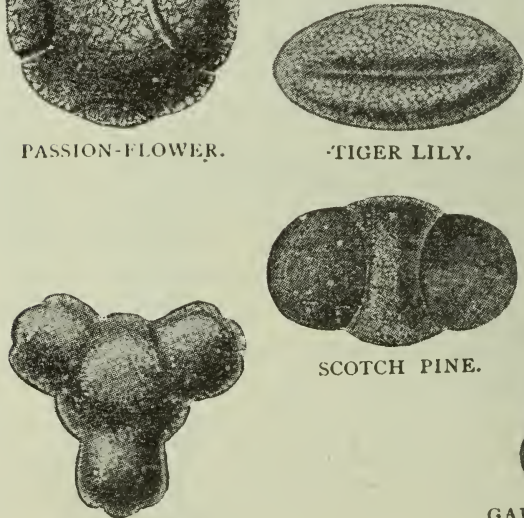

'TIGER LILY.
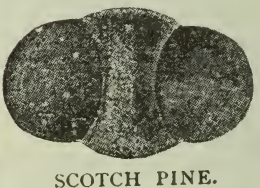

GARDEN WILLOW-HERR.

CLARKIA ELEGANS.
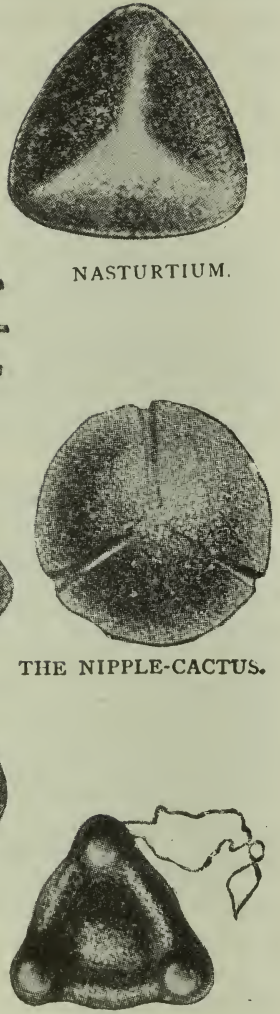

NASTURTIUM.

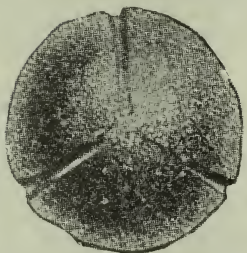

THE NIPPLE-CACTUS.

DESIGN AND BEAUTY OF POLLEN 


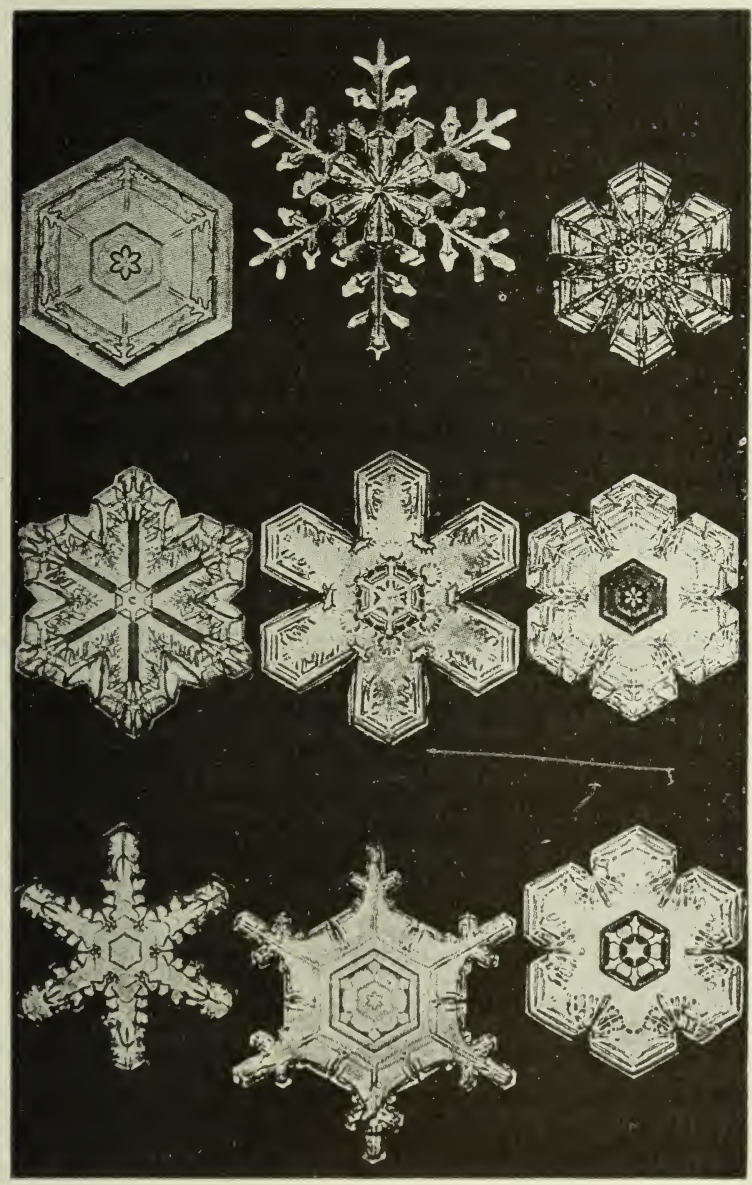

SNOW CRYSTALS (AFTER BENTLEY)-Harpers. 
can only float, another only feel, a third only feed, a fourth only catch prey and repel enemies, etc. Only the harmonious co-operation and the reciprocal support of all its members, only the communal consciousness, only the central soul, linking all together in bonds of faithful love, can impart a lasting stability to the existence of both the individuals and their totality."

Third: From this illustration and the first (man's body) we may fairly presume, for want of a better comparison, that a man's soul is a finer, more delicate, Medusa-like colony of intellect, perhaps to progress under leadership of the Source of all souls.

I ask you now, what is impossible in nature? What is impossible with the Infinite? Why not expect a wonderful, complex, spiritual organization of mind particles in preference to a disorganized, misty force, when even the dusty pollen of flowers are beautiful, intelligently designed, crystaline forms; when even the mold upon neglected food is a miniature jungle and forest; and every flake of snow that falls, although different from every other, seems to have been designed by an artist?

These snowflakes and all crystals may seem mysterious but for real mystery follow Macfie's description of a cell:

"It is very strange that a little association of carbon, hydrogen, oxygen and nitrogen should have the power of adding to their number, and it is stranger still that the addition should take such shape, and produce such a mechanism as a multicellular organism. If a brick were to grow into a pile of bricks, and if the bricks were to 
arrange themselves in the form of a cathedral, what a miracle it would seem; yet every day single cells grow into heaps of cells, and the heaps of cells arrange themselves into trees, and flowers, and birds, and beasts, and men and no one seems particularly surprised."

What force moves in this mysterious way? Is a soul not more mysterious than a cell?

By analogy we show all space is filled with ether. We do not see it, or know of it by any direct sense recognition. We know the energy bringing heat and light from the sun travels by wave action which it produces wherever we have analyzed its motion. We assume there is a substance susceptible to this wave movement as a natural means of conveyance, because this wave traveling element comes to us. Ether is in a similar class to electricity or gravity, in that we discover the existence of either of them usually by what it does to other things, or what other things do with it.

In the same manner that we assume the existence of ether we may assume a soul. We do so by inquiring into the plan and method of all of the work of the Infinite. If an Infinite Intelligence made up the whole material universe of suns and stars by a combination of infinitesmal parts; if plants and insects and animals are all produced and grow by cell division and expansion; if all creation is complex and therefore subject to division and re-division, may we not conclude that the Author of this universal work adopted such a universal system as a principle 


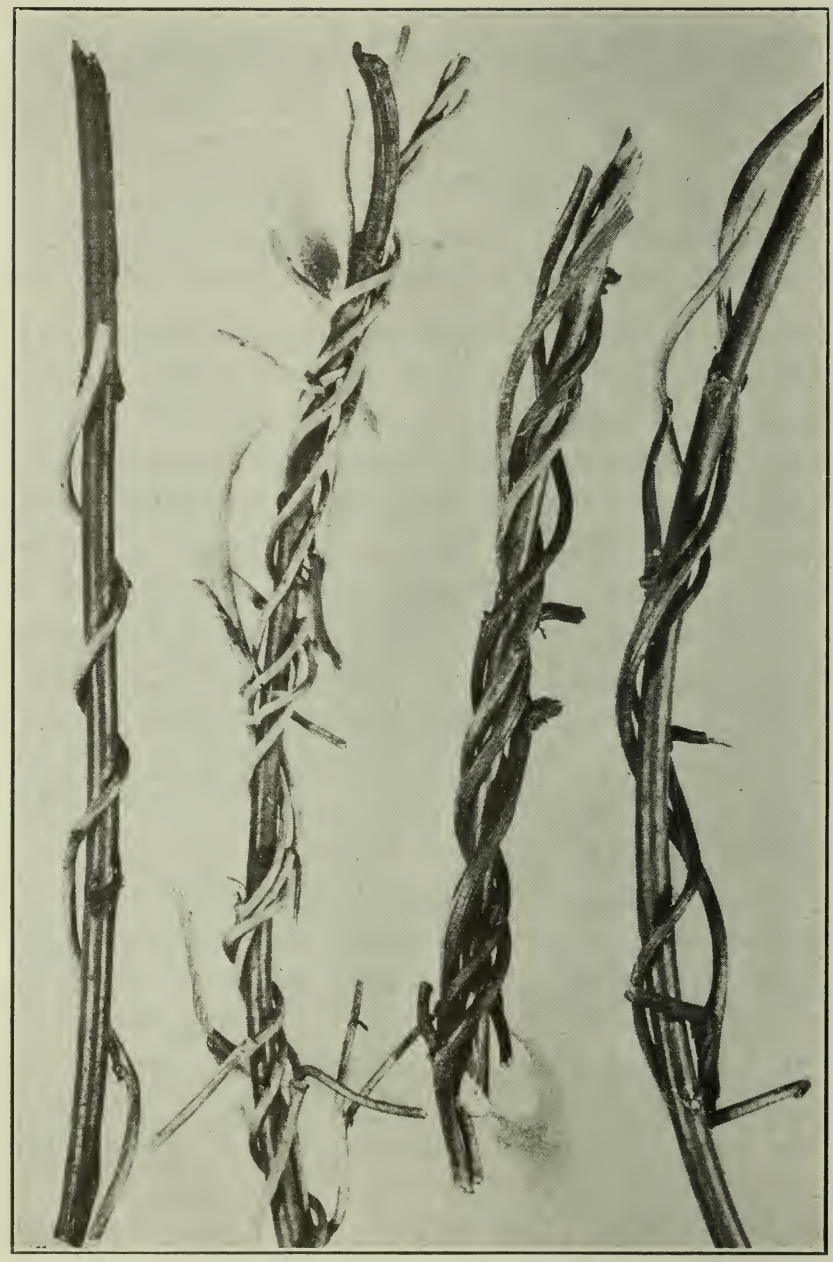

Wild Morning Glory Vines 
of all of the rest of His handiwork? If this principle exists in all we have known, and all we discover in the unlimited diversity of the material world, how can we assert that God has withheld that principle from the rest of $\mathrm{His}$ work which we do not see-from the soul of man?

When the physical cells of men are cast off, mental cells, or cells of life-the germs of soulsare cast off and start independent careers.

We have all been astounded in learning of the magnitude of the universe and being informed the sun is revolving on its axis and is also traveling in an almost uncomprehensible circle, carrying its circling solar system of globes, continually revolving around it, or conversely, as our moon revolves upon its axis, and around this earth and with the earth around the sun and also with it around the greater uncalculated orbit of the sun. But pause a moment.

Go out into your garden and be surprised with the knowledge that every morning glory vine twines itself around supporting stalks from left to right. This is substantially true of every tendril of every vine. Why is this true? It cannot be caused by the wind, or the sun, or the motion of the earth, or any commonly known physical force, because the same phenomena appears below the equator as above, and it also appears in every spiral shell of the sea. Being there and 
upon moving animals, it explodes any theory of such causes as those mentioned. We know that as features are transmitted so are habits as previously mentioned. We know that as these family traits are handed down, so may the back bone always appear in one great family of life known as the vertebrae. In the same way as we find the vertebra of one branch of life a family mark, so is the astronomical circle a mark of universal brotherhood of all life. The animal kingdom, the vegetable kingdom and the mineral kingdom all bear abundant proof of a great family trait of the universal mind in this tendency towards a parental desire to circle from left to right. That tendency to circle in all embryo, and much of later life, is an evidence of intelligence. There is a mind force and not mere resultant haphazard physical force. It is intention rather than chance. But what universal law fixed and emplanted it I do not know. It is not from east to west or north to south, but it is from within the being. Viewing it from within the being, it is from right to left, but viewing it from our standpoint, outside it is from our left towards our right. It is directed from left to right as unerringly as the tender shoot twines or bends and pushes its way upward. It is a very slight proof of our assertion that matter is the product of intelligence rather than, that intelligence is a product of matter, and a very strong proof of a family trait connecting the aniimal and vegetable kingdoms with the scheme of evolution. 

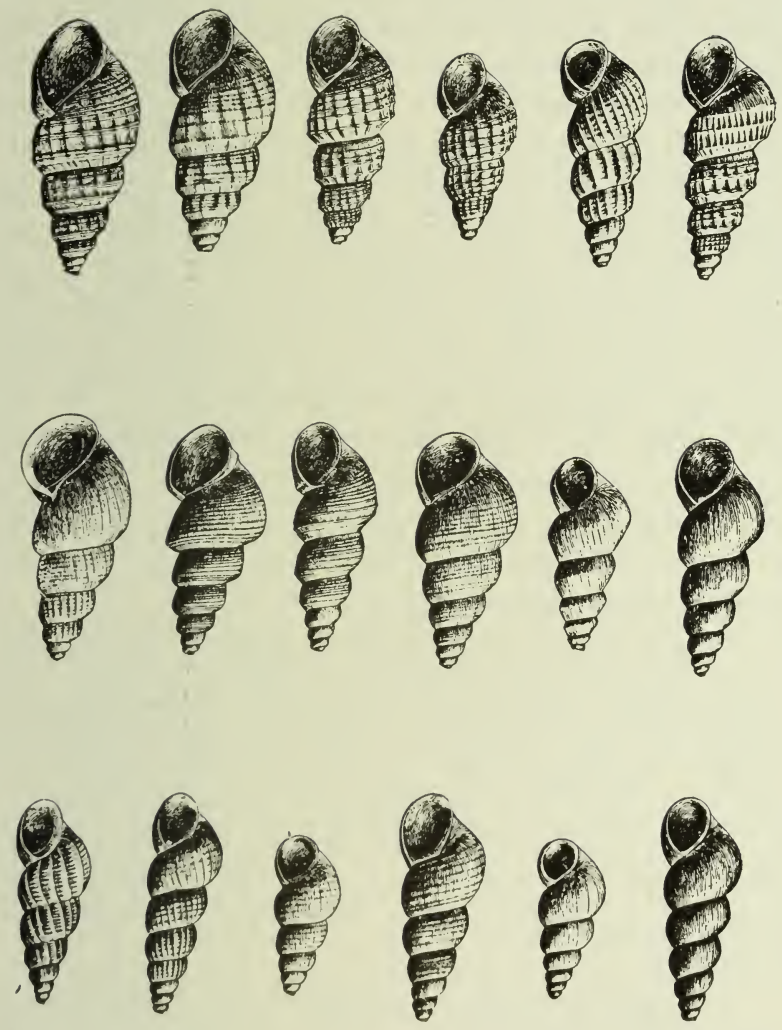
The study of embryology and interesting examination of the backbone, so similar in a certain large class of animals, goes a long way in establishing evidence of evolution. This great family feature proves a very long age of existence, and ties together in relationship, a long list of very different animals. But let us take another inherent force cropping out here and there. We have often read speculations on why a man is normally right-handed. When this is answered, perhaps the wise man will also tell us why the halibut and flounder almost invariably lay on the left side, with the right the upper and active side" The fish are indeed right-handed. As stated, all sea shells with spiral growth develop from left to right as twining vines climb their support winding from left to right.

Does this not indicate a family relation between man, animal and vegetable, antedating the origin of the backbone millions and millions of years? Is there not some force still existing in divergent forms of life inherited from a time before this world existed? But the unanswerable question is, what created this force that has continued so long?

If man developed through such a pathway as materialists point out from and among other steps, a mere cell of a plant, preserving this tendency even of vines, does that not indicate that this cell must have developed from an earlier source, and will it not be discovered to have existed before anything physical existed? If it came from a 
state anterior to a physical state, it must have come from a metaphysical state. If life came from that state, abides here a while, and leaves this physical state, does it not return to the metaphysical state?

When man has developed this life part so big, way past the intelligence of plants and animals and has such confidence in his consciousness and regards it as so supreme in his makeup, why would he not claim a soul for the human being although doubting such exists in the great careless class beneath him, and although acknowledging that his body developed from the same origin-an origin even earlier than the birth of the world upon which we are now existing.

These things show more than mere evolution on this earth because they show evolution from a state of existence beyond this world. That is all for which the man of religion is contending. He denies that we are a mere product of the physical matter of this earth. He says we are the sons of a spiritual force. We can prove it by these little trifles I am mentioning. Not one alone, but a thousand. Everything we examine and analyze, may be traced back to a Divinity, whether it be the force of right-handedness, or conception and birth, or a knowledge of insects and germs, or the movements of planets and constellations.

The circle is indeed a mystery of creation. The rational, reasoning, hard-headed, scientific 


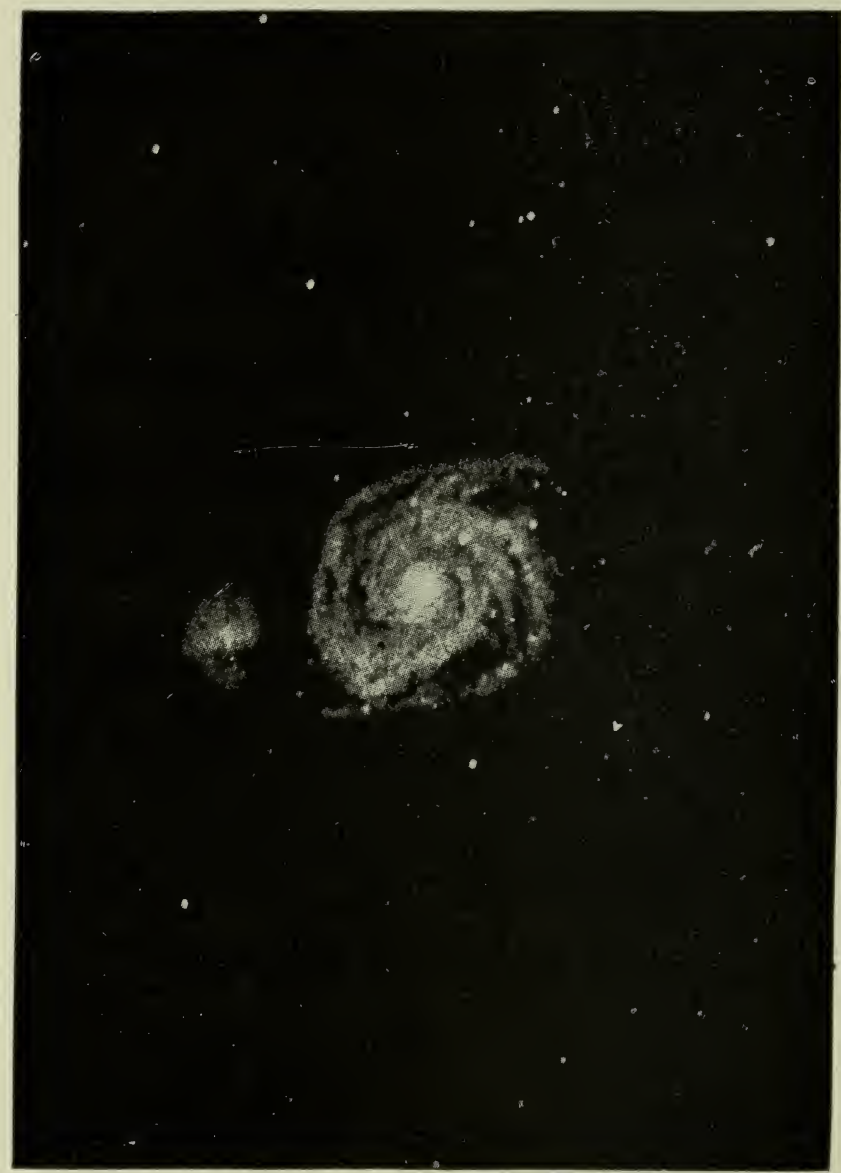

-

SPIRAL NEBULA 
materialists, running these circles back to a time when worlds are reduced to grains of sand, and sand or other material, is separated and reduced to gases, and vapor, and primordial matter, then they commence to build it up again under synthetic philosophy. They say some force starts a circle-they call it a "vortex"-which goes on, and on, growing by the union of other forces, until we behold a spiral nebulae, and then a world is born.

At the other extreme we learn electrons are spinning around, with terrific force, and circling in orbits, within the atom, as the more comprehensible solar system moves. After we recover from such a shock, and return to a consideration of the opinions of astronomers, it is only one step farther for a philosopher to say this first small vortex ring, or parental ring, had a germ or nucleus of mentality, to start with, and attracted particles to the mere idea, against which there was no resistance. This nucleus of mentality, if thrown off by nature, in the usual manner of nature's work, would be started as the circle of a cell is started.

In our botanies we learn that throughout the whole field of vegetable life every seed and every bud and sprout germinates in the form of a circle. Likewise by investigations in biology, it is seen the whole insect and animal world is governed in the same way and starts life, as man does, curled in the same mystic circle. 
Why is not a soul unfolded without a memory, under the same principle of nature as a circular cell of matter is unfolded or rolled into material existence?

May not this also be true of even a thought? Every public speaker has noticed the support or depression of an audience when unusually in or out of harmony with him. Every person has been reminded of the old adage "speak of angels and you hear the rustle of their wings" by the fact that time after time some absent one, while being discussed, interrupts with an uncanny, because unexpected, appearance.

As we talk of a man just before he appears, we have often thought of an old acquaintance, shortly before a letter is received from him. As we sit in our homes, we sometimes abruptly think of another and then the telephone rings. In an instant we find the bell was too slow. The party calling was the one of which we were previously thinking. Again, we think of an invention, but read an announcement from the man who has beaten us to it. A wave of public sentiment, time after time, sweeps over the country, like a great cloud crosses the sky. All these things, so generally noticed, by our hundred millions of people, and the rest of the world, for each generation, over and again, conclusively shows that they are not coincidences. These circumstances are of such recurrence, that the old adage, "speak of the devil and his imps will appear," can never be forgotten. These things must not be disregarded, by 
men as cattle disregard so many common things they see. Our duty demands that we account for such persistent recurrences.

If one mind, merely by thought, affects another in this first delicate suggestion, as shown, we may speculate on how it is done. Is this energy in long unbroken shafts, connecting the two, or is it by usual circular cell-like particles? Is it not sent out like the light and heat giving energy which, when given off, separates from its source and travels on independently until it reaches the object absorbing it? If this reasonable hypothesis is true, why may we not pick up some of the ideas thrown off by men although death results before being absorbed by those who are living? If this be true, why may we not carry it further and concede that thought energy may be picked up, although it may have started as far back as the light of some of the distant stars, which, though started 6000 years ago, is just reaching us, or from some source of intelligence in a different sphere from living men of today.

The assertion that mind is a function of the brain, just as bile is a secretion of the liver, is a very much overworked proposition by physical materialists. This class of men, because their feet rest upon the earth, made up of the skeletons and carcasses of life, and knowing that there must have been an origin of all things, believe that intelligence is the product of matter, and assume that mind is a secretion, because of its localization in, or operation through the 
brain. Because they see more of matter than of intellect, they think it is a mere chemical production. I will agree that, as everything is traced back, it narrows, and simplifies, and discards its branches and complex developments. We trace matter back, division after division, as it was formed by its accompanying life, but we never have yet shown where life was distilled from lifeless matter. The tendency would be towards the establishment of the opposite view, viz.: that matter came from life, vitality or mind. When we have reduced the substance of apparently inanimate matter to the electron, spinning and whirling with greater speed than the planets, we are obliged to try and compare its infinitesimal material body with its terrific speed, vitality, or life. This vitality is its main element, but its body - the matter-is almost nil. If everything was once an electron and possessed of such speed, persistence and vitality, there can be no more than one or two steps farther to pure thought, which has more speed than even the electron, for it is instantaneous. Since mind and matter could not have originated simultaneously-but one must have been the product of the other-I prefer believing that mind is more perfect, possessed of more vitality; hence is older and superior to matter. It follows that matter is more likely to be the product of mind, than mind the product of matter.

Upon the question of mind being a secretion of the brain, what will you say of the man who lis- 
tens to a conversation thus unfolding a wonderful and perfect idea? The man who hears it and accepts it, manufactures nothing from his brain, but he merely receives an idea by means of hearing and sight. The man who unfolded it created nothing, but perhaps an accident or long experience, taught it to him, and he saw a universal principle that he related. Man uses his brain as a receiver, whether voluntarily, or involuntarily, and by his judgment and interest or lack of interest separates, or sifts out and rejects all thoughts which are not of interest to him. He makes nothing in the thought line, but rather gathers it as a matter of educational development.

Mentality is so strong and so attractive, or repellant, that it is often compared to the instruments of wireless telegraphy. As we desire to make ourselves better or worse in a spiritual or material way in any branch of development, we attune ourselves to that environment, or vibration by thinking upon the subject and receive thoughts and ideas as we desire. In this way we enlarge the ego according to the growth desired. "As a man thinketh in his heart so is he." To dwell upon evil with fear is only another way of inviting it by thus attuning our souls to receive the things we fear. It is asserted that to repel a condition feared it is necessary to find the antithesis which will automatically dispel that not desired by making the mind a welcome place for the vibration of that which will take the place of and crowd out all thoughts and their products which are the 
objects of fear. How natural it has ever been to have the information or means of doing things revealed after constant desire, when unneutralized by the negative force of fear. Desire will not bring things to us through a modern express company or on a tray, but only the mental means or knowledge of the power of accomplishment. It is a demonstrable fact that "faith without works availeth naught."

These things indicate the evolution of each soul from an inconceivable primative start, and the powerful energy of the soul to gather all its desires at the proper season without the necessity of an eternal past memory. Memory has not been as necessary as we would suppose excepting as it has been developed for local emergencies and new accomplishments. Memory seems to be a mere pilot-light for the development of instinct, in instinct following animals, and character in higher life. As soon as its function is performed memory leaves and habits are the results. Instinct, or character, appears to be the consolidation of so many memory particles that it becomes a crystalized part of the creature's nature, handed down by means of separation and division of the impressed parental cells.

Instinct is naturally more highly developed in the lower animals, such as some insects, than in man for the reason that these insects existed millions of years before man arrived and they retained and relied upon this inherited memory, while man, a newer arrival, converted the same 
energy, and this organism, if such it is, in the other direction-the future.

Considering the manner of propagation in every form of animal life as traceable to some form of separation from a continuous existing life, and an inherited product of memory, and we may begin to understand the marvelous seemingly intelligent acts of some of the insects. Without the necessity of distinct memory, but only by the aid of its product, so-called instinct, some species perform skillful surgical operations exactly as their millions of billions of ancestors have done. They do these things as innately as the tissues for a human body by their own volition carry out a reorganization for a new human birth. No distinct ancient memory - a sort of mirror or looking glass reflection of reality-is necessary for a settled instinct condition, where knowledge has become an inherent part of the creature.

Is it mere guess-work on the part of the parasite that causes it to attack the cabbage worm, and sting its eggs in the flesh, there to hatch in the midst of the fresh tissues of the worm which remains alive to support this horde of aliens? Is it an accident that the young, so hatched, never devour the vital parts of the worm, which would mean their own starvation, but subsist on the tissues, the destruction of which does not result in an immediate fatality? What can be said of the wasp that stings its prey so carefully, always the same place, a nerve center, and some victims in eight distinct nerve centers, only paralyzing, 
not killing the quarry, which it stores, preserved in their own vitality for the young?

I have cited above only two instances of a large number of established practices, some of which are marvels of intelligence, far surpassing the two given. These illustrations of insect intelligence, handed down for ages, are but the product of composite experiences, balanced against each other, and prorated, as they are passed on to the prevailing species. This apparent result is the delicate, but directing intuition, we call an instinct.

Man has abandoned this pre-birth memory, or instinct, to give heed to his newer senses and mechanical extensions thereof and to look to the present, and future rather, than the musty past. The lower organizations are the same thing over, and over, again. All crickets, bees, ants, flies and moths, of any particular variety, look exactly alike, because they obey their instincts and act exactly alike. They depend upon this inherited, or preserved, memory-sensing of the past for their guidance. They will always remain the same and never progress, because of obeying instinct rather than aspiring for the improvements which gave to man the "breath of life" that made him a continuous living soul.

For the thousands of years that mankind was more inclined to stop than advance, following the precedent of the times and ridiculing all innovation, no great advancement was made. But what may we not now expect from the free education adopted only a generation or so ago? 
I believe the element of hope in the human race, and faith in the future, which are developing, are the result of having actually picked up the sense of instinct, which once trailed along behind, keeping us in the same course, and projecting it so as to feel out and sense tne future in connection with the other new senses we possess.

I repeat we have no distinct pre-birth memory that the soul would recognize because we have reconverted or lost the instinct sense and do not try to exercise it, or even to give any credence to superstition, its last and now unreliable ragged remnant.

How does this suggestion harmonize with the fact that we would question the statement of any man who claims to remember any single incident happening within three, or six months, or a year, after his birth? Why is it that the memorv of even the best of us is so unreliable after a few years, and why is there so much controversy between people who hear and see the same things at the same time? It is largely because memory is a mere hand-maid to recall evidences during the analytical period, when ideas are being considered for absorption, as a part of a man's nature, or forgotten and cast off with all mental excreta. If we do not remember the large percentage of incidents of mortal life, why should we remember details of foreign incidents previous to birth when we were only a subservient spiritual cell of a soul.

There is an inherited memory of an ancestral life and an unconscious memory of incidents of the 
present being. Of the latter class of memory, may I be permitted to give a personal experience? This is so delicate an example that one could easily wonder whether it was in fact recalled or an idea from some unknowable source of ideas.

A few years ago, as his attorney, I was defending a man charged with placing a suit case filled with dynamite on the doorstep of another, arranged with a loaded and cocked revolver, the trigger of which was attached to the floor by a string, so as to explode the cartridge and dynamite when the suit case was lifted. The suit case was found at 2:50 P. M., May 22, 1910, and the time positively fixed by four people who consulted their watches at the moment. Two little girls indentified the defendant and the suit case claiming that at $2: 30$ they walked behind this man, imitating the limp in his walk, until he turned up the alley, back of the house, where the alleged infernal machine was found. Three other witnesses identified the man with the suit case and the witnesses also claimed the little girls were behind him limping and laughing. On cross examination, I learned these little girls were on their way home from church, sixteen blocks distant, where they had been photographed with a confirmation class. Believing my client innocent, and being compelled to work against such tremendous odds, and having such little hope in sight, I personally examined every trace of evidence without permitting assistants to disturb it before I could investigate. I called on the 
pastor of the church, and inquired for the photograph, expecting to find a photographer's imprint upon it and in this way thought it barely possible to find a book entry and date inscribed showing the picture to have been taken upon another Sunday. But investigation revealed that an amateur had taken the picture and with pen and ink the date, "May 22, 1910" was written upon it. Although somewhat disappointed, I then examined this picture very intently for fifteen or twenty minutes, studying every detail, in spite of discouragement, and when I concentrated my mind upon a shadow prominent in the picture, I began speculating upon the angle from the point of the shadow to the corner of the church that cast this shadow, a little south of west, and in imagination I projected this course out in space to the track in which the sun traveled upon that day. I then consulted Prof. William S. Rigge of Creighton University, on these astronomical calculations. On the following day we engaged a civil engineer, with a transit and level and took the measurements and angles from which the astronomer testified the photograph was taken on May 22, 1910, at 3:21 29-100 P. M., or within one minute of that time. From this evidence it is seen the girls were standing upon the church-steps, having their picture taken thirty minutes after the crime had been committed, instead of before, and to walk sixteen blocks afterwards, taking over twenty minutes more, would have placed them in the impossible position of claiming to have seen a man carrying this suit 


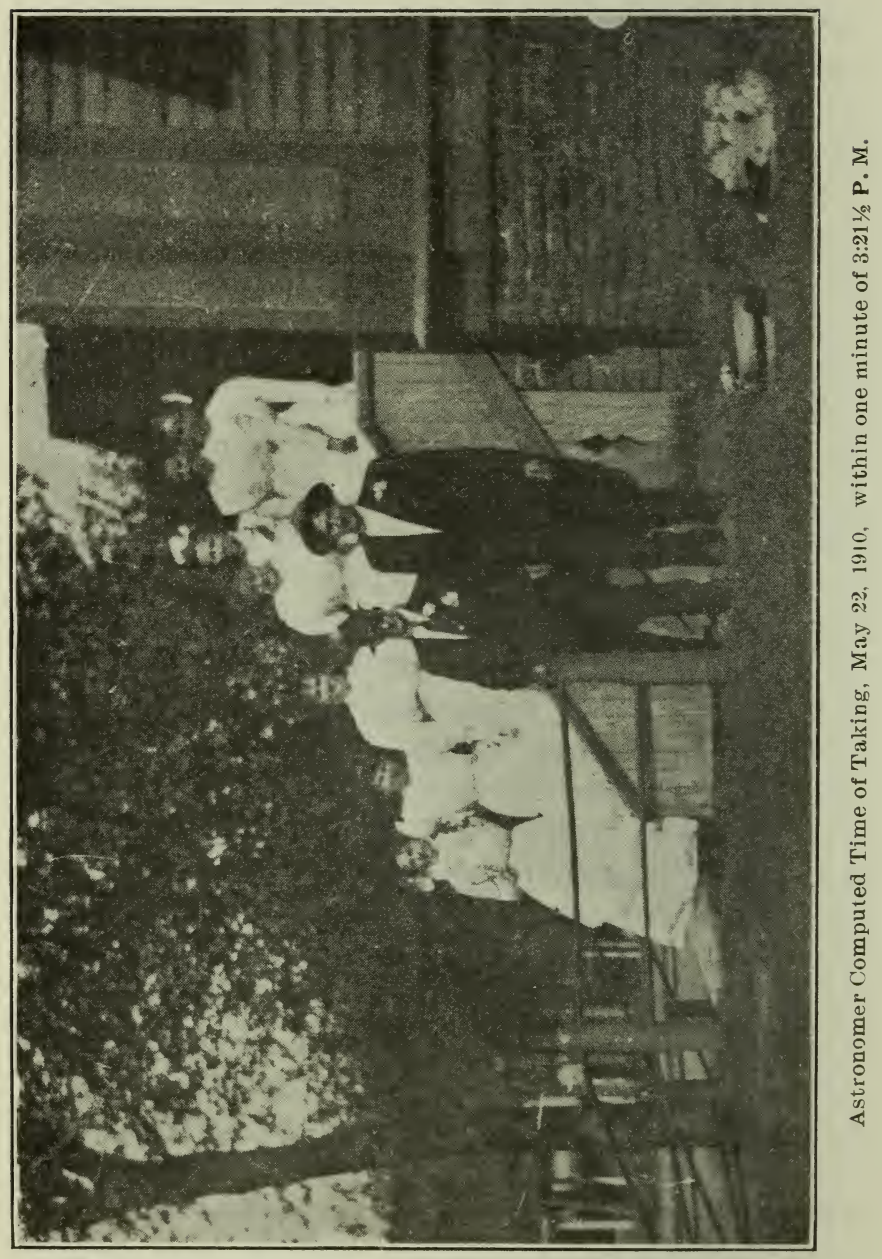




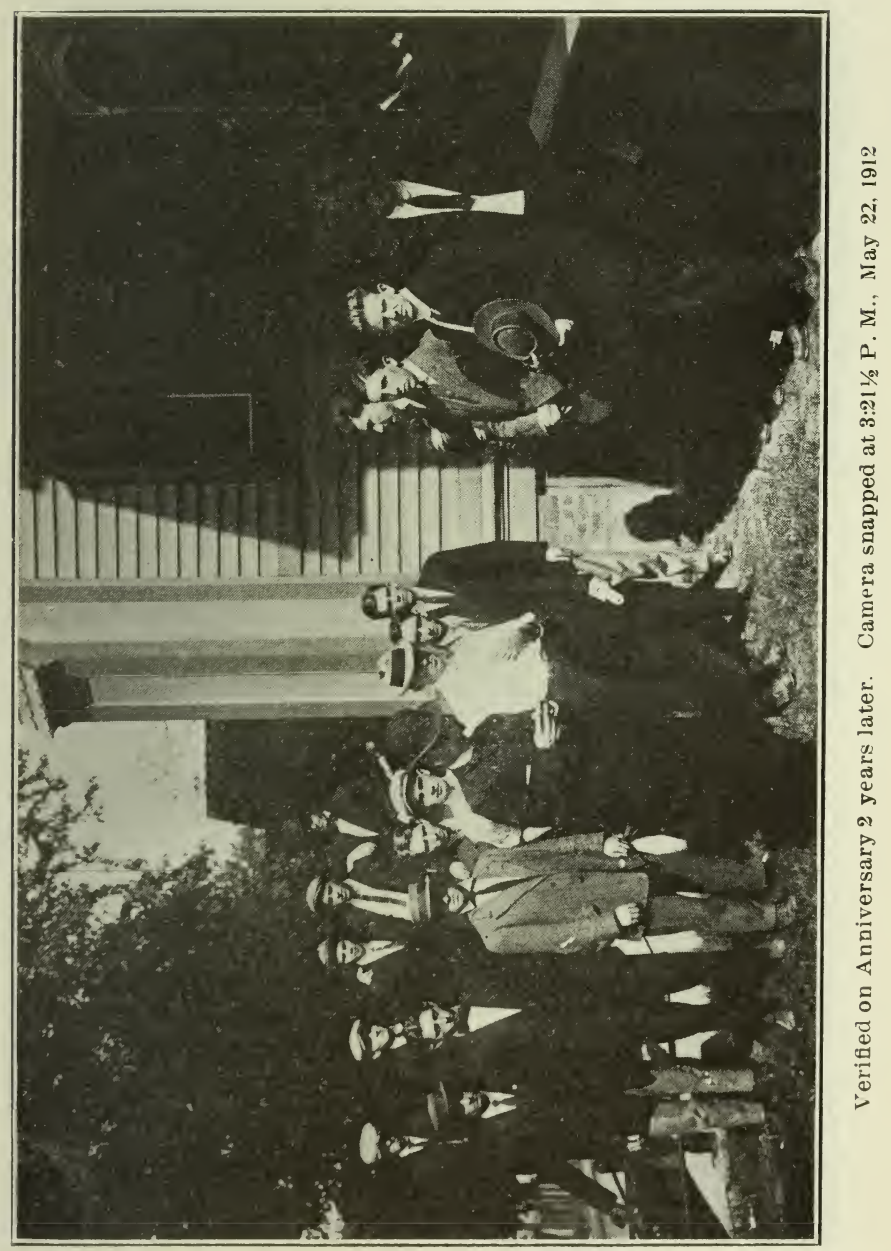




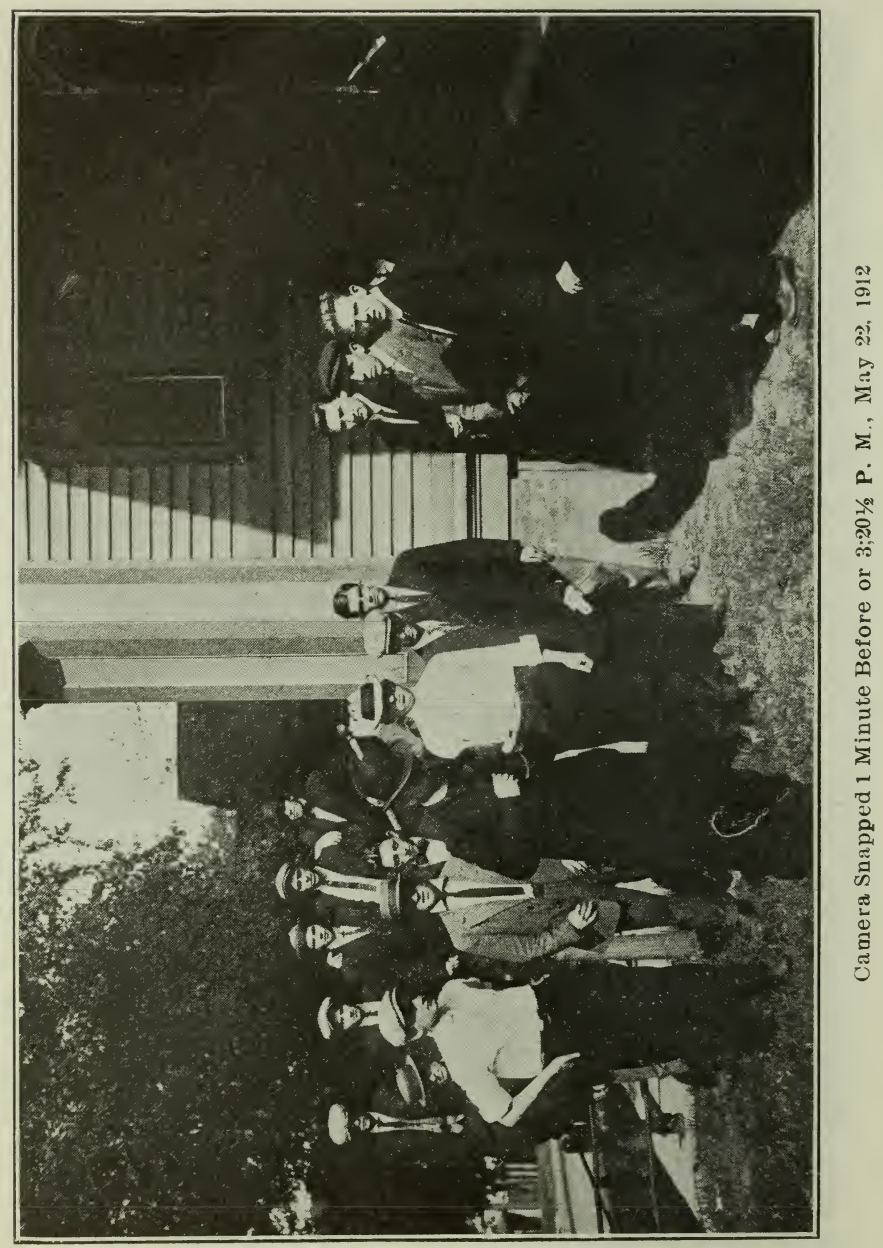


case of dynamite to the house one hour after it had already been carried there. This elimination cf the two girls and their evidence carried with it the elimination of the other three witnesss who positively claimed the two girls were behind the man they identified. By the thinest of defenses, "a mere shadow," the accused was finally acquitted. On the second anniversary of the crime, test photographs were made and the accuracy verified as shown by illustrations herewith.

More than three months after the trial was over I remembered that in some magazine, several years before, I had in merely turning the pages, observed a picture of a hill, a valley beyond and mountains across, and some very small trees in the foreground, and an inscription below saying "Can you tell the time from the picture?" I did not study it, or read about it, or ever again see or think of it, until as I said three months after this trial. Possibly, when the shadow of the picture was being studied, the association of ideas recalled this thought without recalling the picture as the cause of the thought. I seized the idea when observing the shadow and vigorously applied myself to the case. In thinking of the trial during leisure, after this long time, I recalled the magazine picture by the reversed association of ideas.

As I never seek a mysterious foundation for anything under which I can place a practical foundation, I have been inclined to believe the thought received in this law suit, was a recalled subtle memory as described, yet others may think I am 
straining a point to obtain a material foundation. If this was a recalled memory, it is truly wonderful, the same wonder every individual may observe in himself, if he will analyze his thoughts. Yet this example may be a mere coincidence, as all thoughts may not come from material, or physical sense suggestion. Let us gradually approach a grander origin of thoughts, and ideas, that indeed possess much mystery.

A great deal of subconscious memory is utilized throughout the life of all mankind. We are daily thinking of things we believe are original when they in fact are the recalled ideas of our own natures, absorbed from something long previously read or heard, when the author or the incident has been forgotten.

I wish to call attention to an example or two of what some critics may brand as plagiarism.

Poe was a master poet. Why should such a genius steal? The same may be said of other poets. Yet, note the striking similarity of Poe's "Raven" with a Chinese poem of 2000 years ago.

From the Literary Digest of July 13, 1911, I take one stanza from Kia Yi of 200 B. C., for memory comparison with the "Raven."

"Betwixt moss-covered, reeking walls

An exiled poet lay-

On his bed of straw reclining,

Half despairing, half repining-

When athwart the window sill,

In flew a bird of omen ill,

And seemed inclined to stay.

To my book of occult learning

Suddenly I thought of turning," etc. 
Compare, also, Morris' "Woodman, Spare That Tree" with "Kan tang," which was an old ode written in the time of Saul, over three thousand years ago, and collected with other poems by Wan Wang and Duke Chan and later translated by Dr. Wells Williams in his book on "The Middle King.dom."

"Oh fell not that sweet pear tree:

See how its branches spread.

Spoil not its shade,

For Shao's chief laid

Beneath it his weary head.

Oh clip not that sweet pear tree,

Each twig and leaflet spare-

'Tis sacred now,

Since the lord of Shao

When weary rested there.

Oh touch not that sweet pear tree;

Bend not a twig of it now;

There long ago,

As the stories show,

Oft halted the chief of Shao."

While these inspirations may have been coincidences, based upon the same inquiry, and the same responsive hearts, they may also be the unconscious breathing of a part of their own natures developed, by both, from the acceptance of the same thoughts, more coarsely expressed by others. Who is there, weary and footsore, suffocated and thirsty, returning to the shade of the tree in his door yard, and while he lay there, would not think of the possibility of its destruction? How many millions of people who never read a line of poetry, 
when so reclining, have thought "Woodmen Spare That Tree?" What is more natural than to emphasize the same thought by repeating, "Touch not a single bough?"

The refreshing shade recalls the satisfaction, and appreciation, of such a tree as long as the tissues of man have been protected from excessive noon-day heat. Much as the same condition of low temperature in either northern or southern, latitudes will congeal water into ice, so will the same conditions and combinations of circumstances cause mankind in different ages to receive similar thoughts; they may be made profane, or prayerful, according to these different conditions.

All through literature, including the sacred Scripture, many examples of seeming plagiarism appear, as the stanzas above, which should not, in every case, be branded as plagiarism, but which may be as easily accounted for as above suggested, by the absorption of a thought, or a principle, as a part of man's nature, although deserted by memory. In the same way that this may be daily observed in the thoughts and expressions of any great speaker concerning what he has absorbed by reading, or suggestion, during his present existence, why may he not ảlso give some expression in his own language to the things he felt when his soul was a mere bud upon his ancestor's life and most naturally without a memory of the sentiment that so impressed him? Nothing but this hypothesis will account for the so-called inherited gestures and family traits, thoughts, likes, and dislikes, so 
clearly observable throughout the world. May this not be the basis of so-called originality and prolific imagination?

May we not also be impressed with thought disturbances thrown off by those who have died since these discharges were thrown off and before being picked up? Surely if there is continuity of life they are still being thrown off by spiritual life and being picked up by mortal life.

Considering the whole question in a rational way a pre-birth memory is not necessary or material. Neither does a lack of such memory prove that we did not have a consciousness, ages before we were born, which we do not now remember. Even the loss of memory in old age is not a sign of dissolution of mind, or soul, particles, but only the shedding of a memory function becoming useless, that never had a marvelous endurance, regardless of the fact that we have been accustomed to so claiming.

We have lost the limited germ-memory of our previous existence in cell life, excepting as it is recognized in our inherited tendencies of likes or dislikes because it is now useless. We may in the same manner lose unnecessary parts of this mortal memory by the timely development and spiritual birth of a metaphysical seat of memory.

There may be a state where memory is useless, when knowledge of so-called past and present stands out in plain sight, or is impressed upon everything as an undeveloped instrument has 
shown us the possibility of a magnetic impression of music upon a spool of wire.

Dr. Foote, an eminent physician of Omaha, after long and patient microscopic study, feels that he is able to tell much of the racial mentality from which a man has descended by a microscopic study of a section of the femer bone. I think he claims to be able to distinguish much other very remarkable data.

Without the microscope every one knows that creases across the fingernails indicate that a severe fever occurred at a time when these nails were at a period of formation just under tne skin, and we may estimate by the distance it had grown, about how recently this illness occurred.

We know that either extreme winter weather, or extreme heat of summer afford conditions to produce annual rings to form on horns of cattle. And we also know how the change of seasons record themselves in the rings of growth apparent in the trunk of a tree by the changed movements of sap. What would be the result of preserving a section of a modern redwood tree three or four thousands years old if a thousand microscopists worked over this field, comparing the differences of these cells of rings year by year, working backward with the known data of history where we have records of world famines, droughts, or floods, or records of unusual astronomical conditions. Does anyone doubt but that great knowledge could be extracted from the record of such a 
tree just as Dr. Foote is gaining knowledge from cell construction of a bone

We may not know why it is natural for just six beans to appear in a pod, but we do know that if there are less something was the matter with the rainfall, or season or perhaps a scar will tell us of the sting of an insect, or a bruise, to lessen the number. There is even some message in a bean.

If we hammer upon a board, little crystals of dust will form in answer to the number and force of the strokes. From such a knowledge, after thousands of years of ignorance, Edison invented the phonograph and made the world marvel. These dust crystals paved the way for a substance which records and preserves the human voice, and enables us to distribute music of the world's greatest masters into every humble home.

Is there a message in crystals that are formed in rocks or salts, or metals, or elsewhere as additional history of the world's great movements? Some things respond to the greater cosmic disturbances, and others respond to the most delicate of vibrations.

At some time in the future, snow crystals may be understood in an entirely different manner. Like the rule of the circle carrying evidence of relationship, or subserviency to the same law of nature, by worlds and millet seeds, by eggs of hens or alligators, so also may we hope to discover why the rule of three plays such a part in 
life, and is so evident in crystals. Three arms may be counted crossing every snow crystal ever found, or six hands may be seen as invariably as you find six beans in a healthy pod. Since we claim everything created may be traced back to mentality, why is not this rule of three or triangle, a modified circle and a product of that paternal intelligence inherent in every crystal as the backbone marks a relation of certain animals, distinguishing them from others. And if this be so, may not the uncountable millions of little lacey variations of these snow flakes record impressions from outward disturbances forming them? There is one thing specially notable, and that is these multitudenous modifications are in such extravagant numbers that we know mere physical agitation would not likely produce them. If physical, there would be more similarity and less variations, but, if mental agitation could effect this congealing substance, there would be no limit to modifications.

Now, I do not mean to say that men could sit down and read continued stories from crystals, or sand on the seashore, or leaves on the trees, which is perfect nonsense. But I do say that if we ever expect to hear from Mars, or other worlds, we may take a suggestion from these falling crystals of nature and prepare various crystalizing or congealing substances to study the effect of every kind of vibration upon such substances, seeking a key to a possible intelligence expressed therein. 
After passing this exaggerated speculation in the physical world, let us inquire what a fully developed mentality may discover. By a fully developed mentality, I mean one who is no longer restricted by physical limitations; one who has left his germ environment; lived through his foetal evolution; been born a man; and shed his body. The soul of man should understand all of these things and read them as unerringly as we follow the vibration of a needle, tracing the queer quivering lines of a phonograph record.

There must be a language and record of things for the hereafter, better developed than the language and record here. If there be a soul and a hereafter, there must be a language and a record. It is not improper for a man of religion to think of this. Such a language and record may be learned then, as every baby born in this world must within a few months commence to learn its language. An ear drum of the physical body is used only in this life. Therefore the next life may require a reeducation unless we are made to know, as Plato intimates, because of discarding physical hindrances to knowledge. Ordinary memory may be a physical function merely connected with the physical part of life. A physical record may be what we see, hear, taste, feel, or smell. Having so generally relied on these five physical senses, I think the faculty of memory has not risen much above the physical, because of our habits of so limiting the function. 
Upon the thought of this unconscious memory mentioned before this discussion let us inquire if a mother's love is a new creation, because she does not remember a previous ecstasy or is it the same thing over and over again? When a young heart meets an affinity is it a new and strange sensation, or is it a natural satisfying bliss, that it has yearned for and recognizes when it comes? Who cares for ancient memories when he recognizes that he possesses his developed new nature of today which has been ages in the building? Although we do not remember it, we have had a soul long before we were born, as truly as the limb of an elm was the nucleous of a cell that formed the bud for its sprouting birth. 


\section{REINCARNATION DOUBTED}

CHAPTER XIII.

A soul came from somewhere because it is here. It could not be developed without assembling from something and from somewhere. 1 can understand how it could develop in a manner similar to the known ways of nature, and how it could become so intense as to continue without physical obstruction, but I cannot undrestand how there could be such a violent jump as reincarnation, although I will not at this time dispute it. If reincarnation be possible, still I should not believe it desirable to a developed mentality and would not expect an actuality of evidence.

Nature would not waste this development by throwing it back into this long period of repetition or redevelopment. Viewing it from the point of nature-again viewing it from the point of our ego who would wish to consume such a long period of redevelopment to return for the pains of the flesh which, by the way, are mere mental knowledge of local physical disorders. Why should an immortal soul desire to retrace its steps and encumber itself with a mortal body?

We have not seen any evidence that a butterfly ever paused again and turned back to be a worm. Such degeneration (evolution working backward) is possible but I assume these intelli- 
gences do not desire it. Neither would a man's soul.

Should a soul desire to become human again, how could it be reincarnated without taking its place at the foot of the line, or going back to the beginning and building up from a single mental and material cell to the protoplasm and running the entire race of evolution as well as birth? It might by the same possibility, in the first instance, step into a mature human form, as take the short cut of stepping into a fertilized ovum. We do not appreciate the time it took to make us, we do not appreciate the value of our lives, if we claim we originated within a year of our birthday. We do not appreciate the fact that there may be mental laws of nature in the metaphysical universe. If there are, would they not be in harmony with material laws or at least possess such comity as not to violate each other? One of the laws and principles of the metaphysical universe may be that, regardless of the strength of the desire, mentality cannot be both an inedpendently developed soul and a mortal man, any more than a grindstone may be turned backward and forward at the same time. How can a soul again become a man without both evolving in the natural way and being born in the natural way? Anything less is not mortality. We know a man cannot go east and west at the same instant, or have the east and west pass him at the same time, because it is contrary to the laws of nature. It may be that the metaphysical universe is a place 
of anarchistic phantom pursuit and that unnatural things are possible. Considering the various deductions in these pages it seemed unnatural that we should receive short cut violent reincarnations, or material manifestations of souls.

I may be wrong in denying reincarnation because there are some persuading deductions from the knowledge of certain life movements. Protoplasm cells are nearly alike in all forms of life, whether vegetable or animal, and are found as invariably as the backbone is found a family feature in a certain class of animals. These cells of life are in the leaf of a tree and the brain and body of a man. Even these cells are a combination of smaller cells.

Now to illustrate this doubt, consider that as plants and animals decay nitrates are released that pass off without being further separated, and are absorbed by other plants to make the circuit again. So also with ammonia and other complex elements. It may be that some of these socalled elements, containing an unusual accompanying intelligence, though worked over to some extent, push out in the cell of a bud, or a seed, and slightly change the species. In the same way, at some low stage of life we may think, by a strained construction, a soul may adjust itself to push out for a second earth existence. If a soul should so desire and concentrate its intelligence to a degree so simple, as to make a start near enough to the beginning, we might expect the wonderfully rapid reexpansion of mind, like the electrically rapid 
changes, and development, of the ovum to and through the foetus.

If a soul should desire to make the humble circuit through the flesh it would be obliged to reduce and narrow its mentality as stated or do violence to the laws of mortal nature. It may in some instances come again into mortal co-operative existence with matter, like decaying matter resolves itself into nitrates, and again starts on a circle of vegetable life. We know that some low order of intelligence, no larger that an element of nitrate, which was once a part of a tree, or flower, may be absorbed in the cell of an oak and become predominant in the germ of an acorn and being a pattern cell may become, with its unified associates, the king of the forest. Likewise it may be within the range of possibilities, that some soul may push its way from some elementary starting point into the thoughts, and mental cells, of man and then separate with the first intelligence, bud, or sprout, to make this new natural circle of life, but my intelligence refutes the idea. If artificial life should ever be produced by preparing inorganic matter in such a way as to become vitalized it would not shake my faith in a Supreme Being, or in the immortality of man, but I would be more inclined to believe in reincarnation.

On the other hand, since I do not accept the philosophy of reincarnation, I would rather believe in the continuity of a mighty mind, always progressing, greater, and greater rather than in a fluctuating, or pulsating life, once mighty and 
then feeble, because of making these little circles of birth, death, and reincarnation over, and over, again. As surely as we came from some direction we are going in an opposite one; as surely as we came from some state of existence we are going to another and not to nothingness, neither are we marking time. It may be a matter of choice whether it shall be better or worse. We may be able to hold our strong corporate mentality together as a human soul and continue or we may allow our mentality to disintegrate in its movement.

If we are able to hold our mental existence together and go on, why should we, with a man's intelligence, desire to make a circle back through the flesh?

The three known steps of life which man has taken may be likened in plant life to pollen, then to seed and on to the entire plant. Again, like. wise, any inanimate substance reduced to its lowest mechanical division is a molecule. Its further reduction to the lowest chemical division is an atom. And recently we have named its further possible electrical reduction an electron. As we have mentioned the circle with mysterious relationship to all things, so have we speculated upon the trinity throughout all life or the double trinity as in six general points to every crystal. It has been stated that we do not know the reason for the circle or the triangle in their relation to life, but we grant there is a mighty cause. Let us con- 
sider the three known periods of man's physical life.

It is no more reasonable to expect the graduated soul in its magnified eternal sphere of life, progressing under new senses, to return and ningle with narrow-minded men, than it is probable a man should desire and accomplish a return to the habits and customs, and limited expression of the microscopic, wiggling, polly-wog brotherhood of spermatozoa, and struggle again with them, for their one chance in millions to take the human route, in their part of the universal desire to go somewhere. The step from the eternity span of life, back to the forescore and ten span, appears as far backward as the step from manhood back, to the age of a few hour's existence in the other span of life.

How could it be expected that spermatozoa life comprehends any of the magnificence of human life? If this pre-birth life knows nothing of the theatres, railroads, governments, sciences, art and war, how could human life do more than merely desire some grand incomprehensible glory of the future? If we may tell the progress and future path of a comet by its speed and the arc of its past movements, may not we, in the same way, speculate on the development and direction of our life, judging it, to some extent, by three steps of its past development?

One does not remember his existence, while evolving for birth, and yet intelligence has been active in every fibre and cell of this metamor- 
First Step-Spermatozoa Life.

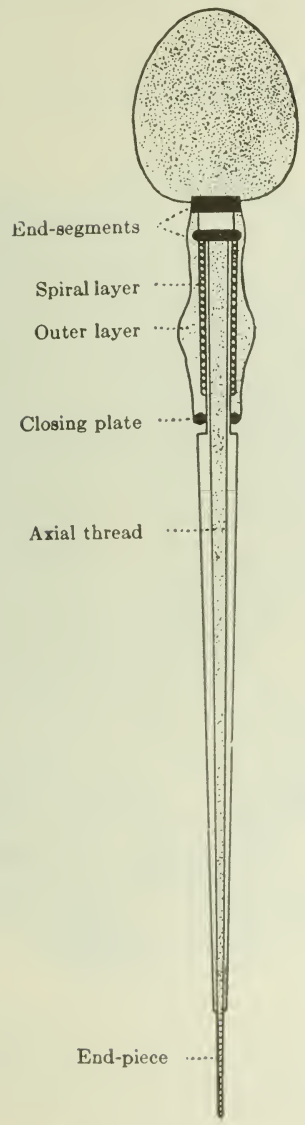

It is estimated that 227 million spermatozoa come into sperm existence about the same time. All of these are lost excepting in some rare instances only one of this multitude, of which over a million exist in the capacity of a single drop, developes into the foetal life. The above figure was drawn on a highly magnified scale. 'I'he natural body including tail would require 2500 to make an inch in length. The head is $1-15000$ of an inch wide and $1-40000$ of an inch thick. 


\section{Second Step-Foetal Life.}

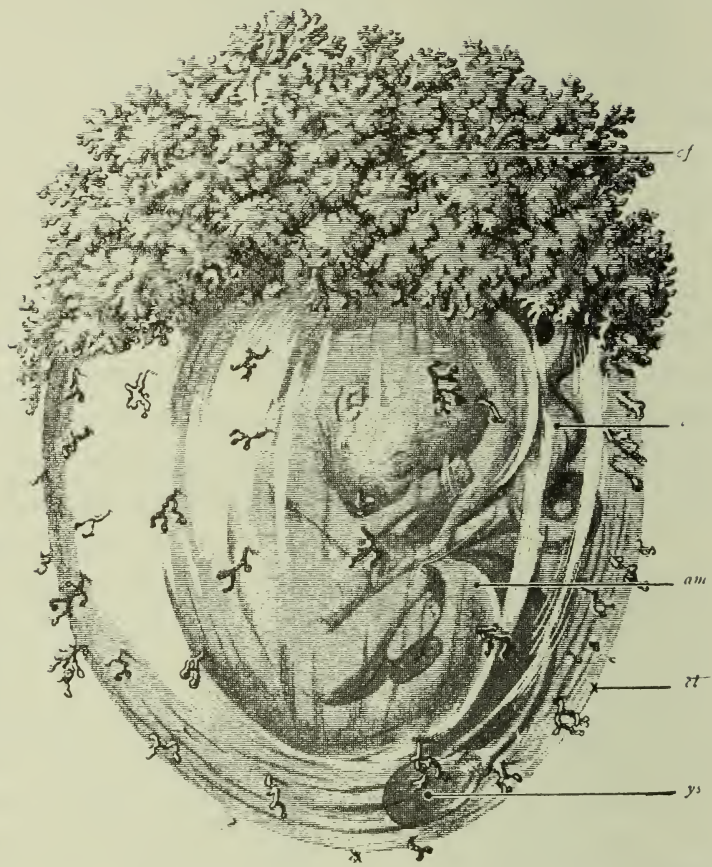

Human Foetal at the End of the Fourth Month.-From Kollman. am, ammion, $c$, unbilical cocd, $c f$, chorion frondosum. $c l$, ceorion laeve. $y s$, yolk-sack. 


\section{Third Step-Human Life}

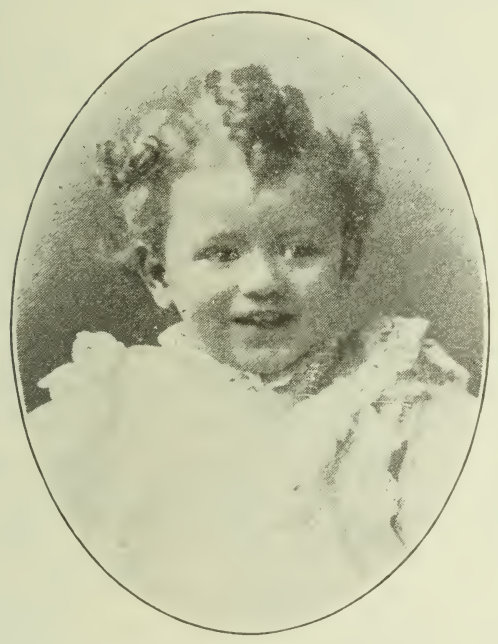

The subject of this book is on the next step. 
phosing body. Some continuity of memory even of ancestor-development for ages accompanies this marvelous change. When the work is done a babe is born, with a new seat of memory, specially designed for a life in this world. Any independent cell, from which this curious development sprung also had a mind. It may have had a memory, from second to second, as we now have from year to year. And back of this, outside of the universe of matter, was the potential progenitor of this particular germ of life, to which we are indebted for our being, that had a mind, or rather was nothing but a mind. Indeed, it was only a purpose or a principle.

Considering the ordinary memory of man, with the aid of this knowledge of his origin and we may make oureslves feel that we should remember some shade of things of the past. This may be stimulated by knowledge that we have for many steps backward, through our ancestral pathway, had a minature mind that did think sufficiently for our being then and which flickered sometimes bright and sometimes dim as it journeyed on to man. Therefore if man's mind was once a cell mind, why not expect another change to a greater mind than we ever had before: one that could clearly recall, without deduction, all of the many steps of the past, and a new related faculty that will pierce the future.

Considering the sperm life, we are able to distinguish a slight difference between the various species. But after a union with the ovum they 


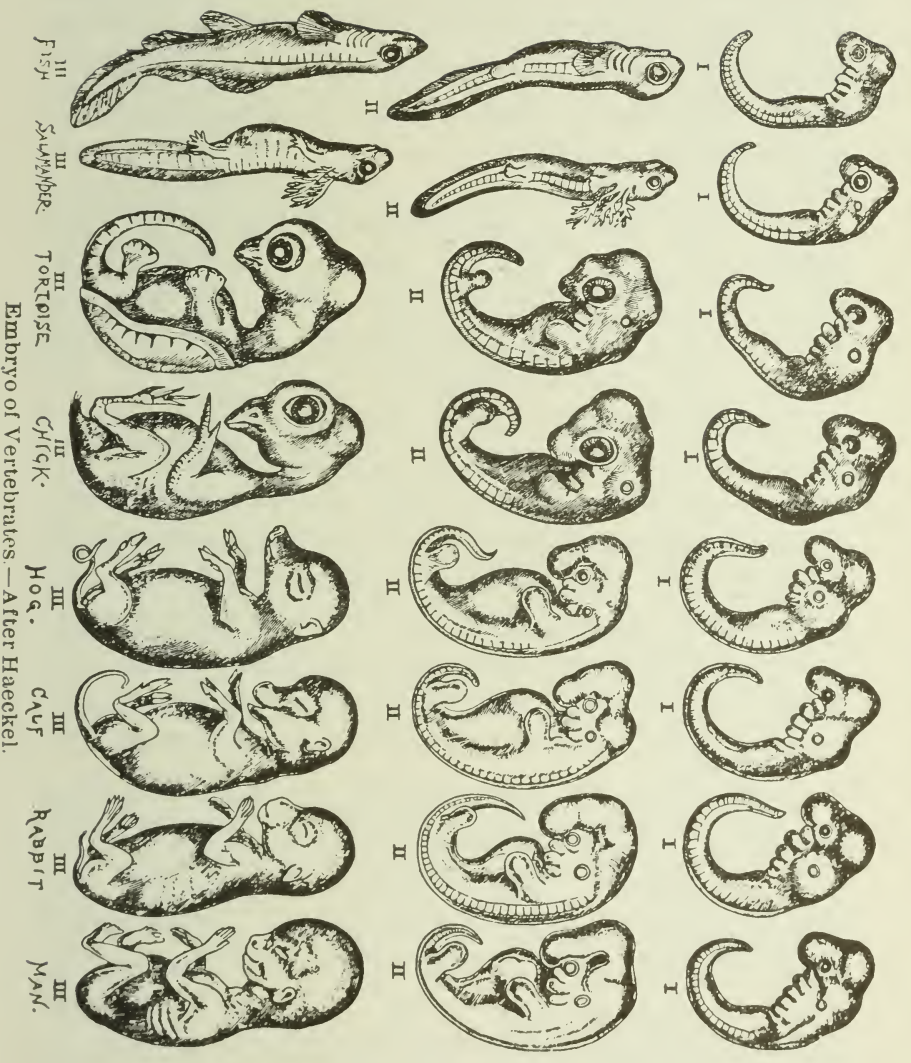


revert to a pulpy protoplasmic mass, as does the caterpillar, from which a particular submicroscopic cell of life begins to develop, so low in the scale of life, that all travel a path of development from which it is impossible to distinguish one species from another.

It is strongly urged that spermatazoa life is only a sort of vegetable life. If biological research should establish this claim beyond any question it would not preclude the theory of mind even in plant life as suggested in Chapter V. As the embryo of man shows the gills of a fish in its development it also shows the formation of the heart of cold-blooded animals before it changes to the higher formation. If we trace the bodily development back through these stages of hundreds of thousands of years of reflected ancestral development, why should it not be traced still further beyond all of this to the primitive plant formation?

This does not detract from the power of God. We have merely discovered something of God's plan of work. This process of evolution has been chosen, or rather promulgated, by the Great First Cause. If God created the Universe, we know enough already to say that, in its immensity of development, He did not make it from nothing. He never made anything that we have ever seen from nothing. Everything is made from something else. One cell is used to make two. One body is divided and becomes two. One sense is traced back to a development from another. 
No miracle has ever been claimed to have been performed without the use of one thing to create another. Every effect has a cause and was once within and a part of the cause. If everything we know that God has done has been done through something else; if every body is sent by God through another body, is it not in accordance with God's law that a soul should be made by development from another soul, a spark from the divine spark, in its course from God rather than to expect that God makes a soul from nothing?

If a man's life and soul came immediately from the life and soul of his parents, it is but another example of God's manner of work in making everything through the changing of something else. Because of this we should not deny the existence, or power of God. We should not look to a moner life as our god, our source of origin, because we are inclined to concede the evolution of a soul, as well as the evolution of a body, and because we are obliged to concede we have evolved from this direction, where the protoplasm and cell are near the limit of any direct sense knowledge. We should think beyond this and into a metaphysical universe that existed before there was anything physical.

Every child born has within the few months before its birth, in obedience to God's law, been compelled to repeat all of the processes its com. bined ancestors accomplished. The origin of each must needs reach back beyond the moner and protoplasm and beyond all things material into a 
state of pure metaphysical existence and travel directly this long road from the Great First Cause, or from God, to the new born babe.

For these reasons, if everything God produces has come from something and never from nothing, why is not God creating human souls under a force and plan similar to the one we have discovered whereby He is creating bodies? When it is all said I don't suppose it makes a bit of difference to many people how He did it. But it is some satisfaction to use the brains God gave us to think about these things.

Using our brain power to project ourselves back through the long slimy path of the past we clearly see much more than the history of man's physical development as re-lived and traced through the development of the human embryo. Take all this as a mere starting point and journey for aeons back of this. It has been demonstrated with reasonable clearness that a life must be started from a primitive cell and do all for itself that all of its ancestors combined have done, before being born as a man. Now, this fact of devolving and evolving in every form of life as well as in man, proves that short cuts are not permitted by nature. It is really a mistake to assume that a so-called new human life begins with the union of the ovum and spermatazoon and that these are the primitive cells that go through this process of evolution. Biology shows us that the spermatazoon, with the contents of the ovum, absolutely dissolves and disorganizes or reverts, and after a 
short season there faintly appears a fine threadlike germ from out of the "distance." It was once far beyond the vision of the most powerful microscope. It approaches like an expected comet which in time is barely discernable through the telescope. From where did this new visitor come? We may only surmise that reproduction required this reversion. Upon a close scrutiny these cells must still further disorganize and go back reverting or traveling within a few days these millions of aeons of the past, back and even out of the physical universe into a state of existence absolutely devoid of matter, and then reappear through this invisible aperture in the physical world as described by a fine, short, mere microscopic line. The end of this line turns or bends over in the same direction and in a few months this long, long road of the rest of ancestral evolution is traveled and the man appears.

The story of foetal life-development, being a history and proof of evolution to some, as they have so clearly stated, indicates to me the same thing, and it also indicates that life is older and superior to all matter. As they point out the gills and other marks in the foetus to indicate that man evolved from lower animal-like forms, and that every child born has to relive all that all its ancestors have lived, I use the same process of reasoning to carry one back of them, beyond the cell of matter, to pure metaphysical existence.

This whole story which traces life back so far as to leave every dimension of matter (there 
is no matter without dimension) tells me it relived, or dissolved back to a time when there was no matter, and then rapidly returned the whole journey and not merely the comparatively late path that Haeckel has pointed out, from the protoplasm to man. It reverted, and kept on reverting, to a state of existence before this young world was formed-aye, before any material worlds were formed. This is no more remarkable than what we see every day in foetal development from protoplasm to man. We are obliged to extend the process, because we cannot by any physical means see any point in the physical world where the return from reversion takes place and starts again in the process of evolutionary rebuilding.

We may plainly understand that every man must have been a baby, but fail to think the same rule would require every soul not merely to be born as a baby but to have entered the physical state in the same manner that the foetal cell of physical matter became physical matter from a metaphysical state. As the physical materialist insists every step of man's evolution is recorded in his foetal development, we may as easily reason that his progress, through this earlier period mentioned, records even the history of the chaos from which the world, of which he is a part, was formed.

What the metaphysical universe is, we have not senses to conceive, but there certainly is such an existence, ruled by order and system. These 
physical things could not transpire, linking, as they do, in every birth the physical and metaphysical in this phenomenal manner, without most strongly indicating that the metaphysical universe is far more grand than our magnificent physical universe.

Contemplating the metaphysical universe, as distinguished from the physical universe, it seems there may be at least two sides, something like the inside and the outside of everything. As to the physical universe, this tiny world of ours, with six known continents, and the greater unknown Ant-Arctic continent, and its mighty oceans, is twenty-five thousand miles in circumference. There are seven other worlds that have a seeming connection with our sun. Jupiter is fourteen hundred times larger than this earth, and the sun is larger than all of its eight planets. The distance between them is most appreciated by an estimate of the time that is required for light to travel from point to point and by making comparisons. Light is said to travel 176,000 miles per second. It requires only nine minutes to trave. from the sun to the earth, a distance of ninety-sir million miles. Now, around us in space, it is calculated that over two billion suns and worlds are shining within the knowledge of man. Some of these suns are thousands of times larger than our sun, and are so far away that it requires thousands of years for their light to reach us. Believing that all physical matter was created from metaphysical forces, and that matter did not al- 
ways exist, because there is no thing, of any material, that is an element, always existing, it seems there must needs be a limit, and boundary, out beyond the farthest confines of this unmeasured universe. We are obliged to conclude, that beyond this outside limit, there is a purely metaphysical space, or a peculiar space of metaphysical forces.

In the other direction, opposite to magnitude, your attention has been called to the minuteness of things dwindling down, and down, until we pass the other boundary of matter, and pass completely out of the physical universe.

The metaphysical universe is, beyond these two extremes, which are also connected, because the metaphysical includes the physical. The metaphysical is both there and here. Wherever life becomes seperated from, or driven out of the physical it is obliged to exist in the metaphysical.

A birth requires an exit of materials dwindling to the metaphysical, and then a reentry of the metaphysical through a similar miniature aperture to the one of departure; and a death is an exit through another boundary. A death is not necessarily the leaving of the location of physical matter, and the passing beyond the pale, even, of the farthest stars, but it is the ceasing to be within the state of materiality, and the act and result of having passed out of matter, or, in other words, the passing of the boundary between the physical and the metaphysical. The soul is therefore invisible, inaudible, and unattached to matter. 
All of these things appear to be contrary to reincarnation, which theory is too small for the grander theory of eternal progress.

Reincarnation involves the thought of the possibility of souls within animals. Whether, or not, they have, I do not care to argue. Surely they go through the same processes, as does man, in the wonderful start and development of all forms of nature. God must have created them, and has the power to care for them. But one is disinclined to believe there is continuity of life in animals, because in the whole animal kingdom, of all ages, not one single animal, or bird, has ever been discovered that revealed any sign of worship, or preparation for life after death. These billions of billions of creatures are, without exception, atheistic in every thought, because thoughts are bound to be indexed by some form of action, or non-action. Therefore, we assume animals have never had that very essential hope, and faith, to qualify and save themselves. It is a dismal thought, that man should ever be returned to this earth as an animal, and it is an abysmal fall for one, even in thought, to enter the animal class, to satisfy mere bodily passions and live a life as blank, and as atheistic, as these poor dumb creatures, that live merely for the sake of their bodies.

If man feels, and is assured of a future life by faith alone, what hope is there for either animal, or man, not having faith? What ultimate good is there, in the eternal plan of nature for any hopeless material? 
Having considered the origin of both body and soul let us again in contrast consider the future through the eyes of Plato in the language of Schopenhauer although he criticises Plato upon the authority of Kant:

"That which knows in us an immaterial substance, fundimentally distinct from the body called soul; the body being a hindrance to knowledge. Hence all knowledge through the senses is deceptive, the only true, accurate and certain knowledge being that which is free and removed from all sensibility (i e, from all perception,) in other words, pure thought, or that which functions exclusively by means of abstract conceptions. For this instructs the soul entirely by its own methods, and consequently will work best after it is separated from the body, that is, after we are dead."

Man's soul came from the Infinite-from God - completing its cycle it returns to its sourcethat is, to a pure metaphysical existence. The mind next inquires where God comes from? But the limitations of mortal man precludes understanding the answer even though one had been given. In the life to come we may be permitted to understand. But in this life science agrees with the Bible that we may go no further in such an inquiry. The Bible relates that God has said: "I am that I am."

If we have a soul, as we believe, we are not all equal hereafter any more than we are all equal here. There must be souls of greater age and wisdom. It is impossible to conceive that there is not a Supreme Soul-a God.

An inquiry is made as to whether there are three great divisions of man. Have we distinctly 
a body, a soul and a mind? We know there is a body and believe there is a soul. Such being the case, the mind would be the connecting link. If such is the case the mind would have a soul element, or attribute, and also possess some relationship to the material. It would naturally follow that a weakening of the body would exhibit itself in the material expression of the mind. In this respect concerning the relationship of the soul and the body we should reverse the usual saying that "man (a body) has a soul" and say "man is a soul and has a body," which is in effect, the way Epictetus spoke centuries ago. This suggests that the body may be like the heavy leaden shoes of the diver. As shoes hold the diver down, in his submarine work, so the body holds the soul in its sub-spiritual place upon this earth.

This old idea of the body being cast aside, as a mere shell for this period of life development, follows the precedent of the shedding of the placenta immediately before birth. Even this followed a prior shedding of the serolemma, and that followed a prior shedding of the allontais and before this there was the shedding of the amnion. Therefore, when this body becomes useless there must be something left, when it is shed. Each successive envelope, as discarded, reveals an increasing cause for wonder. Is the babe the climax of what represents millions of years of evolution from a germ cell? Or is there not another, more enduring life to come and is not the loss of this body but the shedding of another shell? 


\section{HEAVEN AND HELL}

CHAPTER XIV.

Is there no heaven in this vast and limitless star studded universe? Shall we decide there is no heaven merely because no such place has been seen by astronomers? Although gazing out upon that boundless globe of space delimited by man's inability to see the infinity beyond the furthest visible stars, shall the existence of a heaven be denied because we find no physical substance suitable for a mere mental home? The circumference of this sphere of vision, whose diameter is calculated by billions of billions of miles, is a mere speck of the universe, that may require the fourth dimension to measure, and what we see, or hear, therein is entirely different from what insects see and hear, or what a metaphysical being could see, hear, or experience. An astronomer of reputation once said he had searched this radius his whole life with the most powerful telescopes and never found the least sign of heaven. Oh! what conceit, and ignorance, to justify his claim against immortality. Many persist in saying there is no place for life after death. I grant that heaven is not visible to the human eye. Because we may not be permitted to see such a place is not proof of its non-existence.

Take a glance into the immensity of this space, with Prof. Garrett P. Serviss, who has measured a mere starting point: 
"The stars marking the upper line of the celestial dipper are ten degrees apart, and since their distance from us is $950,000,000,000,000$ miles, it follows that the real distance between them is $95,000,000,000,000$ divided by 5.73. This gives, for the length of the upper edge of the dipper 16,580,000,000,000 miles very nearly.

The lower edge, or bottom line, of the dipper is eight-tenths of this or 13,264,000,000,000 miles. The height is one-half of the upper line, or 8,290,$000,000,000$ miles. Adding together the upper and lower lines, and multiplying their sum by half the height, or $4,145,000,000,000$, we get for the area of the entire trapezoid whose corners are marked by the four stars, 123,701,000,000,000,000,000,000,000 square miles, throwing away the least significant figures.

If they construct celestial dippers on the plan of a terrestrial scoop, we may assume the width to be about two-thirds the length, or say 11,000,$000,000,000$ miles. We then multiply the area of the side by the width of the bottom, and obtain for a final result the stupendous amount of one duodecillion,three hundred and sixty undecillions of cubic miles

Perhaps you would like to see that in figures, so here it is: $1,360,000,000,000,000,000$,$000,000,000,000,000,000,000$. I have cast aside as of no consequence more than seven hundred decillions.

Now that we have got the capacity of the Great Bear's mighty dipper, let us compare it with 
some more comprehensible things. This earth of ours contains about $268,000,000,000$ cubic miles. So it would take about five octillions of earths, packed and crushed into a mass, to fill that supercapacious dipper.

The volume of the sun is about $348,000,000$,$000,000,000$ cubic miles. Then nearly four sextillions of suns, smashed like strawberries in a grocer's basket, would be required to brim the dipper with solar nectar!

But let not the Great Bear boast too recklessly of his big dipper. Huge as it is, after all, it fills but a speck of space in the universe. It is near enough to us to make a great showing in the sky, and paralyze our minds with amazement when we apply our petty measurements to it, but it could dip but a spoonful from the Milky Way; it would be lost in the gorgeous blazonry of the Great Magellanic Cloud, and would drop, like a tin cup down a well, through the tremendous opening of the awful Coal Sack that yawns beside the constellation of the Southern Cross, and seems to have no bottom in the rayless blackness of the infinity beyond!"

In following this we have comprehended merely space. This space is not necessarily void.

A glass may be filled with light, then without dispelling the light, be filled with water, and a third time filled with an electric force without dispelling or diminishing the other two elements, and yet by releasing a coin above the thrice filled glass you will observe the force of 
gravitation there just as it would be, were the glass not beneath the falling coin and demonstrating that the space occupied by the glass is filled with another; possibly many other forces.

By the duplex system of telegraphy four different messages may be sent in two directions over one wire at the same time. Four telephone messages may be added, which also establishes that where some forces are so vastly different in nature, one is no hindrance whatever to the other, even in the same space.

By the X-ray it has been demonstrated that where space is filled with matter such substance does not prevent its penetrating glance. As the rays of the sun penetrate the solid window pane, so may our mortal gaze search on beyond a home at hand. As some of these material forces penetrate some substances, so may a spiritual force penetrate all material substances.

If a man's consciousness of himself is a soul and spiritual force, its home must necessarily be spiritual and its existence would not arrest the mortal gaze through the telescope any more than the telescope, man's body or man's world would interfere with a spiritual force.

The law of gravitation, as yet so little understood, which so greatly affects matter may have no more influence upon a human soul than it does upon thoughts and even mountains and oceans may not be considered any impediment to the force known as intelligence. A beautiful dream consummating all of the pleasures of the 
mind with none of its sorrows, and lasting forever, may locate a heaven in illimitable space, not to be disturbed by the rending of the body nor the rolling of planets.

When we consider how materialists reasoned everything down to an atom which they erroneously called dead matter and from which they reasoned all forms of life were constructed; when we consider how they had knowingly accounted for concentrating these atoms into worlds and suns, continually attracting each other and enlarging until their logic prophesied a time when all will become a frozen sphere of dead matter, we think of how the families and friends of such atheists were made to prematurely shiver. But the atomic theory has been exploded and the dead matter Alpha is upset. There was a beginning to the atom. It was constructed from something else, close to the line between material and immaterial and we find, consequently, that this alleged basic matter did not always exist. Then if all the universe of matter, in constellations and suns and worlds, and the different substances thereof, are combinations of atoms-which atoms were created-they had a beginning, and the universe of matter had a beginning.

In the continuous discovery of ultra sense forces there is reason to suppose the existence of another greater non-material universe from which the limited material universe was developd. Outside, or inside, beyond and above, or rather distinct from and more powerful, there must needs 
be a First Cause creating with purpose and design and a plan before there was a planet.

That the material universe had a beginning we may reason not alone from the construction of an atom, but from the greater bodies of the universe which we know. This earth is said to gain in meteors and settling particles about ten million tons per year, or a little less than one sixhundred-thousandth of its weight in a hundred million years. Reasoning backward without allowing for the diminishing power of attraction with its diminishing weight, and without considering any loss, and its birth was considerably over six hundred trillion years ago. (Even the crust of the earth is now claimed to have been the abode of living organisms for some five hundred billion years). If we obtain the ratio of increased power of attraction with the increase of size, we may use this knowledge to estimate the annual increase of the bulk of the sun or any star for a period of years; and by reasoning backward with proper diminution, we may estimate its planetary age. We may even make a rational guess on the age of what we know of the physical universe. Now if this is a universe of dead matter and life is a mere byproduct and these bodies have been gradually increasing, men could estimate in years. and write with figures, the time when the largest globe in the universe was smaller than the last discharge of a roman candle.

If the material universe always existed, the largest stars we have located and measured are too 
small for the theory. Again if the material universe is Infinite and there is no limit to material bodies, chained together by attraction, and floating in the greater metaphysical sea of the nonmaterial universe, it has been pointed out that the ever increasing star light would be immensely greater. All of the most potential arguments of materialists, and their dead matter theories, are being ground to powder and blown into Oblivion by volumes of scientific discoveries.

As far as the worlds of the physical universe -all of them-are concerned, they are being born, and they die and disintegrate as effectually as the bodies they support. They cannot grow too large without causing internal combustion and gradual radiation, as from a retort, because of the pressure of their own external weight upon the internal parts, unless discharged prematurely by collision. If there be a beginning and an ending of each and every one of our stars and of the earth, there was a beginning and will be an ending of them all, there was a beginning and will be an ending of the whole physical universe in spite of our claims of the eternity of matter. Just as water may be unlocked and turned to steam and then transformed, or further expanded to hydrogen, something else may send it whence it originally came.

When our sun throws off its energy, do we realize what an insignificant part is arrested by this earth and where the rest is destined? When we consider the size of the sun and the force of 
explosives, the conduct of bodies expelled by explosives and the effect upon the body from which exploded, we are obliged to hesitate about accepting the theory of any force upon the suns of the universe expelling light the millions of billions of miles as claimed. It is easier to believe that when something unlocks the energy there is a drawing force-a magnetic pull-back to the greater nonmaterial universe, instead of the repelling influence of a luminary. The earth intercepts and converts a part of this energy and the organisms it carries with it and the stars claim their portion, even the ether of interstellar space may claim a share, but, if this material universe came from a non-material universe, why is its destiny not the state from which it was drawn? In all the fields of unsensed forces, from which the material has come, there is an abundance of metaphysical area for the location of an unlimited heaven-a metaphysical universe-which may be a place without dimension. Length, breadth and thickness may be mere physical terms which have no significance in a metaphysical universe where other relations exist for spiritual comparisons.

Space, such as we know, may be entirely eliminated, if there be a metaphysical existence, because space is related to time in the requirement of time to move from point to point in the physical universe. In fact, space is one of the attributes of the material-it is a part of the physical universe. So also is time closely related to the material and to space. Indeed both time and space are wholly material. 
In respect to time, we have all noticed how a child of two or three years has remembered a summer day as lasting as long as we in later years look upon a generation. In infancy a day is an unbounded period of time. In childhood it is a terrible punishment to be compelled to stay in for an hour. When the child becomes an old person, oh, how fast time flies. This is reasonable to expect, when we know how many ages have been repeated and pressed into its foetal development. The first forty-eight hours following its conception, perhaps, meant the repeating of millions of millions of years. In the succeeding months every day meant thousands of years. As the man matures, time becomes of less importance. It flies. An eternity becomes a minute. It seems to leave the man with a great memory of the past and a knowledge of the future. The past and the future have seemed to steadily draw to a point. The two extremes of time, the past and the future, narrow down closer and closer, until it is not far to project a state when both the past and the future become the present, or one great Eternal Now.

If we may approach a state where by mere desire we may know whatever has happened and whatever will happen and instantly avoid, or take part in whatever we wish, as one may examine any department of a great exposition where everything in the world is grouped, this would give us some notion of Eternity.

Future power to comprehend all time eliminates future and past, which are the only periods 
we know in this life. If everything becomes the present it is a state no mortal has ever enjoyed, because in this world the very instant a thing ceases to be in the future it becomes a thing in the past. But, if one may comprehend all past and all future everything becomes in the present and there is no future. If there be no limitations of distance there can be no space. This subject is not exhausted, but barely touched upon to set the mind in motion upon the claims of a time coming when there will be no time and no space; when everything will be now and here; when we become a part of Eternity.

These illustrations show in a faint way, that although the scientists of yesterday have pointed their powerful telescopes in every direction looking for some physical spot suitable for man's metaphysical existence, and failed to find it, such failure is no proof that there is not a metaphysical universe. All the known things which we have considered cannot be true without the existence of a metaphysical universe-a mental, or spiritual, home to which we are destined.

If there be a heaven it follows that there must needs be the antithesis of such a place. If you discover one end of a stick or a wire you know that there is somewhere another end. If there is a place of happiness worthy the name of heaven, we know there is a place of unhappiness. Why not call it Hell?

As there has been no exact soul equality here, there can be none hereafter. We can not all be 
upon a dead level in thought, in sphere of action, or in any state of existence. Some are now, and will ever be, capable of doing and feeling more than others. There is bound to be a highest, with possibilities of achieving even more, and a lowest, with dangers of still lower depths. Can any other name be found to describe this lower place, better than Hell? Any attempt to describe, picture or localize the place would be a dismal failure, even though the immortal Dante were eclipsed a thousand times. Hell exists, but the conditions are to be discovered, and experienced by man when he reaches another state of perception, unless as previously stated, disintegration of a soul takes place which would be in fact but another kind of hell. Fire is the clearest possible illustration of disintegration. It releases, separates and scatters. Thus fire and hell may be synonymous.

If the human race and all life among man's associates had never developed the sense of smell what would we know about odors? If some philosopher of such a world had tried to demonstrate and theorize that there must be distinctly marked radiations of everything existing which some fifth sense could distinguish, try and imagine how he would have proceeded and how he would nave been criticised and ridiculed.

He would probably have argued, that small microscopic particles being given off from certain flowers, which possess great beauty, some intelligence, and no harmful qualities, which flowers naturally discharge these globule atoms on account 
of some intelligence, purpose, energy, or push, and should carry some distinctive impression, or attribute, of what they came from, so that a person could tell, without seeing that he was in the neighborhood of a rose garden or a den of rattlesnakes. He would have claimed that, as the phonograph needle impresses in the wax the distinctive combinations of vibrations of some quality of sound to reproduce the human voice, so does all life impress, with a delicateness far below the microscopic conception, each particle given off by radial birth and sent as a messenger bearing some picture sounds or unknown sign, if not long messages. (Everything vibrates he could claim.) If this philosopher in such a world, otherwise like ours, had written this way and had insisted that a fifth sense would be developed to distinguish the presence of many things by these little astral-like particles he would have been the butt of much high class ridicule. Society would have been even more severe on him if he further said, man may only faintly distinguish these odors, but dogs and such animals will develop this sense with more acuteness while some of the insects would interpret these messages so faithfully that they would not require sight.

He would also argue that nothing exists which does not impress something else. He would point to the spectrum analysis of the light of any star, and show that even these electric particles come to us so impressed of their origin that we may know the material of which any star is made 
without ever having touched a grain of its substance.

In the same way that he would have been obliged to struggle, guessing some truth and some fiction because of the absence of the sense of smell, it is even more difficult for us, with only five material senses, to understand and describe any conception of the greater metaphysical universe where entirely new, or much more highly developed and divided senses are probably necessary.

However, we know that if a blind cell of matter, with but the primitive sense of touch, evolved, and divided; to include taste, and in time developed an eye, the hearing, and the sense of smell, (each opening worlds of knowledge) the spiritual cells of intellect, as distinguished from material cells of matter, would not be idle, but in their evolution of a soul, of which the body of man is an image, would give us the rudimentary metaphysical eyes and metaphysical means of obtaining knowledge in the future life, as eyes are slowly developed in the womb, not to see with while in the womb, but to be used after birth. (In a similar manner, a soul is probably developed in the body, not for mortal use, but for the later metaphysical life.)

Why should we marvel at the quotation of Paul that "Eye hath not seen, nor ear heard, neither have entered into the heart of man, the things which God hath prepared?" Return to this quotation after considering the vibrations from 
which we determine light and sound, reaching way on beyond and above human sight and hearing, and as far in the other direction below the lowest waves we may recognize. We can not even imagine the new colors that await us in a spiritual life, or the pictures from new combinations of colors there to be seen. No human ears have ever heard these new sounds that will open new fields of music. Are there not other vibrations existing to effect new spiritual senses that may awake in the future, as the perfect but previously unused eyes of the new born babe blink at "strange" lights the first hour of its birth?

The five senses of the body are all related; four having evolved from the sense of touch. Any new senses the body develops must come or be developed from some of these. In the same way, rew soul senses may be expected from this soul life that develops with the body.

This is why St. Paul did most truly say: "Howbeit we speak wisdom among them that are perfect; yet not the wisdom of this world, nor of the princes of this world, that come to naught. But we speak the wisdom of God in a mystery, even the hidden wisdom, which God ordained before the world."

May we not evolve a new soul sense? We are justified in using any work of nature for illustration because it is clearly established that all development of life came from something else. If everything must develop from something else, this points of necessity to a constantly narrowing 
common origin. Because all life must have come from a common origin, we pause for an inquiry as to insect sense evolution. An author tells of an interesting experiment of Prof Bruner of the Nebraska University:

"He had built a stone house with walls sixteen inches thick. It had no windows and with but one door, which was air-tight. He had put a breeding cage of ants inside the house. He would go inside and study their habits. He noticed that other ants would collect on the outside of the wall and try to find a way in. He found that the ants were always as near as they could get. He placed the cage of ants close to one wall of the house. After a time he went outside and found the ants had collected on the wall nearest the cage on the inside. He changed the cage from side to side and found that the outside ants would follow the cage and collect on the wall just opposite, thus getting within sixteen inches of the cage. He repeated this experiment so often as to eliminate the possibility of co-incident."

Professor Bruner seemed to think they were possessed of an X-Ray sight and Prof. Olston thought it was telepathy. I believe they were both wrong, because of the following experiment I had with an ant recently: One Sunday afternoon I noticed a large ant crawling down the couch on which I was sitting, where it had evidently entered from the north window, the screen of which was not tightly fitted at the bottom. I tossed it back with an envelope and it immediately returned like Bruce's spider. I snapped it back, as many as ten times, and each time it instantly retraced its same course which was very slightly e:ast of south. In nearly every instance it would 
light, headed in the direction it seemed determined upon. In a few instances it would drop, headed nor'th, and instantly whirl, without hesitation, or wavering, and pursue this determined direction. I then removed it some distance to a large dining tabie and repeated the same experiments, four or five times, with the same results. I next placed a large paper in front of it and upon its reaching near the center I would slowly and rapidly twist the paper around, anchored with a pin as its axis, trying to confuse the ant upon direction. It would keep itself headed in this south-easterly direction, no matter which way I turned the paper. By moving the paper around in a circle, at the same speed the ant was walking, I kept it making a circle on the paper because of its ability to maintain its course regardless of my interference and attempt to confuse and lose it. I then turned the paper perpendicular and the ant would sometimes go up and sometimes down, evidently seeking a path for its desired direction. I then removed it respectively into two other rooms of the house some distance apart to test its knowledge of distance, independent of any possible landmark, trail, or scent. The general course of its travel was the same. I next took it to the front yard, placing it in the sun on a cement walk, and with a greatly increased speed it seemed to run in the same course just a little east of south and as it left the walk and crawled through the grass I stuck little twigs in its path every two or three feet, following it one hundred feet. I then took it up 
in a box and citing back found its course would be considered as unvarying. I then took it over 150 feet west of the point where I started it outside and releasing it again in the grass I followed in the same way, marking its course as before with little twigs. It traveled about the same distance when a dinner call caused me to look up to explain my engagement. The result of this home politeness was that I lost my insect friend ard could follow it no further. However, from the an rle of these two courses marked with little twig's 1 estimated that its objective point was about 600 feet off a little east of south. From this observatim I drew a few conclusions that may be of interest to others. The ant is said to be both blind and desif. If such is the case they are deprived of two senses which man possess. If these little creatures are unable to hear, or see, we five sensed creatures woinld assume it would use the senses of smell, taste or touch to find its way. But with all the moving to strange places and the distracting experiment detailed above there is no necessity to assume that this ant used any of the senses that man uses in determining and keeping a direction for an apparently fixed mental desire. It seems clear that this power was inherent with the insect, as it knew and could not be deceived in its determination and knowledge of where it was going. After this observation of an ant I am inclined to accept the view that homing pigeons, migrating birds, dogs, cats, horses and oxen are more or less endowed with a sense of divining 
some things which man does not possess. I do not agree with knowing materialists, who have argued that animals depend upon memory, or land marks, $\mathrm{i}_{\mathrm{ii}}$ their many marvelous trips. It is certain they have such power although not so strong as is evidenced by the ant. I regret that my duties would not afford a further experiment this season to gather some of the ant's natural enemies to place in its path and observe whether or not this strong mental determination could be interrupted by such an influence, also watch their traveling away from the home to see if there would be any interruption of action at the instant some assistant destroys its home by fire or water or other calamity.

Regardless of what the future may develop we know, from the vast amount that has been written about the ant, they contain storehouses of information for the future. The little we know along this line is enough to indicate there is a sense developed in these insects that man does not possess. If they have it, as seems probable, this sense was evolved from something else. If insects have evolved this sense, man's soul, when conceded to exist, is capable of a much greater and a never ending evolution.

I do not fear that any person can prove that a man's soul would not have a spiritual form which could be recognized by some better developed sight of other souls; would not have a sight of its own and not only all the senses of man but even divided and sub-divided into more; that it would not feed and nourish itself on knowledge 
instead of matter, because then divorced from matter; that it could not pass among and enjoy all of the original beautiful ideas of eternity, that may have been borrowed for imperfect copies in matter by architects, artists, orators and musicians and which may be arranged in artistic order through the metaphysical universe, so that there will be no limit to new and changing things which all nature craves.

If no man can disprove a future state, and the things, infinitely hoped for, can even be thought of as mere illustrations, by any member of struggling mortality, and every material thing can be traced to the very door-step of mind, what puny man can destroy such a mental place, or mental progress, by denying that there is a heaven for those who desire it furnished to the limit of the highest ideal of mental conception and a hell as gruesome as it may, by mental conception, be made.

On the same eternal principle that matter in motion will continue at the same speed forever unless its speed and course are changed by the properties of other matter in affinity, what can be said of this challenge? If it cannot be disproved when everything may be resolved back to pure mentality it may be necessary to concede that when freed from matter, any mental realization is a reality.

Motion is eternal. It may be divided and diverted from the general current but will return. It cannot be annihilated. If an obstruction is met 
with when occupying one body it will instantly transfer itself to another body and continue as illustrated by the movement of the last one of a row of billiard balls when the first ball is struck by another. It has often been postulated that energy and life are closely related when traced toward their origin. There is no question, that intelligent life is more highly organized and spiritualized than ordinary energy. Now, if it be conceded, as it is, that plain energy or force can not be destroyed, but only changed or diverted by crossing or opposing it with another energy, what has the physical materialist to say in defense of his theory, of death destroying intelligence? If you can not annihilate or absolutely stop plain ordinary force, what becomes of the extraordinary spiritualized self conscious, self satisfied, immortality-desiring energy of man's life? If the energy that moves a billiard ball, leaps to another, and then goes on in mystery, when the last ball stops, what of the energy that moves a human body, when that body makes its final stop? This illustration is not presented to show the movement or migration of souls exactly as energy in billiard balls is transmitted, but only to show by this experiment that the materialist can not maintain his position, that spiritualized or incorporated intelligence-energy, if such he may claim it to be, ceases to exist, or ceases to be a soul, with the destruction of the body. If there be eternity of plain ordinary motion, or energy, there may be expected an eternity of spiritual energy, or mental 
consciousness-the human soul. In other words an intelligence, absorbed in its own physical perfection and physical satisfaction, never recognizes the soul, or life of another, unless manifested in a similar physical body. But that does not justify the assertion that it does not exist.

It is now conceded by the world that the energy coming from the sun called light, is not light until it penetrates the resistance of the atmosphere. Beyond the earth's atmosphere, space is as dark to us as the deepest sealed cavern of this earth. The energy is there or passing through, but it is not light which the physically intoxicated life of this earth could see, until it reaches our state of existence. Some idea of this may be formed from permitting a shaft of sunlight to penetrate a perfectly dark room. The rays that might pass through the room, and be trapped out by a light-muffled aperture, into another room, could not be noticed excepting for the atmosphere, heightened by the particles of dust, that twinkle like the stars of the universe, defining the diameter and circumference of this shaft of light producing energy. There must be physical contact before the physically dominated mentality can recognize it. It must be translated or transposed by the touch of our nature, like a foreign language must be translated before we know it. Light must be earthized or naturalized here, before earth beings sense the force. Life must be earthized or encompass some material form, or it will not be recognized by earth beings. Life with equal, if 
not more, mystery than light, came from somewhere and will go elsewhere. Light may illuminate or heat a body it meets, and life may animate, and fill with ideas and notions the material of its body. Whether life goes in disintegrated swarms, or organized and individualized, may rest with our own determination or desire.

Energy is never known to exist unless found in association with matter. It is transmitted from body to body; sometimes by direct contact and at other times by immeasurable leaps. There must be some period-even if imperceptible-of the existence of energy not within the universe of matter. Energy is an alien in the universe of matter. It is a mere transient visitor that we recognize at no time excepting when associated with matter. But dare we say that energy does not exist somewhere and sometime, in its travel from body to body, while not associated with matter? In such a way a soul may never have been recognized excepting in the body of a man, but when it ceased to exist in the body, it follows that its existence is somewhere else beyond the universe of matter.

Conceding some wonderful change yet the mind hesitates to wonder over the perplexities of eating. We do not understand how a soul could exist without a body of physical matter to feed upon other physical matter.

A future life without banqueting and its accompanying slaughter, and waste, at first, causes a feeling of revulsion against an existence without these allurements. But here permit a quota- 
tion from J. Henri Fabre in "The Life of the Spider:"

"I find them at the age of seven months the same as when I saw them at their birth. The egg supplied the materials necessary for their tiny frames; and, as the loss of waste substance is, for the moment, excessively small, or even nil, additional plastic food is not needed so long as the beastie does not grow. In this respect the prolonged abstinence presents no difficulty. But there remains the question of energy-producing food, which is indispensible, for the little Lycosa moves, when necessary, and very actively at that. To what shall we attribute the heat expended upon action, when the animal takes absolutely no nourishment?

"An idea suggests itself. We say to ourselves that, without being life, a machine is something more than matter, for man has added a little of his mind to it. Now the iron beast, consuming its rations of coal, is really browsing the ancient foliage of arborescent ferns in which solar energy has accumulated.

"Beasts of flesh and blood.act no otherwise. Whether they mutually devour one another or levy tribute on the plant, they invariably quicken themselves with the stimulant of the sun's heat, a heat stored in grass, fruit, seed and those which feed on such. The sun, the soul of the universe, is the supreme dispenser of energy.

"Instead of being served up through the intermediary of food and passing through the ignominious circuit of gastric chemistry, could not this solar energy penetrate the animal directly and charge it with activity, even as the batters charges an accumulator with power? Why not live on sun, seeing that, after all, we find naught but sun in the fruits which we consume?

"Chemical science, that bold revolutionary, promises to provide us with synthetic food-stuffs. The laboratory and the factory will take the place of the farm. Why should not physical science step in as well? It would 
leave the preparation of plastic food to the chemist's retorts; it would serve for itself that of energy-producing food, which reduced to its exact terms, ceases to be matter. With the aid of some ingenious apparatus, it would pump into us our daily ration of solar energy, to be later expended in movement, whereby the machine would be kept going without the often painful assistance of the stomach and its adjuncts. What a delightful world, where one would lunch off a ray of sunshine

"Is it a dream, or the anticipation of a remote reality? The problem is one of the most important that science can set us. Let us first hear the evidence of the young Lycosae regarding its possibilities.

"For seven months, without any material nourishment, they expend strength in moving. To wind up the mechanism of their muscles, they recruit themselves direct with heat and light. During the time when she was dragging the bag of eggs behind her, the mother, at the best moments of the day, came and held up her pill to the sun. With her two hind legs, she lifted it out of the ground into the full light; slowly she turned it and returned it, so that every side might receive its share of the vivifying rays. Well, this bath of life, which awakened the germs, is now prolonged to keep the tender babes active.

- "Daily, if the sky be celar, the Lycosae, carrying her young, comes up from the burrow, leans on the kerb and spends long hours basking in the sun. Here, on their mother's back, the youngsters stretch their limbs delightedly, saturate themselves with heat, take in reserves of motor power, absorb energy.

"They are motionless; but if I only blow upon them they stampede as nimbly as though a hurricane were passing. Hurriedly, they disperse, hurriedly they reassemble; a proof that, without material nourishment, the little animal machine is always at full pressure, ready to work. When the shade comes, mother and sons go down again, curfeited with solar emanations. The feast of energy at the Sun Tavern is finished for the day. It is repeated in 
the same way daily, if the weather is mild, until the hour of emancipation comes, followed by the first mouthfulls of solid food."

As the young spider possibly acquires its bodily tissue directly from the physical sun, why would not a soul absorb its vitality directly from a metaphysical sun or center that even created our sun and the millions of other suns and their systems of worlds and all incubating life thereon? We do not know this to be true, but it is possible.

Passing from food to raiment and the resurrection of the body, some of us may carry an erroneous notion as to what the body may be. No vanity of man would desire his antiquated finger nails and the bushels of shedding cuticle, disfiguring moles, or superfluous fat and wasting tissues, for the rest of eternity. That is not the body. The body is the mental outline, plan and form, upon which physical material is laid, for the purpose of materializing the same for residence upon this material world. The body is the design, upon which material cells expand through the periods of embryo, infancy and childhood, until a man is built. This plan or body-this individuality-shall be preserved. The flesh and bones we have are a mere shell of parasites, as the moss upon some precious jewel, before its beauty is revealed. It is all but a mere excrescence, perishable in a few days, months, or years at most. The resurrection of the body is probably the resurrection of a recognizable form not of earth material for mortal recognition, but of spiritual form for 
spiritual recognition. What would we do with a cumbersome, perspiring, decaying body of water and fibre tissues, with nerves for pain and cells or complex matter, in an eternal life? I crave the resurrection of the body for my conscious soul, but I should be glad to be rid of all blemishes, including flesh and bones, just as long ago I was overjoyed at shedding the warts of boyhood days. I do not believe this great mentality-the soul of man, is complete without a distinct form. The form to be resurrected for the spiritual enfoldment of man in the future estate, is what we probably most desire-that of our own bodies. Perhaps we may dress in a spiritual glow, changeable at will by a mental desire, measured with terms incalculably greater than the physical power of the chameleon and tree frogs and certain fishes that instantly change their hue. If in this world, fur, feathers, fabrics and fashions are an improvement over the covering of the individual as a germ, it tollows that in a correspondingly improved state of existence the design and effect will never possess such limitations as are fixed upon by Paris and the Orient.

Throughout the Universe an invisible ether exists linking and even pervading suns and worlds and even the atoms and molecules thereon. Confined to the body of man there is something that pervades it all, like the pervading ether, which we call a soul. Even the man who doubts immortality knows that the cells and divisions of cells are comparatively separated and made of minute individ- 
ual organisms. However, that part of the man that connects and unites all of these mental and physical particles into one is a consciousness of personality imparted from before birth, that succeeds in holding these individual mental and physical cells together as effectually as gravity holds the substances of this earth in their proper places. It is that force that appears to catch or germinate mental crystals, or ideas and expresses them through the complex body-it is the soul. The soul will never be found in any knot of nerves or celis, in any organ or in the brain, because it is all through the man; on the surface as much as under the skin. The physical body appears to be the mere instrument of the soul. Where was this soul before the world was created and where will it go wen this world is gone, if it does not leave before? There is no physical boundary or limitation for a purely mental being.

Niay we inhabit another star if we desire a physical base from which to calculate? Why not? Fiven matter can migrate this distance. It moves now from star to star. Matter by friction or an awful cataclysmic impact of two worlds may be resolved down to electrons. Electricity may be converted into heat and light. For centuries we have known that light in some mysterious way travels from the sun to this earth in less than eight minutes. It comes as some refined quality of electricity or energy and as it approaches the resistance of the earth it is transformed to heat and light, which are essential to and become the 
main staff in creating all animal and vegetable growth. It may be this vitalizing force is due to a subtle persistence of this product of violent energy reasserting itself in the slower restful tissues of life. This electric force, changed to heat and light, then to vegetable growth, and on to animal tissue, may have been a similar tissue on some other planet and combustion drove it on in ocean waves and electric form, piloted perhaps by mentality,-it carries with it at about one-fourth its speed material organisms from the sun, scattered among all the stars of the universe. We absorb the light of stars as we absorb the sunlight. Part of the physical bodies of this earth, in the same way, may some day migrate into space at the rate of twelve million miles a minute.

If matter be rarified and scattered at such a speed, stopped, condensed and absorbed like this and actually does move in this manner and through this natural force, how much more sray we expect of its superior, the intellect, when combined in mighty individual corporations of rnentality? This little earth is not our future home. The Universe is not too large for the future life.

Let us take a glance at the known physical universe. The earth is estimated in weight at $6,000,000,000,000,000,000,000$ tons. The sun is said to weigh 320,000 times as much. Beyond this it is estimated there are the millions of stars. Some of these suns, from intense heat, are great globules of gas, and others cooling down and still 
others cooled, concentrated and frozen into seemingly dead worlds waiting for the terrific impregnating vitality of contact with another world. Whatever and wherever they are, whether solid substance, or gas, they are made up of living, throbbing, moving molecules, atoms and electrons. But of what is an electron made, if not materialized from life, or mind?

In this incomprehensible caldron of the universe, worlds are being made inhabitable, and then uninhabitable, over and over again. Life is everywhere; sometimes in one place and sometimes in another; sometimes in a higher form and sometimes lower. When this world becomes unfit for both human habitation and spiritual interest there are millions of other places, physical and metaphysical, in exact harmony with what any stage of life may desire.

While I have been exceedingly careful that statements of physical facts are authentic, I do not claim to know that these metaphysical deductions are right but I do claim that they are reasonable enough to be worth thinking over. If there is a future state, as I firmly believe, there must be a future place supremely suitable for such a state.

We can only think and measure heaven by the limited senses of man. Nevertheless it is a speculation in the right direction as sure as we are born. I say this not as a trite expression, but because birth indicates life and life is the antithesis of death. If we were 
born and live, life should continue just as motion continues and is what man would ordinarily concede to be a primary element. It may be asserted with great force that a strong evidence of immortality is the fact of a consciousness that we are now alive. If we are alive, we should live on. Life and motion are not a part of, or associated with, or related to death and rest. Death, as it is ordinarily considered, is that which was never born; that without life, provided you can find it. It will be as difficult to locate matter eternally dead as it is to locate matter eternally at rest. Besides eternity in time, eternity in space, eternity in motion, eternity in matter, eternity in everything implies eternity in life. Life, in fact, is the progenitor of so-called eternal matter. None but the densely ignorant will deny it; none but those who feel they are hopelessly lost will refuse to think upon the subject.

After all has been thought and measured and said, we return with some assurance to that constantly recurring death-bed conviction of immortality. We have observed and been told repeatedly that nearly every man who approaches dissolution with his reasoning faculties and who meets the proposition of death face to face, whether he has been a life-long atheist, a profound scientist, a man of the world or of literature and learning or a thief and a murderer, the instant he gives up all hope in his fellowmen he begins his search for God. That something buried 
within his shriveled soul, even by lifelong erroneous teaching will inevitably reassert itself as an irrepressible instinct. Because a man's soul came from the Infinite, we should expect that at the instant it becomes conscious of its separation from man, it will begin to recognize the God from which it came.

The recognition mentioned here is merely mortal recognition. I do not pretend to say that, when the transition through death is made, consciousness is retained through this period. Some devout people claim there is a period of sleep and then a resurrection of the body. It may be true that the short period of mortal unconsciousness before death is followed by a season of immortal unconsciousness after death. This question along with that of communication with the dead or with evil spirits, believed in by other classes, are matters I have intentionally avoided.

I can not be drawn into any other discussion, than the physical evidence of immortality. Immortality is the mainspring of every religion of the ages. There never was and never can be a religion without a belief in immortality.

I have endeavored to present my argument in such a manner as will enable men of every belief to appropriate these evidences for their own religion, and at the same time afford no weapon for conflict among the different churches. It may, therefore, be detrimental to the good I hope to accomplish, even, to say a few words for the particular church to which I belong. My church is 
of no particular concern to the reader, and his church should not concern the writer. Upon such a question every man does what he thinks is right or he has lost faith in all religion.

I will say, however, in a general way the Christian religion is more helpful to me, because I understand and believe more of its teaching than the teaching of any other religion. This may have resulted from being raised in a Christian country.

My advice is that every man should stick to his religion and never leave it to hunt for a better one he does not thoroughly know. Change when an overwhelming conviction demands it. Any church, as a matter of demonstrable philosophy is helpful to those who believe in it while materialism is the acme of damnation.

Materialism compels its supporters to give up and expect nothing, destroying all hope-hope, which is a force.

I appeal to the heads of the churches who have the interpretation of inspired words and are responsible for the guidance of their communicants who trust in them-I appeal to them, whether Christian, Mohammedan, Buddhist, or of any other faith, to study the handiwork of God through nature as an aid to the meaning of His words. 


\section{CONCLUSION.}

CHAPTER XV.

Returning to physical and practical things, the theory of evolution, corroborated by entomology, biology, geology and other sciences applied to the theory of a future life, holds out more than a grain of hope; affords encouragement to the occasional thought of a life beyond the grave; and justifies a university investigation. There is much psychological investigation of spiritual existence of the soul. Assertions concerning these experiences become intensely interesting immediately upon being satisfied of th natural possibility of a future life. Many are frauds and errors but some are wonderfully prophetic of what we may expect the truth to reveal. I have studied the problem of death from this point of view as well as from other sides and the more I investigate the more confirmed I become in my opinion that we may retain our individual mental conscious existence after death.

Commonly understood death is natural. It is necessary to life. It has often been asked (and we have marvelled at the conclusions) what if every tree lived and every seed germinated and grew and every egg of the salmon, the bee, and the insect hatched and matured and never passed away but multiplied, and every man born 
were still living. This would have been impossible upon this earth if not in the vast universe.

It has been estimated that if the bodies of all men who have inhabited the globe could be returned and stacked up they would cover the face of the earth nine feet deep. Death, therefore, or the return of the body to earth, is necessary after being used to develop the soul. It was impossible for us to arrive until others had departed. Therefore we must improve our opportunity and leave for others to take our places for their development in this incubator of immortality.

Nature has demanded this so-called death, or surrender of the body, just as a chick must cast aside its shell. But there is one consolation, nature has ordinarily made death painless at the moment, hour, or day, of the separation of the soul and body as it has also made man's birth into this life painless, or without a memory of the occurrence.

Upon the death of a body the last installments of borrowed matter, with the elements of life hasten to leave the body transformed into gases. The lighter gases are first to follow the departure of the soul-life but all undertake to leave so quickly as to do so in the greatest of disorder, immediately on the departure of the soul of man. This little understood incident of socalled bodily death indicates immortality when we understand how the deserted body will not rest or stay dead. 
Too many good men are dead, for us to say there is nothing in death. Why are we rushing pell mell towards the grave, if at that point the force of life stops, and ceases to be a force; and that something becomes the questionable nothing. It is unbelievable to any man of ordinary intelligence.

By this process of reasoning I have not only satisfied myself that a future life is possible, but that the teaching of the Bible is in harmony, with such view. They strengthen each other. Any religion and any church, which teaches a future life, will be an aid to this state of existence. The one which gives you the strongest conviction will be your greatest help. No new Bible, no new book of revelations, no new religion, no new church is necessary.

This position is taken, because I believe that the strongest physically demonstrable assurance of a future life, that the Bible contains, and which nature reveals is that which requires us to have faith to have eternal life. It required faith and strong desire, for man's ancestors to see and hear and taste; it required persistent desire and constant practice, spurred on by faith, for aquatic animals to leave the ocean and walk on land for constantly increasing periods. It has taken the same kind of faith the Bible mentions to save a soul. We may live on, I am satisfied, if we will. 


\section{APPENDIX.}

\section{LETTER}

To the dear friends of various beliefs who have written to me upon the subject of immortality and those urging that $I$ incorporate into the final resolutions of a revised version of "Immortality" some specific combination of the idea and their particular religion:

These requests give me pleasure and encouragement, coming as they do, from various religions, because they indicate a measure of success in keeping the work free from all religious division and confined to the one question they all stand for-Immortality.

That all religions could and do unite on immortality as the ultimate realization, is true. But that this belief could be made the unifier is not possible. In the great scheme of things immortality means, in a way, the faith, something that exists as a verity and a power, while religion must ever stand to us in the meaning of "works." The church that works with such simplicity that it attains perfection has not been evolved by time-hence many antagonizing churches. With man's jealousy of another's ascendency, scepticism of true motive is inherent. Then who shall co-operate if none may initiate? This condition precludes any ambition to unite either churches or religion. Such a work is beyond the power of any man and is a part of God's work being realized, as individuals are made more and more to understand His laws.

People have a right to inquire of a writer's opinions sufficiently to understand the viewpoint from which things have been examined and to consider and weigh the credibility of the writer, and be satisfied he is not an adherent of some obscure, new or fanatical religionwhen he presumes to write upon immortality. Again it may prove useful to give this information of how these 
thoughts confirmed my early religious ideas to be used as an illustration of how they may be applied to satisfy those of different religions, so long as they teach the immortality of the soul. This reason alone justifies appending this mere personal letter, which I do not wish to be regarded as any part of the foregoing volume.

This work, interesting me in a purely scientific investigation irrespective of the Bible, led to the results given, but some people, especially of the Orient, expect some statement of the writer's process of harmonizing the conclusions with the prevailing religion of his country.

Being raised in a Christian country, I was under the influence of the Bible and had, as the world goes, the usual unshaped knowledge of it. Perhaps this condition invited the rather broad unstandardized inquiry pursued.

In considering, for argument's sake, and for the time being, anything which upon its face appears to have been proved, I ask the same fairness upon the part of all non-Christians in considering these statements, and this work, offered for these purposes.

There being such vastness of physical nature, and it being so wonderfully systemized and complex, every particle of life, and of matter being traced back to intelligence, back to a metaphysical existence, back to a nonmaterial state, under such arbitrary rules of progress as we observe, could there be such metaphysical, or spiritual rules, without a Spiritual Ruler? (Manifestly, man is not the greatest intelligence.) There is a UniverseCreating Intelligence, that induced this development, and to Whom we must look for further progress. It follows that since we are developing, and may develop much more, we should have expected to hear from such Ruler as soon as we became qualified to understand. Some means would have been utilized by such a Universe -Ruler to communicate His Rules. As an instinct would be sufficient for a possible insect-life development, a flimsy crude superstition may have been sufficient to inspire faith in many aboriginal types of men for their hope in the future. But 
it requires more than superstition for most men of today, who analyze and reject unsupported assertions. When the more intelligent types, who learned to preserve and communicate thoughts in languages by writing and reading, that system would likely be the easiest and most reliable channel through which men of this increasing intelligence could be induced to understand God. Why would not this Ruler of the Universe, in dealing with man, to encourage his faith for a spiritual life, use the instrument of writing, and inspire the work to be written?

The instant we assume there is a God, we are bound to admit that we should have heard from Him. This thought being so natural, no better plan could have been accepted by us than an inspired written message, proved by the appearance of a prophesied Personal Representa. tive.

In one of the prophecies of the coming of Christ we are cautioned against necromancy and certain psychological practices as abominations, which have been fully demonstrated as dangerous, but we seem to have been cautioned mostly to distinguish imposters from the true Prophet we were to expect.

For many reasons the attention of the non-Christian should be challenged to a consideration of the Bible and the claims of Christianity. We should have been and should be most intently on the lookout for some communication from this Ruler, just as science is studying disturbances of ether, and every phenomenon upon Mars for some communication from there. We should consider the endorsements and faith of the thousands of millions of intelligent people who have lived and died with confidence in the Bible. With the broad basis of Nature, warranting an expectation of communication, and with the recommendation for this particular book, we should read the Bible, and read it as a whole. We should read it with these things of Nature in view, and not merely to discover some stumbling block in a phrase. 
No doubt some by reading, will be unsatisfied. I have been that way during many years of my life, although I have never wanted to be.

As a boy I listened to sermon after sermon by my father and by many other ministers, hoping to hear something I longed for, making tangible for me a faith so apparent in others. Time after time I felt unfortunate in not being able to hear the sermon of such anticipation. Attendance at revivals did not produce the satisfaction craved, yet nevertheless this stimulated the childhood faith. Casual articles on materialism gave me staggering blows, until I undertook a deep personal and unbiased study for my own satisfaction. The result of this study was such that, if the Bible had been impeached and shown a bundle of forgeries, I would, from the evidence presented to you in this book, still have a religious hope, and remain in much the same position to which the Bible originally elevated me in this early period. (Religion is natural wherever not yet divine.)

On the other hand, while in this state of doubt, the materialist took me to the other extreme from religious convistion, where I followed to material limitations. Refusing to stop there, I went on upon my own resources, by the same process of reasoning, which the materialists so logically use, until reaching as great a mystery, or a greater mythology, if it be mythology, than the Bible has ever been accused of representing. The alleged material source of evolution must needs be spiritual, because it is not, and cannot be located, or stopped, within any dimensions of the material. There is so much mystery, speculation, sophistry, and so many gross mistakes, in science and matter, as time and again shown by new discoveries upsetting long lines of calculations, that, in my opinion, one becomes so weary, and bewildered, that it is a relief to return to the Bible for genuine stability.

When we read in Genesis and John that in the beginning was the "Word," and when we consider this beginning referred to as a mist with darkness over the face 
of the "deep;" and when we further consider that this mist was separated, and only that part below the firmament was mentioned thereafter-where the dry land was made to appear-what a picture we have of the scientific development of the earth, considering all that is to be found in a spiral nebula!

If this nebulous matter was heated by the friction of coming together, or from any other cause, when it cooled we know that it would begin at the poles, and that that part of the globe would naturally become first habitable to life. The Garden of Eden could have been nowhere else, according to Nature, than upon the land around the north or south pole of that time. The north pole is favored in this conclusion, because there is much less evidence of our land connections with the south than the north pole. Corroborating this view is the Biblical mention of the flaming sword that guards this sacred spot, which may be the Aurora Borealis. Lieutenant Peary and Dr. Cook must both produce more proof than they have ever presented before I will become satisfied that either have ever entered that mystery-land, which was withdrawn, frozen, and perhaps submerged from man.

In prophecy, concerning the political world, how startling is the statement, that, man may neither buy, nor sell, without a number in his hand, when we see the organization of union labor making warfare upon non-union men, and when we see the numbered licenses of plumbers, of milkmen, of barbers, and many trades, extended to hundreds, and thousands, of callings. In some countries of the world men of every vocation are licensed, and men almost literally carry a number in the hand.

In prophecy concerning the mechanical world, we have a perfect picture of steam engines, electric lines, automobiles, traction engines and telegraphy. These things in the Bible were never understood by the people three hundrd years ago, nor one hundred years ago.

The three, or four, Biblical views, merely referred to, without strict quotation, may not be the real and cor- 
rect understanding, as intended by God, but are given as illustrations of the result of man trying to understand God's Word and His World.

A most interesting volume could be written upon the changing sciences and the staid old Bible. But the further we progress the more our sciences are harmonizing themselves with the Bible. And in this respect I do not regard these investigations, where carried on with the right determination, and faith, as the least sacriligious, or detrimental, because God approves knowledge and wisdom. Yet, we must remember how little the greatest of men really know. But, before leaving the subject we must not overlook the climax of prophecy and fulfilment in the wonderful story of Jesus Christ, His foretold birth, His unparalleled life-never approached by any of the great men of the succeeding nearly two thousand years, His crucifixion, and His resurrection.

The hundreds of millions of men who follow others, as prophets of God, may not agree with me. But, if any of you have found these things helpful in your religion and if I have pointed out wherein they are helpful in my religion does it not indicate some correlation between all religions.

Although honest and conscientious in all I have written, with my best understanding, if any statements made, or conclusions drawn, in my work are not in accord with the Bible, in my judgment, as a Christian, they should not stand and newer science will some day condemn them. You surely understand that I do not mean to assert, that, what I have said harmonizes with man's conception of all of the Bible. Some people have, in my judgment, very queer notions about the meaning of the Scripture, and some of us do not understand many portions clear to others. Some people believe that God molded a man out of clay and water, with hands, in a minute, much as a molder forms a brick in a frame. But I think-and claim a right to think-that God made man enter this world through matter, figuratively speaking, as inconsequential 
as the dust of the earth; that the breath of life He breathed into the man was the first faint knowledge and hope of a spiritual existence, and the faith so necessary to salvation. Of course, non-Christians, or sect divided Christians, need not believe as I do. My views are not by any means offered as religious tenets. Your own faith, from your own religious conception, is more valuable to you than anything I may offer along this line, unless that faith has been exceedingly weak. Besides I may wish to change many of these material views, as I would surely do, if given a clearer light to understand God's Word.

If these chapters aid Bramins, Buddhists, Jews, Theosophists, Spiritualists and men of other religions as well as Christians, it is my hope that they may be strengthened in their belief in a future life. Expecting a future existence makes him a better man during this life. The better we are here, under every theory predicates a better existence hereafter. However, it appears to be perfectly proper to invite any non-Christian, who is unstable in his faith, or philosophy, to examine the claims of Christianity, as compared with any other doctrine, or philosophy.

It is suggested at this point to men of all religions, that, if there be but one God, as ought to be clear, and He has sent us His Word in writing, it was in one Bible, and with one Personal Representative to aid in its interpretation. The weakness upon the part of man, which required an Interpreter to select, separate, correct and point out, was according to some views, necessary, at that period of development, to distinguish inspired writings from merely good books. Many of the same truths of the plan of God are, no doubt, in other books and entered the minds of men by divine guidance, but there was one set of writings in this way particularly distinguished.

That which has been presented should help those who believe even in a different bible, as I have said it has helped me even though my Bible should be discredited. But in my opinion, as a Christian, it not having been discredited, I feel that I am a better Christian than I have 
ever been, and have no reason to change my manner of prayer, or worship. On the other hand, if needs be, although I do not see the necessity, I stand ready to bundle my work with the work of Haeckle, Darwin, Huxley, Kant and others, and throw them upon the burning brush-heap of public condemnation, and take the Christian Bible as the truest standard of life, of death, of science, of the here, and the hereafter, abiding by the anathema upon him who addeth to, or taketh away, from the Holy Writ. I know that I never would have thought of making this investigation, had it not been for the books mentioned.

These books may have been necessary to destroy a too narrow past conception of the Bible. Galileo was a courageous and useful man to make the church give up its erroneous opinion that the world was square merely because reference was made to the four concerns of the earth. Knowledge of the process of evolution will not affect the Bible any more than the knowledge foreshadowed by Galileo has affected the Bible. What were the four corners of the earth, more or less, than the whole surface of the earth? The meaning conveyed was all of it. The writer of these passages of the Bible and the people of the time believed the world square. Therefore they would accept the message with such a conception. To have called it a globe then might have made the Bible too vague in the eyes of the people. Yet, in fact, the Bible did and does say: "He stretcheth out the north over empty space and hangeth the earth upon nothing."-Job 26-7. Let us not be too hasty in condemning Galileo, or Darwin, or Huxley, or others. However, if they are, in your judgment, wrong in everything they say and I am also wrong in my disagreement with them, consider what is said in this book as a mere counter irritant.

As we take into the human system an alkali poison to counteract an acid poison, or an acid to counteract an alkali, I am willing and anxious, if it may have any such value, as it appears to me, for this work to stand as long as these other works may stand, for those in need of 
something as an antidote to the devil's disease of materialism.

Although this research has helped me much at a time when in need of help, now I feel satisfied I was taught substantially right as a child. It may be that this work will help you to come back, as it has helped me. If so, it has more than performed its mission. You may later discard its use, as I have, excepting to meet the arguments of philosophical atheists, and you may then happily spend the rest of your life in the comfort of your religion, and the society of your church. Any hope of life based upon philosophy alone makes one a religious wanderer and destroys that certainty necessary for faith, which is the foundation of our future.

I have no religious reforms to offer and no new thoughts to teach. I believe the Bible was written as claimed therein, for all men and all times, and nothing new will be discovered to permanently show any part of the Bible is out of harmony with itself, or with Nature. Being written for all men and all times may be a reason why there are portions we do not understand. However, it is both a history and a revelation, so truly written that its inspiration must be divine.

I insist upon having it understod that I am not fighting any church, even though I may not agree with its doctrine. My only contest is with that class of egotists, who proclaim there is no basis for any religion, and that contest is only to be a contest of reason.

In my closing words, as a Christian to Christians, let it be repeated as I have tried to keep before your minds, the injunction, that, if I have given utterance to any thought contrary to the teaching of the Bible, you should strike it out of your consideration. I want nothing to remain in your minds as a distrubing element, from such a flimsy "religion" as science or philosophy is, unless it squares with the Word of God. To men of other religions, let nothing I have said disturb you in your religion, if the result be a tendency towards atheism. No intelligent 
man will study these great questions and deny there is a God. Had investigations led me merely to a cell of matter as the origin of life, and then stopped with a Darwinian Adam and Eve-a pair of bugs-a cell that divides itself, and no means existed to go any further, I would have admitted, reluctantly, that the materialist had delivered a severe blow to religion and immortality. Since it does not stop there, I must concede an Infinite. There is Immortality, and that is a basis for all religions. Some one religion may ultimately be the best. It may be yours, and it may be mine. Until a better one is pointed out I expect to retain my own satisfying religion, based upon faith in the Bible, but concede to you the same broad privilege of a perfect freedom to choose your own religion, or manner of serving God. However, who has a more important business in this world than to find out, and.live the preferred and commanded religion of God?

Sincerely,

JOHN O. YEISER. 


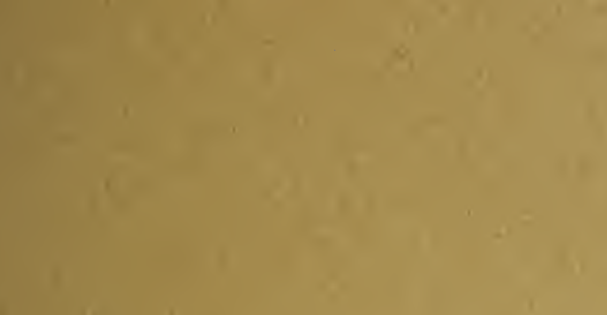

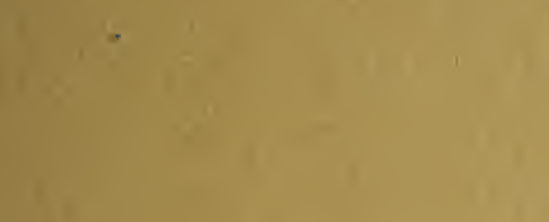

$$
\begin{aligned}
& \text { (1) }
\end{aligned}
$$

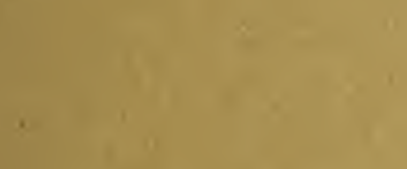

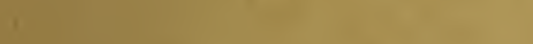$$
1=1,
$$$$
\text { (1) }
$$$$
\text { 11 }
$$

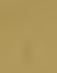

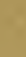<smiles>C1CCC2CCC2C1</smiles>

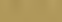<smiles>CC1CC1</smiles>

$-$

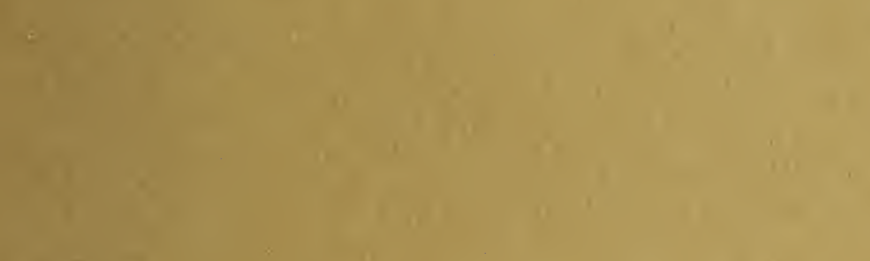

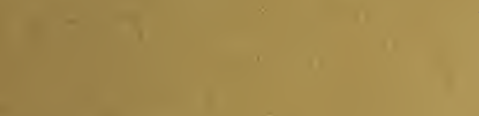

I

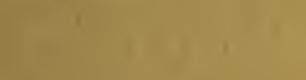

18<smiles>C1C[C@@H]2C[C@@H]12</smiles>

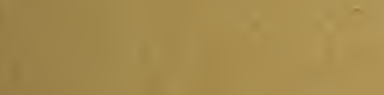

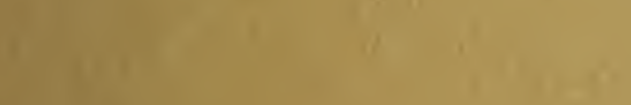

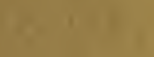

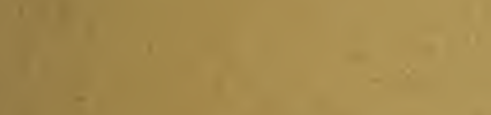

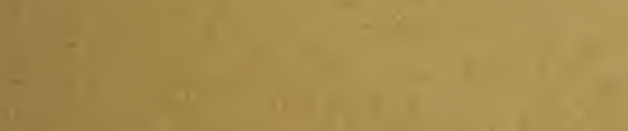




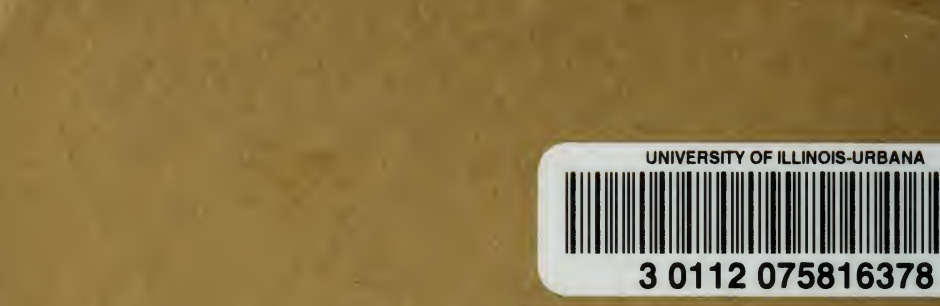

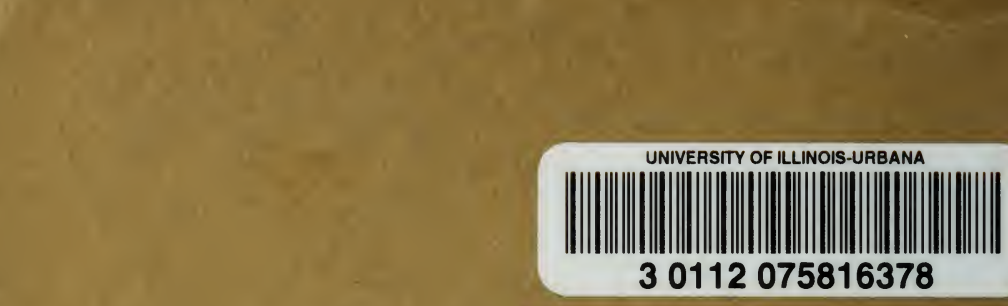

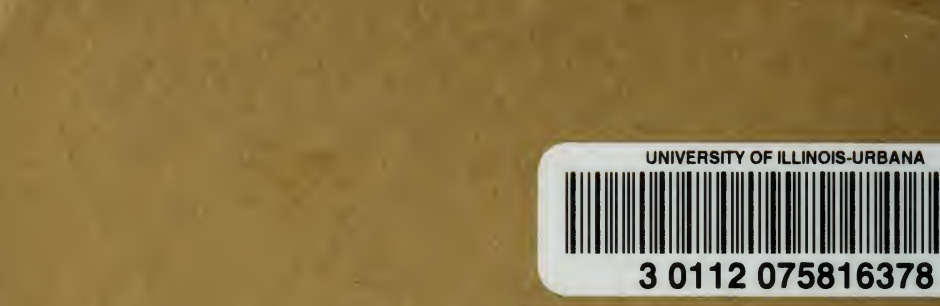
(n)

\author{
. \\ .
}

\title{
(3)
} . 